OPEN ACCESS

Edited by:

Emmanuel S. Tzanakakis,

Tufts University, United States

Reviewed by:

Natesh Parashurama,

University at Buffalo, United States Salman Khetani,

University of Illinois at Chicago,

United States

*Correspondence:

Joana P. Miranda

jmiranda@ff.ulisboa.pt;

jmiranda@ff.ul.pt

†These authors have contributed equally to this work

Specialty section:

This article was submitted to

Stem Cell Research,

a section of the journal

Frontiers in Cell and Developmental

Biology

Received: 06 November 2020

Accepted: 21 January 2021

Published: 22 February 2021

Citation:

Serras AS, Rodrigues JS,

Cipriano M, Rodrigues AV, Oliveira NG and Miranda JP (2021) A Critical Perspective on $3 D$ Liver Models for Drug Metabolism

and Toxicology Studies. Front. Cell Dev. Biol. 9:626805. doi: 10.3389/fcell.2021.626805

\section{A Critical Perspective on 3D Liver Models for Drug Metabolism and Toxicology Studies}

\author{
Ana S. Serras ${ }^{1 \dagger}$, Joana S. Rodrigues ${ }^{1 \dagger}$, Madalena Cipriano ${ }^{2 \dagger}$, Armanda V. Rodrigues ${ }^{1}$ \\ Nuno G. Oliveira ${ }^{1}$ and Joana P. Miranda ${ }^{1 *}$ \\ ${ }^{1}$ Research Institute for Medicines (iMed.ULisboa), Faculty of Pharmacy, Universidade de Lisboa, Lisbon, Portugal, \\ ${ }^{2}$ Fraunhofer Institute for Interfacial Engineering and Biotechnology IGB, Stuttgart, Germany
}

The poor predictability of human liver toxicity is still causing high attrition rates of drug candidates in the pharmaceutical industry at the non-clinical, clinical, and postmarketing authorization stages. This is in part caused by animal models that fail to predict various human adverse drug reactions (ADRs), resulting in undetected hepatotoxicity at the non-clinical phase of drug development. In an effort to increase the prediction of human hepatotoxicity, different approaches to enhance the physiological relevance of hepatic in vitro systems are being pursued. Three-dimensional (3D) or microfluidic technologies allow to better recapitulate hepatocyte organization and cellmatrix contacts, to include additional cell types, to incorporate fluid flow and to create gradients of oxygen and nutrients, which have led to improved differentiated cell phenotype and functionality. This comprehensive review addresses the drug-induced hepatotoxicity mechanisms and the currently available 3D liver in vitro models, their characteristics, as well as their advantages and limitations for human hepatotoxicity assessment. In addition, since toxic responses are greatly dependent on the culture model, a comparative analysis of the toxicity studies performed using two-dimensional (2D) and 3D in vitro strategies with recognized hepatotoxic compounds, such as paracetamol, diclofenac, and troglitazone is performed, further highlighting the need for harmonization of the respective characterization methods. Finally, taking a step forward, we propose a roadmap for the assessment of drugs hepatotoxicity based on fully characterized fit-for-purpose in vitro models, taking advantage of the best of each model, which will ultimately contribute to more informed decision-making in the drug development and risk assessment fields.

Keywords: in vitro liver model, fit-for-purpose models, hepatotoxicity, paracetamol, diclofenac, troglitazone, three-dimensional culture

\section{INTRODUCTION}

The process of development of new drugs is a costly investment with the pharmaceutical industry facing considerable challenges regarding the balance between the political pressure to increase drugs safety while reducing the cost of medicines. According to a recent study by Wouters et al. (2020), the median investment of bringing a new drug into the market, also accounting for failed 
trials, was estimated at $\$ 985.3$ million over the period of 20092018. It is a process that usually takes $10-15$ years, with a success rate from phase I to launch of less than 10\% (Dowden and Munro, 2019). This is mostly due to lack of drug efficacy or safety issues that occur essentially in the clinical phases IIb and III of drug development (Kola and Landis, 2004; Paul et al., 2010). Even after reaching the market (phase IV), there is still a relevant number of drug withdrawals for toxicological reasons. Approximately $18-30 \%$ of such withdrawals are caused by hepatotoxic effects, showing that the liver is the most frequent organ for adverse drug reactions (ADRs) (Onakpoya et al., 2016; Siramshetty et al., 2016; Zhang X. et al., 2020). Importantly, about $40-50 \%$ of the drug candidates associated with hepatotoxicity in humans did not present the same toxicological concern in animal models (van Tonder et al., 2013). Indeed, besides raising ethical issues, animal models often fail to correlate with human toxicity, since several toxic features disclosed in human trials were not predicted by animal studies (Olson et al., 2000; Shanks et al., 2009). One of the reasons for this discrepancy is the differential expression and activity of drug metabolizing enzymes between animals and humans that might confound the extrapolation of data derived from non-clinical species (Martignoni et al., 2006; Ruoß et al., 2020). Moreover, drug-induced liver injury (DILI) is a rare, but potentially fatal event, resultant from the poor translation between clinical trials and clinical practice and highlights the importance of targeting population variability at non-clinical stages (Jones et al., 2018). Within DILI, the idiosyncratic category is particularly difficult to identify by the pharmaceutical industry as it is almost undetectable in animal models (Kuna et al., 2018; Walker et al., 2020). Altogether, this has led to the proposal that the better the quality of non-clinical safety profiles, the higher the success rates for moving phase II upward (Cook et al., 2014; Walker et al., 2020). Consequently, in vitro liver models are growing strong while new drugs advance into clinical trials.

The search for more accurate non-clinical models along with the concern about animal welfare, reducing time and cost associated to drug development and the ever-increasing number of chemicals that need testing, made the establishment of relevant in vitro culture systems a priority in the toxicology assessment of drugs by the pharmaceutical industry, as these allow a higherthroughput capacity. Novel cell culture and tissue engineering technologies along with integrated endpoints have been adopted for improving liver cell metabolic performance in vitro and are expected to generate more robust data on the potential risks of pharmaceuticals (Davila et al., 2004; Andersen and Krewski, 2009, 2010; Krewski et al., 2009; Giri et al., 2010; Shukla et al., 2010; Balls, 2011; Mandenius et al., 2011). Existing strategies include three-dimensional (3D) structures, flow-based cultures, co-cultures and stem-cell differentiation.

In this review, we discuss the dissimilarities of the $3 \mathrm{D}$ in vitro hepatic systems currently used in research and drug development and their actual contribution for unraveling the mechanisms of drug-induced hepatotoxicity. Special emphasis is given to the features of 3D culture systems, cell organization and architecture, the effects of stirring and perfusion and how these characteristics modulate the phenotype and functionality of liver cells. In addition, we take a step forward by presenting a comparative analysis of the $\mathrm{IC}_{50}$ values for cytotoxicity and mechanistic endpoints, obtained either with two-dimensional (2D) and 3D in vitro systems for the classical hepatotoxic drugs paracetamol (acetaminophen), diclofenac and troglitazone. In this context, it seems clear the need for harmonized and fully characterized models. Moreover, it is also important to highlight that the hepatotoxicity assessment and the choice of the in vitro liver models depend on the questions that need to be addressed. These strategies stand out as crucial when evaluating the model's relevance value for mechanism-based hepatotoxicity assessment.

\section{DRUG-INDUCED HEPATOTOXICITY: OVERVIEW, LIVER METABOLISM AND MECHANISMS OF TOXICITY}

The liver is responsible for most of the metabolism of orally administered drugs since its anatomical proximity to the gastrointestinal tract and histological structure, including the sinusoidal space and the blood supply from the portal vein, allows the efficient transport of drugs and other xenobiotics (Vernetti et al., 2017). It is a complex organ composed by $\sim 60 \%$ of hepatocytes, parenchymal cells responsible for multiple functions, including metabolism. Non-parenchymal cells (NPCs) include cholangiocytes lining the bile ducts; sinusoidal endothelial cells, which constitute a permeable barrier between the blood and the space of Disse; Kupffer cells, the liverresident macrophages; and stellate cells, which synthesize fat and produce vitamin A and collagen (Kuntz and Kuntz, 2008).

Drug-induced hepatotoxicity is defined as the hepatic damage caused by the exposure to prescription-only or over-thecounter medicines, herbs or other xenobiotics. DILI represents a major challenge for clinicians, the pharmaceutical industry, and regulatory agencies worldwide. As above mentioned, it corresponds to the leading cause of attrition of compounds in drug development, being also frequently associated to drug withdrawals from market or to use restrictions (Stevens and Baker, 2009; Devarbhavi, 2012; Jones et al., 2018).

Classically, DILI can be classified as intrinsic (e.g., caused by paracetamol) or idiosyncratic (e.g., caused by troglitazone) hepatotoxicity. Intrinsic hepatotoxicity is direct, dose-dependent and predictable, whereas idiosyncratic hepatotoxicity occurs without obvious dose-dependency, in an unpredictable fashion and with a short latency time, particularly after re-exposure (Russmann et al., 2009; Roth and Ganey, 2010). Idiosyncratic DILI can be an allergic immune-mediated hypersensitivity or the result of a non-allergic metabolic injury (Larson, 2010). DILI may also be categorized according to the duration (i.e., acute or chronic) and location/typology of the injury. The latter can be classified as hepatitis (mostly due to hepatocyte necrosis), cholestatic (i.e., bile duct damage or cholangiolitis) or mixed injury (Stefan and Hamilton, 2010). Despite the variety of its clinical presentations, DILI still does not display specific biomarkers, leading to abnormal liver tests and often the dysfunction is only identified by exclusion of other etiologies, which can lead to life-threatening clinical situations (Devarbhavi, 2012; Fu et al., 2020). Indeed, the identification of new molecular 
biomarkers has been investigated in order to improve diagnosis and treatment of DILI. However, its applicability is still limited (Fu et al., 2020). Thus, DILI is largely unrecognized and underreported, such that the true incidence is unknown.

There are several examples of clinically relevant drugs that have received prescription restrictions or the inclusion of a black box warning for potential hepatotoxicity. Among hepatotoxic drugs, paracetamol is the most frequently studied. Nevertheless, the most commonly hepatotoxicity-associated pharmacological groups of orally administrated drugs are antibiotics (e.g., amoxicillin-clavulanate and rifampicin), antiretrovirals (e.g., nevirapine), non-steroidal anti-inflammatory drugs (NSAIDs, e.g., diclofenac and ibuprofen), antidepressants (e.g., paroxetine), and anticonvulsants (e.g., phenytoin, carbamazepine, and valproic acid) (EMEA, 2000; Paniagua and Amariles, 2018). Among intravenous administration, antibiotics, and antineoplastic drugs are the pharmacological groups mostly associated with hepatic toxicity (Ghabril et al., 2013). It should be mentioned that during the past decades, particularly in the last 20 years, several medicines such as troglitazone, bromfenac, trovafloxacin, ebrotidine, nimesulide, nefazodone, ximelagatran, lumiracoxib, pemoline, tolcapone, and sitaxentan have also been removed from the market in some countries in Europe and in the United States due to severe DILI (Fung et al., 2001; Qureshi et al., 2011; Babai et al., 2018).

\section{Liver Metabolism}

Drug metabolism is a major determinant of hepatotoxicity, as both detoxification and bioactivation processes can occur, and are most frequently responsible for inter-individual differences in drug-induced toxicity.

Liver metabolism encompasses phase I biotransformation reactions, also known as functionalization reactions, leading to the hydrolysis, oxidation, and reduction of a given drug or xenobiotic. Key enzymes in this phase belong to the CYP450 family, but can also be epoxide hydrolase and monoamine oxidase, among others. The metabolites generated can be detoxified or bioactivated by further phase I biotransformation or by conjugation through phase II metabolism (e.g., glucuronidation, sulfation, and acetylation). The role of liver transporters (e.g., organic anion-transporting polypeptides, OATP, multidrug resistance-associated proteins, and MRP) is of great importance for the excretion, being this step also known as phase III (Gomez-Lechon et al., 2010; Yuan and Kaplowitz, 2013). A significant feature of liver drug metabolism is that it may transform the parental compounds into chemically reactive intermediates or electrophilic metabolites (i.e., bioactivation) that attack tissue constituents, potentially leading to mutations, cancer or tissue necrosis (Pessayre, 1993). Drug-induced hepatotoxicity can thus be consequence of the toxicity of the parental drug per se or the result of one or more of its metabolites that arise from liver metabolism (Figure 1). Therefore, the toxicity of a given xenobiotic greatly depends on the equilibrium between detoxification and bioactivation. Hence, in a new drug development scheme, the biotransformation processes should be widely studied in order to predict the physiological effect of the new compound.
There are several prodrugs that take advantage of liver metabolism, e.g., cyclophosphamide (Preissner et al., 2015) and L-Dopa (Di Stefano et al., 2011), as the initial molecule is only active after biotransformation near the target site, decreasing its potential toxicity and also increasing its bioavailability. On the other hand, paracetamol is an interesting example in which hepatotoxicity is dose-dependent and occurs since its metabolic pathway switches at a high dose exposure from the detoxifying phase II metabolism to phase I metabolism, generating the hepatotoxic metabolite $N$-acetyl- $p$-benzoquinone imine (NAPQI). This metabolite can covalently react with proteins, leading to necrosis, apoptosis and, ultimately, to liver failure (Hinson et al., 2010). Additionally, phase II metabolism may also lead to hepatotoxic derivatives, such as for example carboxylic acids, e.g., bromfenac (and other NSAIDs) or valproic acid (Sidenius et al., 2004; Skonberg et al., 2008). These can be bioactivated to acyl-coenzyme A thioesters, which are intermediates in phase II conjugation reaction, and may lead to reactivity toward reduced glutathione (GSH) and covalent binding to endogenous proteins (Sidenius et al., 2004; Skonberg et al., 2008). Hence, factors including the inhibition or induction of any of the biotransformation enzymes, drug-drug interactions, or genetic polymorphisms, may lead to increased activity and toxicity or, on the other hand, to an absence of effect.

Several widely prescribed drugs are themselves potent CYP450 enzyme inducers, e.g., phenobarbital, carbamazepine and rifampicin, or inhibitors, e.g., fluoxetine, ritonavir, fluconazole, and ciprofloxacin (Baxter et al., 2010; Wooten, 2015; Wolverton and $\mathrm{Wu}, 2020$ ). Subsequently, in the context of multiple drug prescription, the biotransformation of drugs that are substrates of CYP450 enzymes or other phase II enzymes and hepatic transporters can be severely altered when administered simultaneously. Some antiretroviral drugs, such as efavirenz (Grilo et al., 2017) or nevirapine (Pinheiro et al., 2017), may be simultaneously the substrate and the inducer of an enzyme, such as CYP3A4 and CYP2B6, and can regulate its own biotransformation (auto-inducer) (Kappelhoff et al., 2005). Indeed, enzyme induction is included within the pharmacokinetic (PK) tolerance concept, as it can lead to overdose reactions (higher parent drug/metabolite activation) or to sub-therapeutic exposures (lower parent drug/metabolite inactivation) to drugs when normal doses are administered (Dumas and Pollack, 2008; Omiecinski et al., 2011; Jaeschke, 2013). However, the effect that xenobiotics can exert on the induction or inhibition of biotransformation enzymes is especially difficult to predict with the currently existing in vitro and in vivo drug testing models, mainly due to interspecies and inter-individual differences, or decreased cells functionality (Reder-Hilz et al., 2004; Zanger et al., 2007; Godoy et al., 2013).

Genetic polymorphisms are particularly relevant risk factors regarding drug-metabolizing enzymes and may represent susceptibility biomarkers, important for predicting potential hepatotoxicity risks. Genetic polymorphisms are common gene variations that might encode for impaired/altered metabolic enzymes and generate different population subgroups in terms of metabolism assessment (Meyer and Zanger, 1997; 




FIGURE 1 | Schematic representation of the mechanisms of hepatotoxicity including examples of associated drugs. Drug biotransformation (phase I and II metabolism) is based on the chemical modification of a parent drug into a metabolite which may become inactive (detoxification), leading to its rapid and innocuous excretion, or reactive (bioactivation), leading to potential toxicity. Specifically, hepatotoxicity may result from direct damage, from failure of repairing mechanisms or from immune-mediated responses, leading to alterations in lipids metabolism, mitochondrial dysfunction, oxidative stress and accumulation of bile, amongst others. Moreover, the saturation of cells stress defense mechanisms may lead to carcinogenic events and promote tissue necrosis or fibrosis, resulting in liver's functions impairment. For a given hepatotoxic compound different mechanisms of toxicity can be involved. GSH, reduced glutathione; ROS, reactive oxygen species.

Andrade et al., 2009; Ahmad and Odin, 2017). As this event is not rare, these subgroups need to be accounted in a drug development scheme and, thus, properly mimicked at the non-clinical stage. Interindividual variability concerning phase I, II, and III enzyme expression can also justify some cases of hepatotoxicity. Genetic polymorphisms are reported to affect the biotransformation of drugs dependent on CYP2C9, CYP2C19, CYP2B6, CYP2D6, CYP3A4, and CYP3A5 subfamilies, phase II enzymes uridine $5^{\prime}$-diphosphate glucuronosyltransferase (UGT) 1A1, UGT2B7 and $N$-acetyltransferase (NAT) 2, and hepatic transporters multidrug resistance protein (MDR) 1, breast cancer resistance protein (BCRP), MRPs, and OATP1B1, amongst others (Wienkers and Heath, 2005; Zanger et al., 2007; Brockmöller and Tzvetkov, 2008; Shah et al., 2015; Krasniqi et al., 2016; Saiz-Rodríguez et al., 2020). Some classical examples include CYP2D6, due to its clinical impact in the bioactivation of drugs such as codeine, tramadol, or tamoxifen within low or extensive metabolizers (Cavallari et al., 2019). Another classical example are NAT2 polymorphisms, reflected in slow, intermediate, and rapid acetylators of drugs, particularly isoniazid (antituberculosis drug), in which the former presents potentially more ADRs than the latter (Brockmöller and Tzvetkov, 2008). Moreover, an inherited mutation in the adenosine triphosphate (ATP)-binding cassette subfamily $\mathrm{B}$ (ABCB) 11 gene, which encodes for bile salt export pump (BSEP), may lead to the diminishing of the bile acids transport and clearance, potentially leading to cholestasis (Kenna and Uetrecht, 2018).

\section{Mechanisms of Hepatotoxicity}

The liver is a prime target for drug-induced damage due to its central role for concentrating and metabolizing the majority of drugs. Therefore, earlier and better understanding of drug modes of action and toxicity are essential (Kola and Landis, 2004; Paul et al., 2010; Padda et al., 2011). As above mentioned, following exposure, the toxic effect of a given drug may be attributed directly to the interaction of the parent drug or the product of its biotransformation, with an endogenous target through covalent or non-covalent binding, hydrogen abstraction, electron transfer, or enzymatic reactions, resulting in dysfunction or destruction of the target molecules (Chan and Benet, 2017). Moreover, besides arising from direct damage by the molecule, hepatotoxicity may also be resultant from a failure of repair mechanisms or due to immune-mediated responses. The mechanisms of hepatotoxicity more frequently described are depicted in Figure 1 and involve:

i) Mitochondrial dysfunction, an effect that may occur upon the exposure to different drugs, particularly amiodarone (Bethesda, 2012), nimesulide (Singh et al., 2010), troglitazone (Smith, 2003), or valproic acid (Xu et al., 2019); 
ii) Oxidative stress, as observed for instance upon paracetamol or nitrofurantoin administration (Bethesda, 2012; Bruderer et al., 2015; Ramachandran and Jaeschke, 2018);

iii) Covalent binding with proteins that may impair their transporter function leading to accumulation of toxic elimination products and intrahepatic cholestasis (Boelsterli, 2003; Padda et al., 2011), as reported for ethinylestradiol and cyclosporine (Bethesda, 2012). It may also alter their conformation or structure as observed on the inhibition of hepatic synthesis of coagulation factors by exposure to coumarins (Grattagliano et al., 2009; Gregus, 2013);

iv) DNA damage, as suggested in the context of nevirapine toxicity (Kranendonk et al., 2014; Pinheiro et al., 2017; Marinho et al., 2019);

v) Depletion of enzymes or co-factors as observed upon paracetamol overdose (Mazaleuskaya et al., 2015; Ramachandran and Jaeschke, 2018);

vi) Dysfunction of cell repairing mechanisms that can result in: tissue necrosis, as for example by sulfasalazine, ketoconazole, or valproic acid (Kleiner, 2017); in fibrosis, by e.g., chronic exposure to methotrexate, high doses of retinol (vitamin A), and iron intoxication (Zhang et al., 2016); or in carcinogenesis, as a consequence of aflatoxin B1 exposure (Gregus, 2013; Jaeschke, 2013; Cai et al., 2020);

vii) Immunological-mediated tissue damage, that has been linked to NSAIDs such as diclofenac (Aithal et al., 2004), antibiotics such as amoxicillin-clavulanate (Bethesda, 2012) or flucloxacillin (Woolbright and Jaeschke, 2018) and anticonvulsants such as carbamazepine or lamotrigine (Bethesda, 2012).

These molecular mechanisms may intersect with each other leading to a cascade of key events. Indeed, an initial drugrelated reactive oxygen species (ROS) formation may lead to lipid peroxidation on fatty acids chains in the cell membrane. In parallel, $\beta$-oxidation of lipids and oxidative stress may cause mitochondrial membrane permeabilization and dysfunction, ultimately leading to hepatocyte apoptosis. The rupture of the mitochondrial membrane can result in ATP depletion that accompanied by an increase in intracellular calcium concentration may generate liver necrosis. Conversely, inhibition of peroxisomal fatty acid $\beta$-oxidation may result in abnormal triglycerides accumulation in the hepatocyte and result in liver steatosis (Gregus, 2013). Adverse outcome pathways (AOPs) are promising tools in that regard, as they describe existing knowledge concerning the linkage between a direct molecular initiating event (MIE) and an adverse outcome through a number of key events (KEs) at a biological level of organization relevant to risk assessment (Gijbels and Vinken, 2017).

At the cellular level, the paracrine communication between hepatocytes and NPCs is also crucial for the response to a toxic insult. It has been reported that NPCs, after a primary injury of the hepatocyte, exhibit a secondary response that may aggravate or ameliorate the initial lesion, e.g., metabolic alterations and activation of immune cells, such as Kupffer cells and lymphocytes (Figure 1; Godoy et al., 2013; Kostadinova et al., 2013; Messner et al., 2013; Leite et al., 2016; Proctor et al., 2017; Bell et al., 2020; Li et al., 2020).

\section{LIVER IN VITRO MODELS FOR TOXICOLOGICAL STUDIES}

Both liver metabolism and the mechanisms of initial liver injury are important to comprehend the potential toxicity of a drug. Therefore, the development of efficient and fit-for-purpose in vitro models should mimic the complexity of the in vivo hepatic milieu. As such, when building a relevant liver in vitro model, the hepatic cell sources and tissue architecture, flow dynamics and the formation of molecular gradients need to be carefully considered.

No universally accepted hepatocyte source that provides robust, predictive and significant toxicological and pharmacological results is currently available. Cell source selection depends on cell availability and study requirements while understanding the limitations associated to each cell origin, namely metabolic competence, stability, and population representativeness (Soldatow et al., 2013). Regarding culture architecture, efforts have been focused in better mimic the in vivo microenvironment, giving special attention to culture three-dimensionality either by taking advantage of cell selfassembling capacity or by using natural polymers. More complex systems, such as bioreactors, micropatterning techniques, or microfluidic devices can also be employed (Miranda et al., 2010; Bell et al., 2016; Knospel et al., 2016; Adiels et al., 2017). Those platforms should also allow acute toxicity studies and long-term assessment so that the exposure to a xenobiotic generates relevant responses (Jiang et al., 2019). Overall, the value of an in vitro model depends on how well it reproduces the key physiological characteristics of an in vivo system. However, the criteria for defining liver function maintenance in vitro are not consensual, ranging from focusing on the preservation of hepatocyte phase I and II enzyme functions to the inclusion of a broader spectrum of tissue characteristics involved in human liver toxicity, such as the incorporation of NPCs for mimicking cells' crosstalk (Bale et al., 2014; Zeilinger et al., 2016; Langhans, 2018; Bell et al., 2020).

Some common evaluated features to compare hepatic cell-based in vitro culture systems' value for toxicological applications include cell morphology, viability, and functional stability; metabolic capacity; preservation of hepatic-specific gene expression under long-term cultures; and response to a panel of well-accepted reference drugs (e.g., paracetamol and valproic acid) capable of replicating human in vivo intrinsic DILI (Miranda et al., 2009, 2010; Leite et al., 2011; Mueller et al., 2011; Tostoes et al., 2011; Cipriano et al., 2017b; Pinheiro et al., 2017; Vinken and Hengstler, 2018; Bell et al., 2020). Moreover, the generated data should be able to be correlated to clinical observations, reproducible, comparable among laboratories, and analyzed properly to support decisionmaking with a clear definition of the models' applicability and limitations (Dash et al., 2009; Vinken and Hengstler, 2018; Albrecht et al., 2019). 


\section{Liver Cell-Based Versus Stem Cell-Based Models}

Over the past decades, large efforts have been made to establish predictive in vitro liver test models. However, despite the number of reports available, a comprehensive and systematic comparison between cell culture systems adequate to objectively rank or select them for pharmacological and toxicological applications is still scarce.

Several in vitro human-based models for the prediction of hepatotoxicity have been developed using a range of cell sources and endpoints. These include the use of liver slices, genetically engineered cells, human hepatoma cell lines (e.g., HepG2, THLE, and HepaRG cells), primary hepatocytes or stem cell (SC)-derived models (Gomez-Lechon et al., 2008; Asha and Vidyavathi, 2010; Sirenko et al., 2016; Gao and Liu, 2017; Pinheiro et al., 2017; Nudischer et al., 2020). Figure 2 summarizes the advantages and limitations of each cell source for in vitro testing, as well as their in vivo physiological relevance.

Liver slices and isolated perfused livers, containing both parenchymal and NPCs, retain liver's structure and thus maintain zone-specific enzymatic activity. However, within hours, the cell functionality decreases and necrosis takes place (LercheLangrand and Toutain, 2000; Boess et al., 2003; Haschek et al., 2009). It is associated with limited throughput and requires continuous animal experimentation and personnel expertise (Vernetti et al., 2017).

Alternatively, cell-based models are less complex and associated to higher throughput screening for the identification of hepatotoxic compounds. Primary hepatocytes, either obtained from human liver autopsies or biopsies or from animal livers, have been used for cytotoxicity, biotransformation, and PK studies (Vernetti et al., 2017). Human primary hepatocytes (hpHep), in particular, are considered the gold standard in human-relevant liver in vitro models for cytotoxicity and drug metabolism testing, retaining most of the native tissue's functionality, namely phase I and phase II enzymes (Godoy et al., 2013; Zeilinger et al., 2016). However, both the limited availability of primary human cells and its suitability only for shortterm studies under monolayer cultures are major disadvantages. Indeed, in $2 \mathrm{D}$ conditions, it is observed a progressive loss of the hepatic phenotype in a process called de-differentiation, which is a consequence of the disruption of cell-cell and cell-matrix connections (Zeilinger et al., 2016). Additionally, hpHep display inter-donor variability and thus the use of different cell batches to validate results is advised, covering several metabolic genetic polymorphism and phenotypes (Godoy et al., 2013; Zeilinger et al., 2016). On the other hand, rat primary hepatocytes (rpHep), despite being more easily available, present relevant interspecies differences (Sandker et al., 1994; Li et al., 2008; Ménochet et al., 2012; Shen et al., 2012).

Human hepatoma cell lines, such as HepG2 and HepaRG, have no limitations in terms of cell numbers and are easy to culture, but display poor phenotype and functional match to in vivo hepatocytes (Gerets et al., 2012). The use of these cell lines do not consider populational differences and may reflect characteristics that primary cells do not have, e.g., being more sensitive to compounds with anti-proliferative properties (Sirenko et al., 2016). HepG2 present low levels of CYPs and normal levels of phase II enzymes except for UGTs (Westerink and Schoonen, 2007a,b), which make them appropriate for testing the toxicity of the parent compound but less suited for metabolite toxicity testing. Instead, HepaRG cell line composed of a mixture of both hepatocyte-like and biliary-like cells, have been reported to maintain hepatic functions and expression of liver-specific genes comparable to hpHep without the inter-donor variability and functional instability issues (Guillouzo et al., 2007). Nevertheless, it should be noted that a cell characterization study at the mRNA/gene expression and CYP activity levels, by Gerets et al. (2012), revealed that although it is a suitable model for induction studies, these cells were not as indicative as hpHep for the prediction of human hepatotoxic drugs, being comparable to HepG2 cells. On the other hand, Lübberstedt et al. (2011) showed that HepaRG presented similar or even higher CYP2C9, CYP2D6, and CYP3A4 enzyme activity than that of hpHep, whereas Aninat et al. (2006) confirmed the presence of relevant UGT1A1 and GST activity levels. Still, high metabolic capacity in cell lines does not necessarily correlate with high sensitivity for the hepatotoxicity detection (Gerets et al., 2012). Thus, unfortunately, even the most promising and differentiated hepatoma cells do not constitute an ideal surrogate system for human hepatocytes for hepatotoxicity studies, as they do not reproduce the drug-metabolizing enzyme pattern of human hepatocytes. An alternative approach to overcome the limitations of hepatic cell lines is to genetically modify cells with vectors encoding for human CYP enzymes and other genes involved in xenobiotic metabolism (Coecke et al., 2001; Kanamori et al., 2003; Gomez-Lechon et al., 2008; Prakash et al., 2008; Godoy et al., 2013). However, the number of enzymes that can be satisfactorily transfected into cells is low and the metabolic profiles differ from those of primary hepatocytes (Frederick et al., 2011; Godoy et al., 2013).

To overcome the limitations of the above mentioned cell sources, SC-derived human hepatocyte-like cells (HLCs) have been suggested as a reliable alternative (Szkolnicka et al., 2014; Takayama et al., 2014; Freyer et al., 2016; Cipriano et al., 2017a,b, 2020; Figure 2). SCs represent normal primary cells with a mostly stable genotype than hepatoma cell lines. Moreover, compared to hpHep, present unlimited supply, can be maintained for long-term and may also represent a broad patient population (Godoy et al., 2013; Horvath et al., 2016). As such, stem or progenitor cells are an exciting prospect for drug metabolism studies and cell transplantation, providing that high levels of hepatocyte-like functions can be induced and tumorigenicity concerns are overcome. Many protocols have been developed for differentiating SCs into HLCs with different approaches, such as mimicking liver development through the sequential addition of growth factors and cytokines (Cai et al., 2007; Hay et al., 2008b; Brolén et al., 2010), modulation of signaling pathways (Hay et al., 2008a) or by using epigenetic modifiers (Sharma et al., 2006; Dong et al., 2009; Norrman et al., 2013). Currently, most work has been developed using induced pluripotent SCs (iPSCs) isolated from adult tissues in an non-invasive way, with 




FIGURE 2 | Summary of the advantages and limitations of commonly used cell sources for in vitro liver models. HLCs, hepatocyte-like cells; hpHep, human primary hepatocytes; NPCs, non-parenchymal cells. 
promising outcomes (Sauer et al., 2014; Sirenko et al., 2016; Yamashita et al., 2018; Pareja et al., 2020). An example is the work from Gao and Liu (2017), that revealed that iPSC-derived HLCs resembled hpHep more closely than most hepatoma cell lines in global gene expression profiles, specifically in the expression of genes involved in hepatotoxicity, drug-metabolizing enzymes, transporters, and nuclear receptors. Interestingly, Freyer et al. (2016) detected CYP1A2, CYP2B6, and CYP3A4 activities in iPSC-derived HLCs, but also at a lower level than in hpHep. Likewise, Takayama et al. (2014) showed that iPSC-derived HLCs retained donor-specific drug metabolism capacity and drug responsiveness, reflecting interindividual differences, but lower CYP1A2, CYP2C9, CYP2D6, and CYP3A4 activities when compared to the correspondent hpHep donors. Besides hepatocytes, efforts have also been made to generate NPCs from iPSCs, including cholangiocytes (Ogawa et al., 2015; Sampaziotis et al., 2015), Kupffer cells (Tasnim et al., 2019), LSECs (Koui et al., 2017), and hepatic stellate cells (Koui et al., 2017; Coll et al., 2018). Nevertheless, iPSC technology has some limitations related to the genomic instability and to residual iPSC-specific methylation patterns that links these cells to their tissue of origin, which ultimately may affect their final differentiation (Robinton and Daley, 2012). Still, iPSC-derived HLCs show powerful value not only for toxicology applications but also for disease modeling and personalized drug therapy.

Alternatively, adult liver SCs (LSCs) are a particularly interesting SC source. LSCs can be obtained from liver biopsies, propagated in vitro and differentiated into mature hepatocytes (Huch et al., 2015; Wang et al., 2015; Luo et al., 2018). LSCs are located in the epithelium of the canals of Hering and contribute to liver regeneration in response to an injury (Overi et al., 2018). LSCs are bipotent, being able to differentiate into hepatocytes or cholangiocytes. As such, these cells express SC (e.g., SRY-box transcription factor 9, Sox9), cholangiocyte (CK19), and hepatocyte (CK-18) markers (Overi et al., 2018). The identification of populations of proliferating and self-renewing cells that can replace injured hepatocytes can be performed with lineage tracing approaches using Wnt-responsive genes such as Axin2 or Lgr5 (Huch et al., 2013; Wang et al., 2015).

Mesenchymal SCs (MSCs) including liver, bone-marrow, adipose, or umbilical cord tissue-derived MSCs have also been used for deriving human HLCs (Snykers et al., 2006, 2007; Banas et al., 2007; Kazemnejad et al., 2008; Okura et al., 2010; Yin et al., 2015; Fu et al., 2016; Yang et al., 2020). From those, human neonatal MSCs stand as a promising choice due to the noninvasive access and to its more primitive origin (Hass et al., 2011; Lee et al., 2012; Cipriano et al., 2017a; Yu Y. B. et al., 2018. The first report using human neonatal umbilical cord tissue-derived MSCs (hnMSCs) was from Campard et al. (2008). Therein, hnMSCs were differentiated into HLCs with impressive results, i.e., presenting hepatic-specific markers, urea production, glycogen accumulation, and CYP3A4 activity. Afterward, other researchers also differentiated hnMSCs into HLCs exhibiting hepatic markers, urea and albumin (ALB) production. However, their biotransformation activity was not assessed (Zhang et al., 2009; Zhao et al., 2009; Zhou et al., 2014). More recently, Cipriano et al. (2017a) generated hnMSC-derived HLCs with more partial hepatic phenotype, sharing expression of gene groups with hpHep that was not observed between HepG2 and hnMSCs, as shown by genome-wide analysis (Cipriano et al., 2017a). Importantly, when resorting to the 3D culture technology, MSC-derived HLCs demonstrate an improvement in phase I biotransformation activity, urea and ALB production, as well as relevant diclofenac and nevirapine biotransformation capacity, which supports its potential usefulness for toxicological studies (Cipriano et al., 2017b, 2020). Nevertheless, despite the growing efforts made in this research field a complete mature hepatocyte phenotype of HLCs derived from MSCs has not yet been achieved. Perhaps liver MSCs may be the best choice, because they are originally committed to hepatic lineage, but an accurate comparison of hepatocytes derived from human liver MSCs and other sources must still be done (Kholodenko et al., 2019; Shi et al., 2020).

All these strategies are not deprived of challenges as they require specialized personnel and expensive culture medium supplementation, whereas a complete mature phenotype has not yet been achieved. The fetal HLC phenotype is still a challenge, revealing the need to further understand hepatic differentiation mechanisms and optimizing differentiation strategies (Raju et al., 2018; Raasch et al., 2019). Moreover, the use of diverse differentiation protocols across different laboratories hinders the robustness assessment of the use of HLCs for toxicology applications. To address this issue, some authors proposed a set of cellular markers and functional assays to control the quality of iPSC-derived cells, since these are the most common type of SCs used in vitro (Daston et al., 2015; Beken et al., 2016). Although the specific metrics to monitor cell characteristics may vary according to the differentiation protocol and cell line used, this guide provides an important reference for quality control of other types of SC-based models. For HLCs, the most important markers to be analyzed are CYP3A4, CYP2B6, CYP1A1/2, CYP2C9, CYP2C19, CYP2D6, alpha-fetoprotein (AFP), ALB, Sox17, C-X-C motif chemokine receptor 4 (CXCR4), hepatocyte growth factor (HGF), hepatocyte nuclear factor 4 alpha (HNF$4 \alpha$ ), tyrosine aminotransferase (TAT), transthyretin (TTR) while functional assays include urea and ALB synthesis, glycogen uptake, fibrinogen secretion, ATP, and GSH levels, CYP3A activity in particular, phase II activities and drug transporter capacity (Beken et al., 2016). Nonetheless, due to overall unsatisfactory phenotype of the currently available cell sources, at least for some hepatic features, the improvement of the cell culture system has been explored as will be further described in the following sections.

\section{Three-Dimensional Liver Systems}

The major shortcoming of the currently available in vitro liver preparations lays on insufficient hepatocyte-like functions and metabolic competence. In fact, none of the hpHep-, HepG2-, or HepaRG-based 2D models are suitable to indicate the risk of hepatotoxicity for novel chemical entities unless PK data are incorporated in the study, supporting the need to employ more sophisticated technologies to increase prediction sensitivity (Sison-Young et al., 2017). Accordingly, recent reports emphasize a shift, by the industry, from $2 \mathrm{D}$ in vitro 
A

mechanisms.
B

D

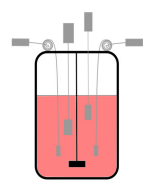

Bioreactors

- Remote monitoring of culture parameters and metabolic function - high control in oxygen, nutrient and drug gradients;

- Operation under perfusion is possible;

- Scalable;

- Possibility of PBPK/TKTD studies

- Adaptable to high-throughput screening.
Static spheroid cultures

- Spheroids are formed due to cells capacity to self-aggregate; self-aggregate; Allows testing

fewer cells;
Step to produce spheroids for dynamic cel cultures.
C



Dynamic spheroid cultures Mimicking of blood flow and in vivo oxygen, nutrient and drug gradients; Operation under perfusion is possible; Mass production of liver cells.

\section{D liver systems}

E



F

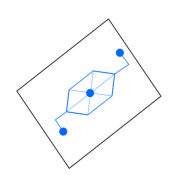

Microfluidic platforms

- Designed in a fit-for-purpose fashion;

Low reagent volumes and cell number needed;

- Control of fluid flow and spatial arrangement;

Allows to represent multiple tissues in interaction, useful for PBPK/TKTD studies and for assessing system-based toxicity mechanisms;

- Enables high-throughput screening.
Advantages of 3D cultures

Modulation of:

- Fluidic flow;

- Oxygen tension;

- Medium gradients;

- Cell-cell and cell-matrix interactions;

- Intra- and inter-tissue interactions.

Co-culture of hepatocytes and NPCs is possible.

Disadvantages of 3D cultures

- Higher complexity;

- Labor intensive;

- Requires trained personnel and specialized equipment/material.

FIGURE 3 | Summary of the characteristics of complex 3D in vitro cell culture systems for hepatotoxicity studies. (A) Sandwich cultures; (B) static spheroid cultures: (C) dynamic spheroid cultures; (D) bioreactors; (E) bioprinting; (F) microfluidic platforms. PBPK, physiologically based pharmacokinetic modeling; TD, toxicodynamics; TK, toxicokinetics.

approaches to more complex 3D assays where multicellular microphysiological devices are being evaluated within a vision to replicate the characteristics and response of human tissues in vivo (Vivares et al., 2015).

Traditionally, 2D cultures are employed as in vitro models due to their ease of use to quickly screen large numbers of compounds. However, this culture approach negatively impacts cell expression profiles (Engler et al., 2006) and causes primary hepatocytes to rapidly lose their differentiation markers (Treyer and Müsch, 2013), compromising long-term and repeated dose studies. On the other hand, 3D cell culture systems have been shown to improve the biotransformation capacities in primary hepatocytes (Tibbitt and Anseth, 2009; Miranda et al., 2010; Mandenius et al., 2011; Mueller et al., 2011; Zeilinger et al., 2011; Schyschka et al., 2013), hepatoma cell lines (Fey and Wrzesinski, 2012; Molina-Jimenez et al., 2012; Wrzesinski et al., 2014) and SC-derived HLCs (Gieseck et al., 2014; Freyer et al., 2016; Cipriano et al., 2017b, 2020) over time in culture.

In general, as summarized in Figure 3 and Table 1, 3D cell culture systems are prone to high-throughput adaptation and scale up but vary in complexity and on remote monitoring of cell culture parameters. Three-dimensional systems can comprise extracellular matrix (ECM) sandwich cultures (Chatterjee et al., 2014; Deharde et al., 2016), spheroid and organoid cultures (Miranda et al., 2009; Leite et al., 2011, 2012; Tostoes et al., 2011; Wrzesinski et al., 2014; Huch et al., 2015; Bell et al., 2016; Peng et al., 2018; Ramli et al., 2020), cells adherent to a scaffold (Kazemnejad et al., 2008; Lin and Chang, 2008; Haycock, 2011), or more complex cellular systems such as hollow-fiber bioreactors (Darnell et al., 2011, 2012; Lübberstedt et al., 2011; Mueller et al., 2011; Zeilinger et al., 2011; Hoffmann et al., 2012; Cipriano et al., 2017b), bioartificial livers (Chan et al., 2004), multi-well perfused bioreactors (Domansky et al., 2010; Vivares et al., 2015; Aeby et al., 2018; Mannaerts et al., 2020), and more recently bioprinted systems (Lauschke et al., 2016; Goulart et al., 2019) and microfluidic platforms (MP) (Rennert et al., 2015; Ma C. et al., 2016; Bauer et al., 2017; Danoy et al., 2019).

Three-dimensional cell cultures can also be achieved using either static or dynamic systems. Static systems are less complex and do not include medium flow, while dynamic systems might be stirred and/or perfused, depending on the cell culture system complexity (Miranda et al., 2009, 2010; Tostoes et al., 2011). Static culture systems are compliant with high-throughput and are usually adopted for the optimization of culture medium constitution, to test a diversity of toxic compounds using fewer cells or as a step to produce spheroids to be used in more complex 3D culture systems, e.g., bioreactors (Wrzesinski et al., 2014; Fey et al., 2020). In contrast, stirring conditions facilitate oxygen diffusion as well as medium homogenization, further resembling the physiological blood flow, and create a hydro-dynamic shear stress that must be balanced, by improving cell performance while avoiding cellular stress and death (Conway et al., 2009). Also, a continuously perfused system is particularly interesting in hepatocyte cell culture and in xenobiotic metabolism studies, avoiding fluctuations of basic cell culture parameters such as $\mathrm{pH}$, oxygen, glucose, and lactate concentration and the accumulation 
TABLE 1 | Advanced 3D liver cell models commercially available.

\begin{tabular}{|c|c|c|c|}
\hline $\begin{array}{l}\text { Commercial } \\
\text { name }\end{array}$ & Cell model & Features & $\begin{array}{l}\text { Studies employing the advanced } \\
\text { liver model }\end{array}$ \\
\hline $\begin{array}{l}\text { LiverChip/PhysioMimi } \\
\text { Liver-on-Chip }\end{array}$ & $\begin{array}{l}\text { XHuman or rat primary hepatocytes cultured with } \\
\text { NPCs (e.g., liver sinusoidal endothelial cells, } \\
\text { LSECs; stellate and Kupffer cells) }\end{array}$ & $\begin{array}{l}\text { Liver tissue-engineered perfused bioreactor; } \\
\text { Viability for at least } 1 \text { month; Scalable; Allows to } \\
\text { mimic liver zonation; Allows PBPK studies; Allows } \\
\text { prediction of in vivo hepatic clearances; Expression } \\
\text { of genes of phase I, phase II, and phase III similar to } \\
\text { freshly thawed hepatocytes }\end{array}$ & $\begin{array}{l}\text { Domansky et al., 2010; Vivares et al., } \\
\text { 2015; Tsamandouras et al., } 2017\end{array}$ \\
\hline H $\mu$ REL Technology & $\begin{array}{l}\text { Human, primate, dog or rat primary } \\
\text { hepatocytes cultured with NPCs }\end{array}$ & $\begin{array}{l}\text { Compartments designed to represent } \\
\text { tissue-functional units (microfluidic devices); Viability } \\
\text { for at least } 10 \text { days; Phase I and phase II enzymes } \\
\text { activity similar to freshly thawed hepatocytes; } \\
\text { Allows prediction of in vivo hepatic clearance, } \\
\text { particularly with low clearance compounds; Enables } \\
\text { multi-parametric and repeated-dose readouts }\end{array}$ & $\begin{array}{l}\text { Chao et al., 2009; Bonn et al., 2016; } \\
\text { Hultman et al., 2016; Novik et al., } 2017\end{array}$ \\
\hline HepaPredict & $\begin{array}{l}\text { Human primary hepatocytes cultured with } \\
\text { Kupffer, stellate and biliary cells }\end{array}$ & $\begin{array}{l}\text { Spheroids in well-plates; Viability for at least } \\
35 \text { days; Allows to study inter-individual variability; } \\
\text { Expression of genes of metabolic enzymes, drug } \\
\text { and bile transporters similar to isolated } \\
\text { hepatocytes; CYP1A2, CYP2C8, CYP2C9, } \\
\text { CYP2D6, and CYP3A4 activity; Polarized cellular } \\
\text { organization with functional bile canaliculi; Enables } \\
\text { studies of chronic toxicity, long-term metabolic } \\
\text { analyses, enzyme induction assays, drug target } \\
\text { validation and disease modeling }\end{array}$ & $\begin{array}{l}\text { Bell et al., 2016, 2017; Hendriks et al., } \\
\text { 2016; Vorrink et al., } 2017\end{array}$ \\
\hline HepatoPac & $\begin{array}{l}\text { Human, monkey, dog or rat primary } \\
\text { hepatocytes supported by mouse embryonic } \\
\text { 3T3 fibroblasts }\end{array}$ & $\begin{array}{l}\text { Micropatterned plates; Viability for at least } 4 \text { weeks; } \\
\text { Phase I, phase II, and phase III enzymes activity } \\
\text { similar to primary hepatocytes; Allows prediction of } \\
\text { in vivo hepatic clearance, particularly with low } \\
\text { clearance compounds }\end{array}$ & $\begin{array}{l}\text { Khetani and Bhatia, 2008; Wang et al., } \\
\text { 2010; Chan et al., 2013; Kratochwil } \\
\text { et al., } 2018\end{array}$ \\
\hline $\begin{array}{l}\text { 3D InSightLiver } \\
\text { Microtissues }\end{array}$ & $\begin{array}{l}\text { Human, monkey, dog or rat primary } \\
\text { hepatocytes cultured with Kupffer cells and } \\
\text { LSECs }\end{array}$ & $\begin{array}{l}\text { 96-well format, } 1 \text { microtissue per well; Viability up to } \\
28 \text { days; Albumin secretion; Activity of cytochrome } \\
\text { P450; Polarized cellular organization with functional } \\
\text { bile canaliculi; High mitochondrial function; Allows } \\
\text { hepatotoxicity assessment and disease modeling }\end{array}$ & $\begin{array}{l}\text { Messner et al., 2013, 2018; Proctor } \\
\text { et al., } 2017\end{array}$ \\
\hline $\begin{array}{l}\text { MIMETAS } \\
\text { OrganoPlate }\end{array}$ & $\begin{array}{l}\text { Human primary hepatocytes, HepaRG, } \\
\text { iPSC-derived, UpCytes, and HepG2 cultured } \\
\text { with stellate cells, Kupffer cells, bile duct, and } \\
\text { LSECs }\end{array}$ & $\begin{array}{l}\text { Supports up to } 96 \text { tissues on a single well-plate; } \\
\text { Viability for at least } 2 \text { weeks; Polarized cellular } \\
\text { organization with functional bile canaliculi; Perfusion } \\
\text { supports long-term culture and formation of } \\
\text { adjacent LSECs tubular structure; Defined ECMs } \\
\text { tailored to support liver cells; Allows PBPK studies; } \\
\text { Allows disease modeling }\end{array}$ & Jang et al., 2015 \\
\hline Liver-Chip & $\begin{array}{l}\text { Human, dog or rat primary hepatocytes } \\
\text { cultured with NPCs }\end{array}$ & $\begin{array}{l}\text { Microfluidic device; Viability up to } 2 \text { weeks; Albumin } \\
\text { and urea secretion; CYP1A2, CYP2B6, and } \\
\text { CYP3A4 activity; Polarized cellular organization with } \\
\text { functional bile canaliculi; Allows energy metabolism } \\
\text { studies; Allows the recapitulation of different } \\
\text { hepatotoxicity mechanisms (e.g., steatosis, } \\
\text { cholestasis, and fibrosis) }\end{array}$ & Jang et al., 2019 \\
\hline
\end{tabular}

of metabolites that influence the PK of a specific compound (Conway et al., 2009; Miranda et al., 2009; Shvartsman et al., 2009; Mueller et al., 2011; Tostoes et al., 2011; Vinci et al., 2011; Zeilinger et al., 2011; Lauschke et al., 2016; McCarty et al., 2016; Prodanov et al., 2016). In addition, stirred and/or perfused systems promote a liver-like mass transfer which might mimic liver zonation in vitro (Allen et al., 2005; McCarty et al., 2016; Tomlinson et al., 2019). This wide variety of studies employs distinct cell sources and distinct approaches for creating $3 \mathrm{D}$ culture systems, showing encouraging results for in vitro hepatotoxicity models.

\section{Sandwich Cultures}

The sandwich culture system consists of culturing hepatocytes between two layers of ECM, usually gelled collagen or Matrigel ${ }^{\circledR}$ (Figure 3A). The ECM constitution influences cell disposition and function as the underlay matrix in sandwich cultures controls cell morphology and multicellular arrangement while the overlay matrix impacts bile excretion behavior (Deharde et al., 2016; Langhans, 2018). Sandwich-cultured hepatocytes regain polarity, maintaining proper basolateral and canalicular transporters localization and functional bile canaliculi. This 3D culture system is particularly important for the estimation of 
transport clearance, enzyme-transporter interplay, and bile acid mediated hepatotoxicity (Tuschl et al., 2009; Chatterjee et al., 2014; Deharde et al., 2016; Yang et al., 2016; Zeigerer et al., 2017). Data generated with sandwich models can also be used to establish quantitative relationships between intracellular bile acid accumulation and cytotoxicity and this information can be incorporated into pharmacology models for DILI and hepatic clearance predictions (Ogimura et al., 2011; Camenisch and Umehara, 2012; Umehara and Camenisch, 2012; Yang et al., 2016). Indeed, Chatterjee et al. (2014) used sandwich culture systems from hpHep and rpHep and evaluated the system with a set of compounds correctly flagging clinically known cholestatic compounds (eight out of the nine). The major limitation of sandwich cultures of hpHep is that in the long-term it has been reported leakage, bile canaliculi damage and development of cholestasis in a time-dependent manner (Deharde et al., 2016; Zeigerer et al., 2017). This indicates the need to improve culture conditions and increase the stability of the bile canalicular network necessary to model hepatobiliary excretion processes in vitro (Rowe et al., 2013; Deharde et al., 2016; Zeigerer et al., 2017; Bell et al., 2018). Nevertheless, sandwich cultures are a valuable tool for short-term studies of hepatobiliary drug disposition and for assessing the underlying mechanisms of hepatotoxicity.

\section{Multicellular Spheroid Cultures}

Three-dimensional systems of multicellular spheroids take advantage of the self-assembling capacity of cells to form aggregates and maintain cell viability, over an extended time in culture while keeping a better hepatocyte-like functional phenotype when compared to 2D cultures (Messner et al., 2013; Wrzesinski et al., 2014; Bell et al., 2016; Leite et al., 2016). The different systems for culturing multicellular spheroids are summarized in Table 2.

Non-adhesive surfaces, hanging-drop method, hydrogels, and nanoimprinted structures are some examples of small-scale $3 \mathrm{D}$ systems that allow the formation of organoids or multicellular spheroids of hepatocytes (Messner et al., 2013, 2018; Bell et al., 2016; Koyama et al., 2018; Peng et al., 2018), hepatic cell lines (Ramaiahgari et al., 2014; Leite et al., 2016) or other cell types (Huch et al., 2015; Asai et al., 2017; Cipriano et al., 2017b, 2020; Takebe et al., 2017; Wang S. et al., 2019; Wang Z. et al., 2019; Ramli et al., 2020; Table 2).

The use of non-adhesive surfaces (Figure $3 \mathbf{B}$ ) is the least complex and easier strategy to establish spheroid cultures as it does not require specialized equipment. Herein, spheroid size is controlled by the cell density, media volume and serum concentration. Using ultra-low attachment plates, Bell et al. (2016) showed that cryopreserved hpHep spheroids may constitute a promising in vitro system to study liver function; liver diseases such as steatosis, cholestasis, and viral hepatitis; drug targets, and delayed onset of DILI reactions since proteomic analysis of the spheroid cultures closely resembled intact liver tissues and could reflect inter-individual variability. The adequacy of the model for long-term dosing tests was also demonstrated by the higher sensitivity of 3D cultures to a panel of hepatotoxic agents (Bell et al., 2016). Moreover, spheroids of hepatic cell lines demonstrated an improved phenotype, displaying higher ALB and apolipoprotein B (ApoB) secretion and higher expression of genes related to phase I metabolism, glucose, and lipid metabolism (Nakamura et al., 2011; Takahashi et al., 2015). More recently, immortalized and expandable human liver progenitor-like cells spheroids (iHepLPCs-3D) revealed enhanced hepatic-specific functions and markers and successfully predicted individual heterogeneous toxicities of several drugs (Wang Z. et al., 2019).

Non-parenchymal cells have a key role in liver injury. Thus, the incorporation of stellate cells, Kupffer cells, and sinusoidal endothelial cells in liver cell models has been attempted for improving the prediction of drug toxicity (Messner et al., 2013; Bell et al., 2016; Leite et al., 2016; Proctor et al., 2017; Hafiz et al., 2020; Nudischer et al., 2020). Proctor et al. (2017) demonstrated the higher predictive value of $3 \mathrm{D}$ human liver microtissues (multicellular spheroids), consisting of a co-culture of hpHep, Kupffer cells and liver endothelial cells, due to the increased sensitivity in identifying hepatotoxic drugs within a panel of 110 compounds, when compared to 2D-cultured hpHep (Proctor et al., 2017). Spheroid co-cultures of HepaRG with human hepatic stellate cells also led to the development of a 3D in vitro fibrosis model, maintaining the metabolic competence of the organoid over 21 days (Leite et al., 2016). This 3D model enabled the identification of compounds that induce liver fibrosis, being suitable for repeated dosage studies and displayed differential toxicity and hepatic stellate cell activation profile according to the nature of the compound (Leite et al., 2016).

\section{Dynamic Cell Culture Systems Applied to Hepatic Spheroids}

A limitation of static cultures is that these types of culture do not mimic the blood flow and oxygen, nutrient, and drug gradients that occur in vivo. Therefore, dynamic cell culture systems have been developed to create physiologically relevant versions of such gradients (Miranda et al., 2009, 2010; Leite et al., 2011; Tostoes et al., 2011).

The NASA rotary system, a milestone in dynamic 3D culturing, is a rotating cell culture vessel that simulates a microgravity condition. The low shear force allows spheroid growth as well as high mass transfer of nutrients in media preventing cell death within the spheroid core (Brown et al., 2003). This system has been used to culture spheroids of primary hepatocytes, presenting functional bile canaliculi, up-regulation of hepatocyte-specific functional genes, glycogen storage, as well as ALB production and phase I and II enzymatic activity (Brown et al., 2003; Nelson et al., 2010; Chang and HughesFulford, 2014). It also enabled culturing aggregates of iPSCderived HLCs or of hepatic cell lines with increased upregulation of metabolic and hepatocyte-specific gene transcripts, and expression of tight junction proteins providing a more physiologically relevant system that has even been used for the study of hepatitis viruses infections (Chang and Hughes-Fulford, 2009; Sainz et al., 2009; Berto et al., 2013; Yamashita et al., 2018). Nevertheless, translating this technology to absorption, distribution, metabolism, excretion, and toxicity (ADMET) studies has been challenging due to the expensive equipment and 
TABLE 2 | Advantages and limitations of spheroid forming techniques for in vitro toxicity testing applications.

\begin{tabular}{|c|c|c|c|}
\hline $\begin{array}{l}\text { Spheroid forming } \\
\text { techniques }\end{array}$ & Advantages & Limitations & References \\
\hline $\begin{array}{l}\text { Non-adhesive surface } \\
\text { Ultra-low attachment } \\
\text { plate }\end{array}$ & $\begin{array}{l}\text { Low cost } \\
\text { Easy to perform } \\
\text { Co-culture of different cell types }\end{array}$ & Variation in size/cell number/shape & Leite et al., 2011, 2016; Bell et al., 2016 \\
\hline Hanging drop & $\begin{array}{l}\text { Inexpensive } \\
\text { Easy to perform } \\
\text { Well-controlled spheroid size } \\
\text { Fast spheroid formation } \\
\text { Easy to trace spheroid assembly } \\
\text { Co-culture of different cell types }\end{array}$ & $\begin{array}{l}\text { Labor intensive } \\
\text { Difficult massive production }\end{array}$ & Messner et al., 2013 \\
\hline $\begin{array}{l}\text { Micromolding } \\
\text { Nanoimprinting }\end{array}$ & $\begin{array}{l}\text { Well-controlled spheroid size } \\
\text { Designed aggregate geometry } \\
\text { Co-culture of different cell types }\end{array}$ & $\begin{array}{l}\text { High complexity } \\
\text { Requires specialized facilities }\end{array}$ & $\begin{array}{l}\text { Nakamura et al., 2011; Yoshii et al., } \\
\text { 2011; Chan et al., } 2013\end{array}$ \\
\hline Stirred system & $\begin{array}{l}\text { Low complexity } \\
\text { Massive production } \\
\text { Long-term culture } \\
\text { Dynamic control of culture } \\
\text { conditions } \\
\text { Adaptable to perfusion } \\
\text { Adaptable to online monitoring } \\
\text { Easy to scale up } \\
\text { Co-culture of different cell types }\end{array}$ & $\begin{array}{l}\text { Requires specialized equipment } \\
\text { Requires trained personnel }\end{array}$ & $\begin{array}{l}\text { Miranda et al., 2009, 2010; Leite et al., } \\
2011\end{array}$ \\
\hline Hydrogels/scaffolds & $\begin{array}{l}\text { Availability of a wide range of } \\
\text { natural or synthetic materials } \\
\text { Mimic cues of native ECM } \\
\text { Biodegradable } \\
\text { Protection from shear stress }\end{array}$ & $\begin{array}{l}\text { Batch-to-batch variability of natural } \\
\text { materials } \\
\text { Requires trained personnel } \\
\text { Labor intensive }\end{array}$ & $\begin{array}{l}\text { Miranda et al., 2010; Tostoes et al., } \\
\text { 2011; Tripathi and Melo, 2015; } \\
\text { Christoffersson et al., } 2019\end{array}$ \\
\hline
\end{tabular}

labor intensive loading, maintenance, and harvesting (Hammond et al., 2016).

Alternatively, the spinner flask suspension cultures (Figure 3C) are maintained in a simple and effective stirred system that has been previously described for culturing primary hepatocytes (Sakai et al., 1996; Kamihira et al., 1997; Glicklis et al., 2004; Miranda et al., 2009; Tostoes et al., 2011; Pinheiro et al., 2017), hepatic cell lines (Werner et al., 2000; Chen et al., 2014), and HLCs (Subramanian et al., 2011; Schneeberger et al., 2020). Spinner flask hepatic cultures have been used for mass production of cells for treating liver failure (Sakai et al., 1996; Kamihira et al., 1997; Schneeberger et al., 2020) and for maintaining hepatic cells for toxicological and pharmacological studies (Miranda et al., 2009; Pinheiro et al., 2017). This cell culture system offers the possibility for up-scaling (i.e., $125 \mathrm{~mL}$ to $36 \mathrm{~L}$ of working volume); adaptation to a perfusion system; online culture monitoring (Tostoes et al., 2011); and sampling of cells or cell culture medium for several analyses (Pinheiro et al., 2017), which is particularly interesting for PK studies (Miranda et al., 2009). Some studies resort to the encapsulation of hepatic cells to protect from shear stress while conferring ECM characteristics which may result in enhanced cell performance (Miranda et al., 2010; Chen et al., 2014).

By resorting to spinner flasks, primary hepatocyte spheroids (both of human and rat origin) preserved ALB and urea secretion and biotransformation activity of phase I and phase II enzymes up to 3 weeks (Miranda et al., 2009, 2010; Leite et al., 2011; Tostoes et al., 2011) and were able to metabolize diphenhydramine and troglitazone (Miranda et al., 2009); while hepatoma spheroids demonstrated gradual increase in ALB synthesis and ammonia elimination with increases in rotation speed (Chen et al., 2014). Using a similar system, Pinheiro et al. (2017) also demonstrated the maintenance of the hepatic phenotype through the presence of ALB, cytokeratin (CK)-18, HNF-4 $\alpha$, MRP2, and OATP-C, along with the production of urea and ALB. Stable activity levels of phase I (7-ethoxycoumarin$O$-deethylation, ECOD, and 7-ethoxyresorufin-O-deethylase, EROD, activities) and phase II (sulfotransferase, SULT1A1) enzymes, modulated by nevirapine and its metabolites were also observed (Pinheiro et al., 2017). Positive results have also been obtained with co-cultures of hepatocytes and fibroblasts which demonstrates the importance of ECM interactions in hepatic phenotype (Leite et al., 2011). Moreover, spinner cultures improved $C Y P 3 A 4, A L B$, and MRP2 expression in HLCs and increased ALB and urea production when compared to static cultures (Schneeberger et al., 2020) and were reported for the mass production of liver organoids presenting up-regulated hepatic markers (Subramanian et al., 2011).

\section{Bioreactor Systems}

Bioreactors are containers that provide the optimal requirements for biochemical reactions for the synthesis of a desired product at an industrial scale (e.g., pharmaceuticals, vaccines, or antibodies), and have been primarily developed to grow yeast, bacteria, or animal cells (Mustafa et al., 2018). Bioreactors differ from the previously mentioned dynamic systems by enabling the remote monitoring of cultures, i.e., the accurate control of cell culture parameters that may provide the appropriate stable 
microenvironment for liver cell cultures (Figure 3D; Tostoes et al., 2012; Lübberstedt et al., 2015; Farzaneh et al., 2020). Culture parameters include medium flow, gas tension, temperature, $\mathrm{pH}$, glucose metabolism, lactate production along with the specific determination of hepatic metabolic activity revealed by ammonia detoxification, urea, and ALB secretion, enabling to extrapolate at the cell functional level. As an example, online monitoring of oxygen concentration, which is related with changes in metabolic activity, allows the estimation of cell viability in real time (Mueller et al., 2011; Rowe et al., 2018).

Bioreactors generally operate under linear or circular perfusion. The continuous addition of nutrients, mixing and removal of metabolic by-products ensures that hepatocytes experience smaller gradients of nutrients and hormones which enhance hepatocyte functionality (Tostoes et al., 2011, 2012). Accordingly, when comparing perfusion feeding with 50\% medium replacement, the former showed improved ALB synthesis in non-encapsulated rpHep spheroids whilst urea synthesis and phase I drug metabolizing enzyme activity were improved in alginate encapsulated spheroids (Tostoes et al., 2011). Furthermore, the possibility of running in recirculation and feed mode allows repeated dose testing, reflecting more closely the in vivo situation (Mueller et al., 2011). Tostoes et al. (2012) evaluated the feasibility of using hpHep spheroids for repeated drug dose testing in an automated perfusion bioreactor for 3-4 weeks. These conditions allowed the maintenance of phase I and II enzyme expression and activity responding to induction stimuli, the presence of hepatic markers (HNF$4 \alpha$, CK-18, CYP3A, and ALB) and the maintenance of ALB and urea synthesis rate. The presence of polarity markers and bile canaliculi function further supported the applicability of this system for long-term and repeated drug dose tests (Tostoes et al., 2012).

The hollow-fiber bioreactor is an example of a 3D perfused bioreactor system (Darnell et al., 2011, 2012; Mueller et al., 2011; Hoffmann et al., 2012; Freyer et al., 2016; Knospel et al., 2016; Cipriano et al., 2017b). This system was originally developed to function as extracorporeal liver support system and designed to accommodate a 3D perfusion, high-density culture of human liver cells within a cell compartment volume of $800 \mathrm{~mL}$ (Gerlach et al., 1994, 2003). It consists on a complex capillary network for arterio-venous medium perfusion, oxygen supply, and carbon dioxide removal, with an electronically controlled perfusion device with pumps for medium feed and recirculation, temperature control, and a valve regulated by a gas mixing unit (Darnell et al., 2011; Mueller et al., 2011). Aiming for drug testing applications, the same system was later miniaturized to cell compartment volumes of 8,2 , and $0.5 \mathrm{~mL}$ which enabled a significant reduction of the required cell amounts and reagents while maintaining cell function similar to larger devices (Zeilinger et al., 2011; Lübberstedt et al., 2015; Knospel et al., 2016). Human primary liver cells cultured in such smallscale hollow-fiber bioreactors preserved CYP1A2, CYP2D6, and CYP3A4/5 activities as well as the drug transporters BCRP, MDR1, and MRP2 up to 2 weeks in culture (Zeilinger et al., 2011; Hoffmann et al., 2012). Notably, these systems also displayed relevant biotransformation and toxicity profiles for several drugs, including paracetamol and diclofenac, along with the formation of biliary structures (Hoffmann et al., 2012; Lübberstedt et al., 2015; Knospel et al., 2016).

The implementation of alternative in vitro systems resorting to SC-derived HLCs culture in a bioreactor has also been described (Songyang et al., 2015; Freyer et al., 2016; Cipriano et al., 2017b; Farzaneh et al., 2020). Under such conditions, HLCs present glycogen storage ability, expression of hepatic-specific markers and transporters, including $C K-18, A L B, H N F-4 \alpha, C Y P 1 A 2$, $M R P 2$, and OATP-C, formation of bile duct-like structures, higher ALB production and diclofenac biotransformation (Songyang et al., 2015; Freyer et al., 2016; Cipriano et al., 2017b). Taking advantage of the controlled microenvironment provided by bioreactors, Farzaneh et al. (2020) demonstrated the potent impact of oxygen concentration in the expression of liver-specific genes, ALB and urea secretion and CYP3A4 activity in human hepatic organoids derived from iPSCs.

\section{Bioprinting}

The recent emergence of 3D printer technology (bioprinting), along with the development of biocompatible materials (e.g., hydrogels), has been translated into tissue engineering, constituting a novel fabrication technique. This technology resorts to cell-laden biomaterials as bioinks (Figure 3E) and involves layer-by-layer deposition of cell-embedded polymers guided by a computer-aided design (CAD) software (Ma et al., 2018). It is considered a precise, versatile, and flexible technique that allows controlled cell patterning, thus contributing to create defined heterotypic cell contacts (Nguyen et al., 2016). It may also mimic in vivo ECM and, ultimately, enables to generate a functional tissue or organ. Bioprinting not only constitutes a renewed promise for regenerative and personalized medicine, with the development of patient-specific tissue designs and on-demand creation of complex structures within a short time (Aimar et al., 2019; Tamay et al., 2019), but also constitutes an opportunity for the development of the next-generation devices for toxicology and drug-screening purposes.

Currently, there are already available examples of $3 \mathrm{D}$ bioprinting approaches with enhanced liver cell functionalities in vitro. Liver organoids of HepaRG and human stellate cells printed for mimicking liver lobule presented higher $A L B$ and CYP3A4 expression than HepaRG monolayer cultures (Grix et al., 2018). Similarly, a physiologically relevant bioink allowed hpHep and liver stellate cells to maintain urea and ALB production over 2 weeks while responding to drug treatment appropriately (Mazzocchi et al., 2018). Additionally, Nguyen et al. (2016) developed human 3D bioprinted liver tissues with patientderived hepatocytes and NPCs stable for 4 weeks in culture and identified trovafloxacin toxicity signatures at clinically relevant doses for the first time. Moreover, Kizawa et al. (2017) created a human bioprinted liver tissue maintaining stable drug, glucose metabolism and bile secretion for at least 23 days in culture.

The combination of iPSC-derived hepatic cells and bioprinting technologies has also been reported (Kazemnejad et al., 2008; Ma X. et al., 2016; Goulart et al., 2019; Yu et al., 2019). A 3D-bioprinted structure mimicking liver lobule pattern with iPSC-derived hepatic progenitor cells and human umbilical 
vein endothelial cells and adipose-derived SCs as supporting cells improved the expression of hepatic-specific markers, biotransformation enzymes, and ALB and urea production (Ma X. et al., 2016). Moreover, by taking advantage of the innate biochemical constituents and ultrastructure of the native ECM, Yu et al. (2019) used decellularized ECM and iPSC-derived HLCs as bioink in a hexagonal structure digitally designed, demonstrating the potential of these engineering personalized human tissue platforms.

Despite all the advances brought by $3 \mathrm{D}$ bioprinting, an important limitation is that this technology does not consider post-printing processes that are necessary to better mimic the in vivo environment such as changes in scaffold shape throughout time, resulting from, e.g., coating, cell selforganization, and matrix deposition. To address this issue, a novel technique termed "Four-dimensional (4D) bioprinting" has recently emerged in which constructs continue to evolve after being printed over time, i.e., the fourth dimension (Gao et al., 2016). Four-dimensional adds the advantages of 3D printing while using smart materials able to reshape themselves in response to different stimuli (e.g., $\mathrm{pH}$, temperature, and light) to closely mimic the dynamic responses of tissues (Tamay et al., 2019). The expectation is that using 4D bioprinting technology will produce bioprinted human liver tissues containing human liver cell lines and immunocompetent cells within a defined architecture, with the aim of detecting DILI during the non-clinical phase (Poietis, 2018). Altogether, these technologies seem very promising in the quest for in vitro liver relevant and functional models and motivate further development for advanced pharmaceutical applications. Nevertheless, limitations such as biocompatible materials that can be printed, the inability to create microstructures and low bioprinting speeds are still some important challenges that have been hampering the possibility of running screening studies for toxicology applications (Gao et al., 2016; Mazzocchi et al., 2019; Tamay et al., 2019).

\section{Microfluidic Platforms}

The combination of microfabrication techniques, such as photolithography frequently used to manufacture computer chips, together with the rapid development of tissue engineering led to the establishment and expansion of systems with dimensions in the micrometer scale for cell culture purposes, i.e., the MP or organ-on-a-chip (OoC) systems (Figure 3F; Bhatia and Ingber, 2014).

Although 3D liver models allow maintenance of in vivo-like phenotype for several days or even weeks, the static culture conditions do not enable the removal of medium accumulated substances or metabolites, that can be toxic or introduce selffeedback inhibition of cells functionality/viability, as is the case of urea or ammonia accumulation. The need for flowbased systems granted MP or liver-on-a-chip an enormous potential, as they may recapitulate the in vivo flow rate by removing the metabolites and functional products. Moreover, due to its small size, the experimental costs, reagent volumes, and cell number needed within MP are lower, which is particularly interesting for high-throughput experimentation, while enabling high microenvironment control (Bhatia and Ingber, 2014; Loskill et al., 2015; Sosa-Hernández et al., 2018). Most importantly, by resorting to the microfluidic technology, it is possible to numerically define a downscaling factor of a living tissue into an in vitro tissue-representative functional unit that will support quantitative in vitro to in vivo extrapolations using physiologically-based modeling and PK studies, which may represent an important step toward the replacement and reduction of animal models in the non-clinical phase (Bauer et al., 2017).

Organ-on-a-chip systems display high design and experimental flexibility, offering the possibility to be planned according to the aim of the study, i.e., in a more fit-for-purpose fashion. OoC contain the minimal functional unit of a tissue, recapitulating the in vivo organ's dynamics, architecture, functionality, and (patho)physiological response under real-time monitoring (Bhatia and Ingber, 2014; Mastrangeli et al., 2019), e.g., quantification of oxygen and glucose concentrations and cytokine detection (Zhou et al., 2015; Bavli et al., 2016). As such, some of the most important aspects to consider for the establishment of a OoC system are the chip design; the cell sources and cell types as well as cell density and disposition to enable the formation of functional tissues; the medium composition for each cell type; flow rate, direction, and type of perfusion; and the ability to perform functional endpoint assessment of the tissues in the chip.

Within the OoC technology, modulation of fluid flow, both in terms of direction and rate, have an impact in cells phenotype while enabling media sampling for analyses throughout culture period (Domansky et al., 2005; Wikswo, 2014; Vivares et al., 2015; Sosa-Hernández et al., 2018; Mastrangeli et al., 2019; Busche et al., 2020). MP also enable a more physiological cell-to-media ratio, avoiding dilution of signaling molecules and metabolites. High cell-to-media ratios cannot be achieved in higher scale cell culture systems without extreme costs on cell production and without compromising the maintenance of cell viability (Becker et al., 2014). Interestingly, a recent quantitative comparison on liquidto-cell volume ratios and metabolic burden between the human body and in vitro systems revealed a systemic liquid-to-cell ratio of 0.3 in the human body, with $0.06 \mathrm{~nL}$ of liquid per hepatocyte, while the in vitro systems range from 375 to 0.5 depending on the scale and perfusion system (Wang et al., 2018). The functional importance of high density cell culture in low volume systems was demonstrated by Haque et al. (2016) that observed the accumulation of higher and more physiological concentrations of cytokines (which triggers autocrine signals) and increased ALB production, MRP-2 presence, bile canaliculi formation as well as CYP3A4 and 1A1 activities and CYP1A2 expression.

The spatial arrangement of the cells is another important factor to enhance the functionality of hepatocytes, by maintaining cell polarity and tissue-specific activity (Lee et al., 2007; Kang et al., 2015; Rennert et al., 2015; Busche et al., 2020). Within MP, cells can be seeded in high densities in either a $2 \mathrm{D}$ or a 3D fashion (Sosa-Hernández et al., 2018). Tightly packed hepatocytes in a MP designed to simulate the liver sinusoid structure promoted properties of a functional liver sinusoid such as extensive cellcell contact, continuous nutrient exchange and defined tissue, and 
fluid transport regions (Lee et al., 2007). A further advantage of these systems is that different cell types can be cultured in the same system in separate chambers, having representative cells of the same tissue or even from different organs in interaction through paracrine or endocrine chemical signals like in vivo, constituting multi-organ systems (Zhou et al., 2015; Liu et al., 2019). This enables the study of organ-level responses to a potential toxic compound that involve the interaction of different tissues (Ronaldson-Bouchard and Vunjak-Novakovic, 2018).

At the single organ level, Rennert et al. (2015) used a twochannel MP (Becker et al., 2014) to create a 3D liver model integrating a vascular layer, composed of endothelial cells and tissue macrophages, and a hepatic layer, comprising stellate cells co-cultured with HepaRG cells, separated by a suspended membrane simulating the space of Disse. The complexity of this model enhanced hepatocyte polarity and allowed the observation of hepatobiliary function (Rennert et al., 2015). Moreover, it incorporated a sensor for online oxygen measurement, useful for toxicological screening, as reported earlier (Rennert et al., 2015). On the other hand, Danoy et al. (2019) optimized a culture of iPSC-derived HLCs in a biochip and showed that the microfluidic environment led to a higher degree of mature HLCs than in traditional 2D cultures. In a follow-up study, the same microfluidic culture was used to mimic liver zonation based on the formation of an oxygen gradient in the biochip (Danoy et al., 2020). Moreover, when co-cultured iPSC-derived endothelial cells, iPSC-derived HLCs were able to metabolize quercetin into its active metabolites (Yu et al., 2020).

At the multi-organ level, OoC systems have been developed to recreate the first pass metabolism dynamics by connecting gut epithelial cells and liver cells (Choe et al., 2017). With these systems it is possible to consider the gut-liver axis, including immune cells to study inflammatory responses, important for diabetes and fatty liver disease models (Jeon et al., 2020). These systems can also be used to mimic an oral administration route resorting to liver-intestine co-culture (Maschmeyer et al., 2015); to mimic systemic administration routes using endothelialized liver-skin co-culture (Maschmeyer et al., 2015); and to restitute pancreas-liver functional coupling through insulin release from pancreatic islet microtissues in response to a glucose load that promoted glucose uptake by liver spheroids (Bauer et al., 2017). Finally, they can also be adequate to study drug distribution through the connection of, for example, up to ten different microphysiological systems (MPSs), including liver, gut, lung, endometrium, heart, pancreas, brain, skin, kidney, and muscle (Edington et al., 2018). In sum, MP can indeed represent a game changer for personalized medicine applications and in the development of in vitro non-clinical models (Wang et al., 2018; Ingber, 2020; Sohn et al., 2020).

\section{In vitro Hepatotoxicity Studies: 3D Versus 2D}

The evaluation of the capacity of a given model system to detect and mimic prototypical types of liver toxicity allows to determine its ultimate predictive ability. This toxicity must be assessed both in a short-term (24-48 h) and a long-term (weeks to months) culture conditions as it is known that DILI mechanisms may be developed not only after an acute exposure but also from a chronic type (e.g., by development of drug tolerance or deposition of elimination products) (Jiang et al., 2019). Moreover, the assessment of a prolonged exposure to each compound leads to substantially lower $\mathrm{IC}_{50}$ values obtained in standard cytotoxicity assays, representing a cumulative effect often seen in the clinic and not only in an overdose scheme following isolated supratherapeutic administrations. Therefore, for a more complete evaluation of the strategies used in different studies, it is important to gather the existing data regarding well-known hepatotoxicants. In this work, we selected three of the most DILI-concern medicines, ranked by the United States Food and Drug Administration, based on their impact in human health, either because they are indeed highly prescribed (diclofenac and paracetamol) or are paradigmatic examples in Toxicology (troglitazone) (Chen et al., 2020). In fact, molecules such as paracetamol or diclofenac display a well-known diversity of mechanisms of hepatotoxicity that may help to further validate new in vitro liver models. Several hepatotoxicity studies that evaluate paracetamol (Supplementary Table 1), diclofenac (Supplementary Table 2), and troglitazone (Supplementary Table 3) consider distinct cell sources, culture conditions, and endpoints. However, the available data is not homogeneous and thus it is somehow difficult to compare results between groups, especially considering 3D liver models. Indeed, full characterization of the in vitro liver models regarding metabolic and toxicity capacity is not always described, which may represent one of the reasons limiting their acceptance by the regulatory authorities and further effective application in toxicological studies.

As shown in Supplementary Tables 1-3, toxicities of test drugs are often investigated by evaluation of cytotoxicity biomarkers such as cell viability (e.g., tetrazolium reduction MTT or MTS assays), membrane lysis (e.g., LDH release) or depletion of cellular ATP. However, these represent only latestage toxicity associated with apoptotic or necrotic events and thus do not permit a proper mechanistic evaluation of the toxicological events (O’Brien et al., 2006). Therefore, additional mechanistic endpoints have gained increasing importance when assessing drug safety with the pharmaceutical industry and the scientific community proposing complementary biomarkers' assessment, in order to obtain and cover different mechanisms of injury to diminish hepatotoxicity risk. These include mitochondrial dysfunction, bile salt transporter modification, lipids accumulation, reactive metabolite formation through conjugation with GSH or covalent binding and calcium homeostasis alteration that need to be assessed in a representative number of compounds with different toxicity mechanisms within high-content and high-throughput platforms (Xu et al., 2004; O’Brien et al., 2006; Khetani et al., 2013; Trask et al., 2014; Schadt et al., 2015; Bell et al., 2016; Williams et al., 2020; Zhang C. et al., 2020). Hence, besides including the different hepatic cell source and cell culture systems, Supplementary Tables 1-3 were incorporated to not only accommodate the cytotoxicity data but also the metabolic activity and mechanistic endpoints assessed in each study. The few studies that evaluate these mechanistic 
biomarkers are essential to identify also the models' ability to mimic processes related to cholestasis, steatosis, genotoxicity, and viral hepatitis (Shen et al., 2012; Bell et al., 2016; Hendriks et al., 2016; Leite et al., 2016; Prill et al., 2016; Williams et al., 2020), amongst others.

\section{Paracetamol}

Paracetamol is a widely used antipyretic and non-opioid analgesic agent that constitutes an example of a safe drug at therapeutic doses, but overdosage causes predictable and reproducible hepatotoxicity through mitochondrial dysfunction and centrilobular necrosis in the liver (Hinson et al., 2010).

Paracetamol is metabolized mainly by conjugation with sulfate and glucuronic acid (Riches et al., 2009) and, in a less extent, by oxidation by CY2E1, CYP1A2, CYP2D6, CYP2A6, and CYP3A4 (Mazaleuskaya et al., 2015). As previously stated, its oxidation generates NAPQI that is detoxified by GSH conjugation, through glutathione S-transferases (GSTs) GSTP1, GSTT1, and GSTM1. When large quantities of NAPQI are formed, liver GSH pool can be critically depleted, meaning that excess NAPQI is not detoxified and cell injury occurs, namely trough the modification of cellular proteins. Protein binding leads to oxidative stress and mitochondrial damage (McGill and Jaeschke, 2013; Caparrotta et al., 2018). Paracetamol toxicity is also related to calcium accumulation and activation of endonucleases, DNA damage (Boelsterli, 2003), ATP depletion, Jnk activation, up-regulation of electron transport chain protein components and activation of p53 signaling (Davis and Stamper, 2016).

Supplementary Table 1 summarizes the collected in vitro data for paracetamol. It suggests that mouse primary hepatocytes are more sensitive to paracetamol, with lower $\mathrm{IC}_{50}$ values (Jemnitz et al., 2008; Kučera et al., 2017), followed by rpHep, hepatic cell lines HepG2 and HepaRG, hpHep and HLCs (Lewerenz et al., 2003; Jemnitz et al., 2008; Riches et al., 2009; Zhang et al., 2011; Tasnim et al., 2015; Bell et al., 2017), highlighting not only the interspecies differences but also the importance of choosing a representative cell type (Carmo et al., 2004; Reder-Hilz et al., 2004).

Paracetamol $\mathrm{IC}_{50}$ values compiled in Supplementary Table $\mathbf{1}$ further suggest that $2 \mathrm{D}$ cultures are less sensitive to paracetamol toxicity than 3D cultures (Gunness et al., 2013; Jang et al., 2015; Gaskell et al., 2016; Bell et al., 2017; Li et al., 2020). It was demonstrated increased sensitivity of $3 \mathrm{D}$ human liver microtissues, with subsequently lower $\mathrm{IC}_{50}$ values for a panel of known hepatotoxicants, including paracetamol, in comparison with 2D-plated hpHep (Proctor et al., 2017). Moreover, by using a 3D liver-sinusoid-on-a-chip of HepG2, Deng et al. (2019) showed that not only this system was able to improve cell functions, but also its sensitivity to paracetamol when compared to 2D-plated HepG2. Besides, even within 3D systems, different culture strategies may lead to different results for the same drug. Jang et al. (2015) tested HepG2 in a 3D static Matrigel ${ }^{\circledR}$ culture and in a 3D microfluidic chip and obtained a higher sensitivity for hepatotoxicity in the latter, justified by its improved maintenance of hepatic functions. Foster et al. (2019) found also an increased sensitivity in $3 \mathrm{D}$ co-culture systems of hpHep and NPCs compared to hpHep spheroids. Likewise, Li et al.
(2020) observed an augmented toxicity to paracetamol in the coculture spheroids group (hpHep and Kupffer cells). Interestingly, when both systems were co-treated with lipopolysaccharides (mimicking inflammatory conditions), a higher protective role was detected in the co-culture system, mainly due to Kupffer cells, when comparing to hpHep spheroids. In fact, exposure and response to paracetamol under healthy or pre-inflammatory states may lead to different cytokine release profiles with distinct activation of immune cells (Kim et al., 2017; Li et al., 2020). Although it is generally acknowledged that paracetamol has only very weak anti-inflammatory properties, it should be highlighted that is commonly administered already under an inflammatory condition. This reinforces the need of considering co-cultures for an early identification of possible drug-induced hepatotoxic immunological responses depending on the patient health state.

Although mechanistic endpoints are not often represented in the majority of studies using paracetamol as hepatotoxicant, the reports that present this important information assess mainly mitochondrial dysfunction and oxidative stress (Bruderer et al., 2015; Goda et al., 2016; Zhang C. et al., 2020), followed by reactive metabolites formation and liver cholestasis or steatosis (Lewerenz et al., 2003; Prot et al., 2012; Prill et al., 2016; Kučera et al., 2017; Williams et al., 2020) and liver fibrosis (Leite et al., 2016). Nevertheless, the drastic differences in sensitivity to paracetamol, may be due not only to the cell type but also to the different culture conditions, highlighting the importance of both the cell architecture and the presence of other liver cell types for the study of distinct pathways that may be involved in drug toxicity.

\section{Diclofenac}

Diclofenac is one of the most worldwide prescribed NSAID. It has been linked with rare, albeit significant, cases of severe hepatotoxicity with a fatality rate of $10 \%$ (Aithal, 2004). Diclofenac is mainly metabolized by CYP2C9 into 4-OHdiclofenac and in a lower extent converted into 5-OH-diclofenac by CYP3A4. Diclofenac and its metabolites are conjugated with glucuronic acid by UGT2B7 and excreted across the canalicular plasma membrane into the bile via MRP-2 (Aithal, 2004). There is evidence that individuals that present increased glucuronidation activity as a consequence of a genetic polymorphism in UGT2B7 (C-161T allele) exhibit a 9-fold increased risk of adverse hepatic reactions (Daly et al., 2007). Diclofenac-acylglucuronide may also conjugate with GSH forming a diclofenac glutathione thioester (Syed et al., 2016). Thus, diclofenac metabolism comprises phase I, II, and III activities and its toxic effects can be associated to the reactive metabolites $4-\mathrm{OH}-$ diclofenac, diclofenac-acyl-glucuronide, diclofenac glutathione thioester, and 4-OH-diclofenac-acyl-glucuronide (Aithal, 2004) that cause ATP depletion resulting in mitochondrial toxicity (Syed et al., 2016). As such, diclofenac constitutes an example of a hepatotoxicant dependent on bioactivation.

Compared to paracetamol, the available studies of diclofenac addressing the toxicity in $2 \mathrm{D}$ versus $3 \mathrm{D}$ cell cultures are fewer (Supplementary Table 2). Most importantly, regarding mechanistic biomarkers of toxicity, only a minority of studies assess endpoints for mitochondrial dysfunction (Goda et al., 2016), reactive metabolite formation, calcium homeostasis 
(Ponsoda et al., 1995), and liver cholestasis or steatosis (Bell et al., 2016; Williams et al., 2020).

As shown in Supplementary Table 2, Gaskell et al. (2016) and Cipriano et al. (2017b) obtained $\mathrm{IC}_{50}$ values for the $3 \mathrm{D}$ spheroid cultures of HepG2/C3A and HLCs, respectively, lower than for the corresponding $2 \mathrm{D}$ cultures. This may be due to an increase in phase II (glucuronidation) activity, indicating that the 3D system may be more representative of the biological response. Ramaiahgari et al. (2014) attained higher sensitivity to diclofenac in the 3D culture of HepG2 compared to 2D but the $\mathrm{IC}_{50}$ values were higher than those reported by Gaskell et al. (2016). Yu K. N. et al. (2018) also demonstrated that the addition of both phase I and II enzymes in a 3D miniaturized Hep3B cell system led to a more predictive assessment of diclofenac's toxicity when compared to the $3 \mathrm{D}$ system groups with only CYP450 enzymes or human liver microsomes added and its 2D counterpart. Also, Atienzar et al. (2014) proved that the co-culture of dog hepatocytes with NPCs present similar sensitivity to diclofenac compared to HepG2 but less sensitivity than hpHep in a 5-day exposure culture. This $\mathrm{IC}_{50}$ variation is transversal to the majority of reports presented in Supplementary Table 2, in which most of the studies only evaluate one type of culture system (Wang et al., 2002; Xu et al., 2003; Lauer et al., 2009; Lin et al., 2012; Goda et al., 2016; Knospel et al., 2016; Sarkar et al., 2017), hindering the comparison between both types of cultures. Besides the relevance of the culture system, this observation reinforces the importance to include mechanistic insights in early toxicity assessments rather than rely solely on cell viability quantification. A competent and complete in vitro model may provide a higher amount of valuable information if more variables are taken into account.

\section{Troglitazone}

Troglitazone (TGZ) is a thiazolidinedione derivative developed for the treatment of type II diabetes. Soon after being approved, TGZ was withdrawn from the marked in Europe and 3 years afterward in the United States due to non-immune idiosyncratic toxicity (Chojkier, 2005). It is a classic example of a drug whose toxicity failed to be predicted during drug development. TGZ is extensively metabolized by CYP3A4 and GST, it is a CYP3A and $2 \mathrm{~B} 6$ inducer and is able, as well as its sulfate conjugate, to inhibit BSEP (Sahi et al., 2000; Kassahun et al., 2001). This leads to an increased formation of TGZ metabolites along with its intracellular accumulation, resulting in intrahepatic cholestasis, mitochondrial dysfunction, covalent binding to proteins, and macromolecular damage ultimately leading to apoptosis (Smith, 2003; Chojkier, 2005). TGZ is more toxic in humans than in rodent models (Shen, 2007; Kostadinova et al., 2013). In view of this, TGZ was only identified as hepatotoxic after reaching the market. TGZ is, thus, an example of the importance of identifying species-specific toxicity. In fact, Shen et al. (2012), using 3D gel entrapped rat and human hepatocytes, observed that at clinical doses of TGZ, hepatotoxicity was absent in rat hepatocytes, but present in human hepatocytes. Similarly, Kostadinova et al. (2013) reported TGZ-induced cytotoxicity in human 3D liver cells but only minor effects in rat 3D liver.
In addition, as summarized in Supplementary Table 3, and in accordance with clinical observations, 3D human liver models show increased sensitivity to TGZ toxicity which may be related to higher formation of metabolites as consequence of the higher induction ability of 3D models. Nonetheless, Gunness et al. (2013) obtained discrepant results, with the 3D model of HepaRG cells being 10 -fold less sensitive to TGZ than the monolayer model. On the other hand, this decreased sensitivity might reflect a higher clearance, commonly increased in $3 \mathrm{D}$ cultures due to the cellular architecture. Moreover, HepaRG cells present higher CYP3A4 activity (Aninat et al., 2006) that might interfere with drug and metabolite clearances since TGZ metabolites may also be hepatotoxic (Tolosa et al., 2018). Another explanation could be the known TGZ-induced BSEP inhibition (Jackson et al., 2018), not investigated in this study. Hendriks et al. (2016) assessed BSEP inhibition in two long-term 3D spheroid models of HepaRG and hpHep with repeated drug exposure and bile acids co-exposure and was able to detect the cholestatic effect of several compounds, including TGZ, in both cell types. Independently of the studied mechanisms, the co-culture of hpHep (Kostadinova et al., 2013; Proctor et al., 2017; Li et al., 2020) or hepatoma cell lines (Granitzny et al., 2017) with NPCs displayed a higher sensitivity to TGZ toxicity (Kostadinova et al., 2013).

Using HLCs as alternative sources to hpHep, Tasnim et al. (2016) found similar sensitivity between 3D hESC/hiPSC-HLCs and hpHep upon exposure to TGZ for $24 \mathrm{~h}$, whereas when comparing to its $2 \mathrm{D}$ counterpart, $3 \mathrm{D}$ cellulosic scaffold cultured hiPSC-HLCs showed a slightly lower sensitivity. On the other hand, Takayama et al. (2013) showed that 3D-cultured iPSCHLCs presented a decreased sensitivity to TGZ after $24 \mathrm{~h}$ of exposure when compared to hpHep, but a better sensitivity compared to 3D-cultured HepG2. Moreover, Holmgren et al. (2014) was able to use hiPSC-HLCs in a long-term culture and successfully detected steatosis in the cells exposed to TGZ for 2 days. This is an important step to show that these HLCs may reveal the mechanistic pattern of TGZ hepatotoxicity and stand as a good alternative for hpHep.

\section{CHALLENGES WITHIN THE ASSESSMENT OF DRUGS HEPATOTOXICITY USING IN VITRO LIVER MODELS}

The pharmaceutical industry is clearly interested on the early identification of toxicity cues in models covering different aspects of human liver (patho)physiology (Bale et al., 2014). On the other hand, the chemical/cosmetic industry has been politically stressed to use advanced alternatives for animal testing for hazard identification and characterization. Although each type of industry presents different needs and goals, the early identification of potential hepatotoxic substances and deep understanding of hepatotoxic mechanisms in relevant in vitro models will profit both industries.

In this section, we propose a roadmap with the essential steps to assess drugs hepatotoxicity using in vitro liver models. 








- ER stress

- Disruption of repairing mechanisms

- Bile salt transporter modification (cholestasis)

- Lipids accumulation (steatosis)

- Biomarker analysis

- Calcium homeostasis alteration

- Immunological response

FIGURE 4 | Roadmap for assessing drugs hepatotoxicity mechanisms using in vitro models that might be used alone or in combination at different points and on different scales. Tier 1 comprises single-cell systems that report on immediate chemical/biological effects such as cytotoxicity and bioactivation while Tier 2 includes more complex systems containing liver cells in a more physiologic state, enabling assessment of the consequences of acute and chronic drug exposure. Moreover, phenotypic characterization and the pharmacological and toxicological functionality of a system and the ability to identify toxicity mechanisms needs to be considered before undertaking toxicological investigations to ensure that the most appropriate methods are used. Depending on the complexity, each model might be able to represent one or more liver functional endpoints and can be used alone or in combination depending on the hepatotoxicity mechanisms that are intended to study. To integrate findings from different test systems and to dissect the multilevel impact of compounds, bioinformatics and machine learning models may also be useful, which will ultimately contribute to more informed decision-making in the drug development and risk assessment fields. SC, stem cells; HLCs,

hepatocyte-like cells; MPS, microphysiological system.

As no single currently used model can recapitulate all human hepatotoxicity mechanisms, we further support the need for a systematic tiered approach for drug hepatotoxicity assessment combining more than one model. Indeed, the model systems with increased biological complexity might be efficiently and effectively used alone or in combination, at different points, and on different scales of the drug development process. The final goal is thus to cover the different human hepatotoxicity mechanisms needed to provide accurate hazard identification and risk assessment (Figure 4). Finally, the data generated in such non-clinical assays should be integrated to deliver robust information to drug regulators to improve the decision-making process (Figures 4, 5).

Firstly, the cell source needs to be carefully considered to ensure the appropriate tissue context. Hepatotoxicity involves different mechanisms in a multistep and multicellular process (Grattagliano et al., 2009; Gregus, 2013). As such, there is no single model or test that can evaluate a chemical's risk of inducing liver injury, but rather a set of well-characterized hepatic models with well-defined purposes to be used in a multistep manner. This approach may vary in terms of cell source and culture complexity, allowing to assess specific toxicity mechanisms as well as to properly mimic the different types and stages of liver toxicity.
In particular, human-derived cells, namely hpHep or SCderived HLCs, contribute to more relevant in vitro systems by allowing to capture population heterogeneity and to represent healthy and disease conditions. On the other hand, simpler and single-cell system based on, e.g., hepatic cell lines and monolayer cultures enable high-throughput applications for testing a wide set of conditions and allow to preliminarily understand a drug's basic biological effects in human cells (Figure 4, tier 1). Conversely, more complex systems, such as 3D-based cultures improve data accuracy not only concerning cytotoxicity, but also biotransformation activity and drug accumulation by mimicking tissue architecture, mechanical forces and gradients of oxygen, nutrients, and drugs that are found in vivo (Figure 4, tier 2). Additionally, complex models that include different liver cell types, e.g., hepatocytes and stellate cells or immune cells, allow to explore additional biological responses such as cholestasis, steatosis, fibrosis, and inflammation (Leite et al., 2016; Jeon et al., 2020).

A crucial step within the development and selection of a relevant in vitro model for non-clinical studies is its thorough characterization. The systems' phenotype and functionality need to be assessed to understand which pharmacology and toxicology mechanisms can be accurately represented 




and evaluated in each model. Importantly, the capacity of the models for both short and/or long-term exposures should be evaluated as well (Figure 4). Indeed, the models' comparison presented in section "In vitro Hepatotoxicity Studies: 3D Versus 2D" revealed to be challenging and little informative because most of the hepatotoxicity studies available in the literature focus on cytotoxicity estimation instead of analyzing specific functional endpoints of hepatotoxicity such as altered conversion of primary and secondary metabolites, disruption of repairing mechanisms, immunological response, mitochondrial dysfunction, bile salt transporter modification, lipids accumulation, or calcium homeostasis alteration, which highlight hepatic injury mechanisms such as inflammation, cholestasis, steatosis, fibrosis, or genotoxicity (Xu et al., 2004; O'Brien et al., 2006; Khetani et al., 2013; Trask et al., 2014; Schadt et al., 2015; Bell et al., 2016; Leite et al., 2016; Jeon et al., 2020; Williams et al., 2020; Zhang C. et al., 2020).

Retrospective analysis of approved or failed drugs with a known mechanism displaying the expected hepatic response is a common approach to determine the capability of an in vitro system to accurately recapitulate the human liver biological response (Jemnitz et al., 2008; Kostadinova et al., 2013; Messner et al., 2013; Hendriks et al., 2016; Bell et al., 2017; Cipriano et al., 2017b; Proctor et al., 2017; Sarkar et al., 2017; Foster et al., 2019; Williams et al., 2020), e.g., paracetamol for induced necrosis, valproic acid for induced steatosis, or cyclosporine A for induced cholestasis (Vinken and Hengstler, 2018). The data generated with these systems should then be compared with clinical data as well as with other in vitro methods to understand applicability and limitations of each system for assessing the inherent risk of a chemical or a new molecular entity (Beken et al., 2016; Figure 5). Models are commonly assessed by direct comparison of in vitro to the in vivo maximum plasma concentration $\left(\mathrm{C}_{\max }\right)$ (Godoy et al., 2013; Shah et al., 2015; Proctor et al., 2017), often multiplied by a factor of $20 \times$ to $100 \times$ (O'Brien et al., 2006; Xu et al., 2008; Khetani et al., 2013; Proctor et al., 2017; Vorrink et al., 2018; Yu K. N. et al., 2018). Thus, knowing that the $\mathrm{C}_{\max }$ of paracetamol, diclofenac, and TGZ is $165.38 \mu \mathrm{M}, 10.13 \mu \mathrm{M}$ (Regenthal et al., 1999) and $2.82 \mu \mathrm{M}$ (Loi et al., 1999), respectively, it is possible to comprehend by Supplementary Tables 1-3 that, in general, 3D models present better capability of predicting cytotoxicity than $2 \mathrm{D}$ models. However, this comparison assumes that the ratio of test compounds in blood or plasma in vivo is the same in the cell culture medium in vitro (Vinken and Hengstler, 2018) and that cells response in vivo is the same in vitro. Also, within the same drug, such a big range of concentration $\left(20 \times\right.$ to $\left.100 \times \mathrm{C}_{\max }\right)$ may represent different mechanisms of toxicity (Albrecht et al., 2019). 
A paradigm change from selecting a list of reference chemicals that cause cytotoxicity, to selecting a group of positive and negative mechanistic controls, coupled to a mechanisticbased selection of functional endpoints, including biomarkers assessment, is thus essential for using advanced in vitro models to its full potential. An example of a mechanistic positive control for a test system where biliary excretion is measured would be TGZ since it is a known BSEP inhibitor associated with bile acid accumulation (Funk et al., 2001; Jackson et al., 2018). Moreover, the combination of advanced 3D hepatic in vitro models with other advanced endpoint methodologies and systems biology employing -omics approaches (e.g., RNA-seq, Epigenetics, and ChIP-seq proteomics) could further support better prediction of hepatotoxicity.

Finally, the integration of the biological data obtained with the selected in vitro models may support a deeper understanding of the models' potential to predict specific mechanisms of detoxification and toxicity. The inclusion of relevant positive and negative controls that validate the obtained data will support robust knowledge on chemical's risks and human toxicity mechanisms that has not been detected so far using monolayers of a single cell type.

\section{CONCLUSION}

There has been major progress toward the development of more physiologically relevant hepatic in vitro models, namely through the application of $3 \mathrm{D}$ culture techniques. Despite the wide variety of available cellular models along with distinct cell sources, 3D-based liver systems and co-culture strategies improve hepatic-specific functions and sustain the culture through longer periods than 2D counterparts, emphasizing the value-added capacity of such systems to mimic the multicellular mechanisms involved both in intrinsic and idiosyncratic liver toxicity. This has been demonstrated in paracetamol, diclofenac and TGZ toxicities studies where $\mathrm{IC}_{50}$ values from $3 \mathrm{D}$ cultures confirmed its higher sensitivity.

Nevertheless, the appropriate in vitro system's evaluation and proper extrapolation of the in vitro data requires a paradigm shift from quantitative cytotoxicity assessment to a comprehensive

\section{REFERENCES}

Adiels, C. B., Goksör, M., Wölfl, S., Paukštyte, J., Banaeiyan, A. A., and Theobald, J. (2017). Design and fabrication of a scalable liver-lobule-on-a-chip microphysiological platform. Biofabrication 9:015014. doi: 10.1088/1758-5090/ 9/1/015014

Aeby, E. A., Misun, P. M., Hierlemann, A., and Frey, O. (2018). Microfluidic hydrogel hanging-drop network for long-term culturing of 3D microtissues and simultaneous high-resolution imaging. Adv. Biosyst. 2, 1-11. doi: 10.1002/adbi. 201800054

Ahmad, J., and Odin, J. A. (2017). Epidemiology and genetic risk factors of drug hepatotoxicity. Clin. Liver Dis. 21, 55-72. doi: 10.1016/j.cld.2016.08.004

Aimar, A., Palermo, A., and Innocenti, B. (2019). The role of 3D printing in medical applications: a state of the art. J. Healthc. Eng. 2019:5340616. doi: 10.1155/2019/ 5340616 mechanistic evaluation of the response to chemicals. Advanced $3 \mathrm{D}$ systems provide the opportunity to investigate mechanistic hepatotoxicology if accompanied by a careful selection of adequate positive and negative controls and systems toxicology data coupled to disease-related functional endpoints. Despite the advances in creating more physiologically relevant culture systems, a major difficulty is still the standardization of protocols across laboratories and the selection of critical positive and negative controls to assess the transferability and reproducibility of models across different groups. Importantly, advanced endpoint methodologies are essential to identify the applicability of each hepatic system, further allowing comparison between studies. Such a detailed and complete in vitro evaluation will support future decision on the adequate model to be used in chemical risk assessment and in a non-clinical drug development scheme.

\section{AUTHOR CONTRIBUTIONS}

JM, MC, JR, and AS: conception and design. JM, MC, JR, AS, AR, and NO: writing and critically review the manuscript. JR, AS, and AR: figure design and elaboration. JM: directing manuscript. All authors contributed to the article and approved the submitted version.

\section{FUNDING}

This research has been supported by FCT (Portugal) through the research grants and scholarship PTDC/MEDTOX/29183/2017, UIDB/04138/2020, UIDP/04138/2020, and SFRH/BD/144130/2019 to JR and by the H2020, European Commission, though the MSCA-IF-EF-ST - Standard EF to MC (GA-845147-LIV-AD-ON-A-CHIP).

\section{SUPPLEMENTARY MATERIAL}

The Supplementary Material for this article can be found online at: https://www.frontiersin.org/articles/10.3389/fcell.2021. 626805/full\#supplementary-material

Aithal, G. P. (2004). Diclofenac-induced liver injury: a paradigm of idiosyncratic drug toxicity. Expert Opin. Drug Saf. 3, 519-523. doi: 10.1517/14740338.3.6.519

Aithal, G. P., Ramsay, L., Daly, A. K., Sonchit, N., Leathart, J. B. S., Alexander, G., et al. (2004). Hepatic adducts, circulating antibodies, and cytokine polymorphisms in patients with diclofenac hepatotoxicity. Hepatology 39, 1430-1440. doi: 10.1002/hep.20205

Albrecht, W., Kappenberg, F., Brecklinghaus, T., Stoeber, R., Marchan, R., Zhang, M., et al. (2019). Prediction of human drug-induced liver injury (DILI) in relation to oral doses and blood concentrations. Arch. Toxicol. 93, 1609-1637. doi: 10.1007/s00204-019-02492-9

Allen, J. W., Khetani, S. R., and Bhatia, S. N. (2005). In vitro zonation and toxicity in a hepatocyte bioreactor. Toxicol. Sci. 84, 110-119. doi: 10.1093/toxsci/kfi05

Andersen, M. E., and Krewski, D. (2009). Toxicity testing in the 21 st century: bringing the vision to life. Toxicol. Sci. 107, 324-330. doi: 10.1093/ toxsci/kfn255 
Andersen, M. E., and Krewski, D. (2010). The vision of toxicity testing in the 21st century: moving from discussion to action. Toxicol. Sci. 117, 17-24. doi: $10.1093 /$ toxsci/kfq188

Andrade, R., Agundez, J., Lucena, M., Martinez, C., Cueto, R., and Garcia-Martin, E. (2009). Pharmacogenomics in Drug Induced Liver Injury. Curr. Drug Metab. 10, 956-970. doi: 10.2174/1389200097907 11805

Aninat, C., Piton, A., Glaise, D., Le Charpentier, T., Langouët, S., Morel, F., et al. (2006). Expression of cytochromes P450, conjugating enzymes and nuclear receptors in human hepatoma HepaRG cells. Drug Metab. Dispos. 34, 75-83. doi: $10.1124 / \mathrm{dmd} .105 .006759$

Asai, A., Aihara, E., Watson, C., Mourya, R., Mizuochi, T., Shivakumar, P., et al. (2017). Paracrine signals regulate human liver organoid maturation from induced pluripotent stem cells. Development 144, 1056-1064. doi: 10.1242/dev. 142794

Asha, S., and Vidyavathi, M. (2010). Role of human liver microsomes in in vitro metabolism of drugs-a review. Appl. Biochem. Biotechnol. 160, 1699-1722. doi: 10.1007/s12010-009-8689-6

Atienzar, F. A., Novik, E. I., Gerets, H. H., Parekh, A., Delatour, C., Cardenas, A., et al. (2014). Predictivity of dog co-culture model, primary human hepatocytes and HepG2 cells for the detection of hepatotoxic drugs in humans. Toxicol. Appl. Pharmacol. 275, 44-61. doi: 10.1016/j.taap.2013.11.022

Babai, S., Auclert, L., and Le-Louët, H. (2018). Safety data and withdrawal of hepatotoxic drugs. Therapie [Epub ahead of print]. doi: 10.1016/j.therap.2018. 02.004

Bale, S. S., Vernetti, L., Senutovitch, N., Jindal, R., Hegde, M., Gough, A., et al. (2014). In vitro platforms for evaluating liver toxicity. Exp. Biol. Med. 239, 1180-1191. doi: 10.1177/1535370214531872

Balls, M. (2011). Modern alternative approaches to the problem of druginduced liver injury. ATLA Altern. to Lab. Anim. 39, 103-107. doi: 10.1177/ 026119291103900205

Banas, A., Teratani, T., Yamamoto, Y., Tokuhara, M., Takeshita, F., Quinn, G., et al. (2007). Adipose tissue-derived mesenchymal stem cells as a source of human hepatocytes. Hepatology 46, 219-228. doi: 10.1002/hep.21704

Bauer, S., Wennberg Huldt, C., Kanebratt, K. P., Durieux, I., Gunne, D., Andersson, S., et al. (2017). Functional coupling of human pancreatic islets and liver spheroids on-a-chip: towards a novel human ex vivo type 2 diabetes model. Sci. Rep. 7, 1-11. doi: 10.1038/s41598-017-14815-w

Bavli, D., Prill, S., Ezra, E., Levy, G., Cohen, M., Vinken, M., et al. (2016). Realtime monitoring of metabolic function in liver-on-chip microdevices tracks the dynamics of mitochondrial dysfunction. Proc. Natl. Acad. Sci. U.S.A. 113, E2231-E2240. doi: 10.1073/pnas.1522556113

Baxter, M. A., Rowe, C., Alder, J., Harrison, S., Hanley, K. P., Park, B. K., et al. (2010). Generating hepatic cell lineages from pluripotent stem cells for drug toxicity screening. Stem Cell Res. 5, 4-22. doi: 10.1016/j.scr.2010.02.002

Becker, H., Schulz, I., Mosig, A., Jahn, T., and Gärtner, C. (2014). Microfluidic devices for cell culture and handling in organ-on-a-chip applications. Microfluid. BioMEMS Med. Microsyst. 8976:89760N. doi: 10.1117/12.2037237

Beken, S., Kasper, P., and van Der Laan, J. W. (2016). Regulatory acceptance of alternative methods in the development and approval of pharmaceuticals. $A d v$. Exp. Med. Biol. 856, 33-64. doi: 10.1007/978-3-319-33826-2_3

Bell, C. C., Chouhan, B., Andersson, L. C., Andersson, H., Dear, J. W., Williams, D. P., et al. (2020). Functionality of primary hepatic non-parenchymal cells in a 3D spheroid model and contribution to acetaminophen hepatotoxicity. Arch. Toxicol. 94, 1251-1263. doi: 10.1007/s00204-020-02682-w

Bell, C. C., Dankers, A. C. A., Lauschke, V. M., Sison-Young, R., Jenkins, R., Rowe, C., et al. (2018). Comparison of hepatic 2D sandwich cultures and $3 \mathrm{~d}$ spheroids for long-term toxicity applications: a multicenter study. Toxicol. Sci. 162, 655-666. doi: 10.1093/toxsci/kfx289

Bell, C. C., Hendriks, D. F. G., Moro, S. M. L., Ellis, E., Walsh, J., Renblom, A., et al. (2016). Characterization of primary human hepatocyte spheroids as a model system for drug-induced liver injury, liver function and disease. Sci. Rep. 6:25187. doi: 10.1038/srep25187

Bell, C. C., Lauschke, V. M., Vorrink, S. U., Palmgren, H., Duffin, R., Andersson, T. B., et al. (2017). Transcriptional, functional, and mechanistic comparisons of stem cell-derived hepatocytes, HepaRG cells, and three-dimensional human hepatocyte spheroids as predictive in vitro systems for drug-induced liver injury. Drug Metab. Dispos. 45, 419-429. doi: 10.1124/dmd.116.074369
Berto, A., Van der Poel, W. H. M., Hakze-van der Honing, R., Martelli, F., La Ragione, R. M., Inglese, N., et al. (2013). Replication of hepatitis E virus in threedimensional cell culture. J. Virol. Methods 187, 327-332. doi: 10.1016/j.jviromet. 2012.10.017

Bethesda (2012). LiverTox: Clinical and Research Information on Drug-Induced Liver Injury [Internet]. Bethesda, MD: National Institute of Diabetes and Digestive and Kidney Diseases.

Bhatia, S. N., and Ingber, D. E. (2014). Microfluidic organs-on-chips. Nat. Biotechnol. 32, 760-772. doi: 10.1038/nbt.2989

Boelsterli, U. A. (2003). Mechanistic Toxicology: The Molecular Basis of How Chemicals Disrupt Biological Targets. First. Boca Raton, FL: CRC Press.

Boess, F., Kamber, M., Romer, S., Gasser, R., Muller, D., Albertini, S., et al. (2003). Gene expression in two hepatic cell lines, cultured primary hepatocytes, and liver slices compared to the in vivo liver gene expression in rats: possible implications for toxicogenomics use of in vitro systems. Toxicol. Sci. 73, 386402. doi: 10.1093/toxsci/kfg064

Bonn, B., Svanberg, P., Janefeldt, A., Hultman, I., and Grime, K. (2016). Determination of human hepatocyte intrinsic clearance for slowly metabolized compounds: comparison of a primary hepatocyte/stromal cell co-culture with plated primary hepatocytes and hepaRG. Drug Metab. Dispos. 44, 527-533. doi: $10.1124 / \mathrm{dmd} .115 .067769$

Brockmöller, J., and Tzvetkov, M. V. (2008). Pharmacogenetics: data, concepts and tools to improve drug discovery and drug treatment. Eur. J. Clin. Pharmacol. 64, 133-157. doi: 10.1007/s00228-007-0424-z

Brolén, G., Sivertsson, L., Björquist, P., Eriksson, G., Ek, M., Semb, H., et al. (2010). Hepatocyte-like cells derived from human embryonic stem cells specifically via definitive endoderm and a progenitor stage. J. Biotechnol. 145, 284-294. doi: 10.1016/j.jbiotec.2009.11.007

Brown, L. A., Arterburn, L. M., Miller, A. P., Cowger, N. L., Hartley, S. M., Andrews, A., et al. (2003). Maintenance of liver functions in rat hepatocytes cultured as spheroids in a rotating wall vessel. Vitr. Cell. Dev. Biol. Anim. 39, 13-20.

Bruderer, R., Bernhardt, O. M., Gandhi, T., Miladinoviæ, S. M., Cheng, L. Y., Messner, S., et al. (2015). Extending the limits of quantitative proteome profiling with data-independent acquisition and application to acetaminophen-treated three-dimensional liver microtissues. Mol. Cell. Proteomics 14, 1400-1410. doi: 10.1074/mcp.M114.044305

Busche, M., Tomilova, O., Schütte, J., Werner, S., Beer, M., Groll, N., et al. (2020). HepaChip-MP - a twenty-four chamber microplate for a continuously perfused liver coculture model. Lab Chip 20, 2911-2926. doi: 10.1039/d01c00357c

Cai, J., Zhao, Y., Liu, Y., Ye, F., Song, Z., Qin, H., et al. (2007). Directed differentiation of human embryonic stem cells into functional hepatic cells. Hepatology 45, 1229-1239. doi: 10.1002/hep.21582

Cai, P., Zheng, H., She, J., Feng, N., Zou, H., Gu, J., et al. (2020). Molecular mechanism of aflatoxin-induced hepatocellular carcinoma derived from a bioinformatics analysis. Toxins 12:203. doi: 10.3390/toxins12030203

Camenisch, G., and Umehara, K. (2012). Predicting human hepatic clearance from in vitro drug metabolism and transport data: a scientific and pharmaceutical perspective for assessing drug-drug interactions. Biopharm. Drug Dispos. 33, 179-194. doi: 10.1002/bdd.1784

Campard, D., Lysy, P. A., Najimi, M., and Sokal, E. M. (2008). Native umbilical cord matrix stem cells express hepatic markers and differentiate into hepatocyte-like cells. Gastroenterology 134, 833-848. doi: 10.1053/j.gastro.2007.12.024

Caparrotta, T. M., Antoine, D. J., and Dear, J. W. (2018). Are some people at increased risk of paracetamol-induced liver injury? A critical review of the literature. Eur. J. Clin. Pharmacol. 74, 147-160. doi: 10.1007/s00228-017-23566

Carmo, H., Hengstler, J. G., de Boer, D., Ringel, M., Carvalho, F., Fernandes, E., et al. (2004). Comparative metabolism of the designer drug 4methylthioamphetamine by hepatocytes from man, monkey, dog, rabbit, rat and mouse. Naunyn Schmiedebergs Arch. Pharmacol. 369, 198-205. doi: 10. 1007/s00210-003-0850-0

Cavallari, L. H., Van Driest, S. L., Prows, C. A., Bishop, J. R., Limdi, N. A., Pratt, V. M., et al. (2019). Multi-site investigation of strategies for the clinical implementation of CYP2D6 genotyping to guide drug prescribing. Genet. Med. 21:2255-2263. doi: 10.1038/s41436-019-0484-3

Chan, C., Berthiaume, F., Nath, B. D., Tilles, A. W., Toner, M., and Yarmush, M. L. (2004). Hepatic tissue engineering for adjunct and temporary liver support: critical technologies. Liver Transplant. 10, 1331-1342. doi: 10.1002/1t.20229 
Chan, R., and Benet, L. Z. (2017). Evaluation of DILI predictive hypotheses in early drug development. Chem. Res. Toxicol. 30, 1017-1029. doi: 10.1021/acs. chemrestox.7b00025

Chan, T. S., Yu, H., Moore, A., Khetani, S. R., and Tweedie, D. (2013). Meeting the challenge of predicting hepatic clearance of compounds slowly metabolized by cytochrome P450 using a novel hepatocyte model, HepatoPac. Drug Metab. Dispos. 41, 2024-2032. doi: 10.1124/dmd.113.053397

Chang, T. T., and Hughes-Fulford, M. (2009). Monolayer and spheroid culture of human liver hepatocellular carcinoma cell line cells demonstrate distinct global gene expression patterns and functional phenotypes. Tissue Eng. Part A 15, 559-567. doi: 10.1089/ten.tea.2007.0434

Chang, T. T., and Hughes-Fulford, M. (2014). Molecular mechanisms underlying the enhanced functions of three-dimensional hepatocyte aggregates. Biomaterials 35, 2162-2171. doi: 10.1016/j.biomaterials.2013.11.063

Chao, P., Maguire, T., Novik, E., Cheng, K. C., and Yarmush, M. L. (2009). Evaluation of a microfluidic based cell culture platform with primary human hepatocytes for the prediction of hepatic clearance in human. Biochem. Pharmacol. 78, 625-632. doi: 10.1016/j.bcp.2009.05.013

Chatterjee, S., Richert, L., Augustijns, P., and Annaert, P. (2014). Hepatocytebased in vitro model for assessment of drug-induced cholestasis. Toxicol. Appl. Pharmacol. 274, 124-136. doi: 10.1016/j.taap.2013.10.032

Chen, M., Suzuki, A., Thakkar, S., Yu, K., Hu, C., and Tong, W. (2020). U. S. Food and Drug Administration. Drug Induc. Liver Inj. Rank Dataset. Available online at: https://www.fda.gov/science-research/liver-toxicity-knowledge-base-ltkb/ drug-induced-liver-injury-rank-dilirank-dataset (accessed September 25, 2020).

Chen, Y., Yu, C., Lv, G., Cao, H., Yang, S., Zhang, Y., et al. (2014). Rapid largescale culturing of microencapsulated hepatocytes: a promising approach for cell-based hepatic support. Transplant. Proc. 46, 1649-1657. doi: 10.1016/j. transproceed.2014.03.002

Choe, A., Ha, S. K., Choi, I., Choi, N., and Sung, J. H. (2017). Microfluidic Gut-liver chip for reproducing the first pass metabolism. Biomed. Microdevices 19, 1-11. doi: 10.1007/s10544-016-0143-2

Chojkier, M. (2005). Troglitazone and liver injury: in search of answers. Hepatology 41, 237-246. doi: 10.1002/hep.20567

Christoffersson, J., Aronsson, C., Jury, M., and Selegård, R. (2019). Fabrication of modular hyaluronan-PEG hydrogels to support 3D cultures of hepatocytes in a perfused liver-on-a-chip device. Biofabrication 11:015013. doi: 10.1088/17585090/aaf657

Cipriano, M., Correia, J. C., Camões, S. P., Oliveira, N. G., Cruz, P., Cruz, H., et al. (2017a). The role of epigenetic modifiers in extended cultures of functional hepatocyte-like cells derived from human neonatal mesenchymal stem cells. Arch. Toxicol. 91, 2469-2489. doi: 10.1007/s00204-016-1901-x

Cipriano, M., Freyer, N., Knöspel, F., Oliveira, N. G., Barcia, R., Cruz, P. E., et al. (2017b). Self-assembled 3D spheroids and hollow-fibre bioreactors improve MSC-derived hepatocyte-like cell maturation in vitro. Arch. Toxicol. 91, 18151832. doi: 10.1007/s00204-016-1838-0

Cipriano, M., Pinheiro, P. F., Sequeira, C. O., Rodrigues, J. S., Oliveira, N. G., Antunes, A. M. M., et al. (2020). Nevirapine biotransformation insights: an integrated in vitro approach unveils the biocompetence and glutathiolomic profile of a human hepatocyte-like cell 3D model. Int. J. Mol. Sci. 21, 1-18. doi: 10.3390/ijms21113998

Coecke, S., Bogni, A., Langezaal, I., Worth, A., Hartung, T., and Monshouwer, M. (2001). The use of genetically engineered cells for assessing CYP2D6-related polymorphic effects. Toxicol. Vitr. 15, 553-556. doi: 10.1016/S0887-2333(01) 00061-3

Coll, M., Perea, L., Boon, R., Leite, S. B., Vallverdú, J., Mannaerts, I., et al. (2018). Generation of hepatic stellate cells from human pluripotent stem cells enables in vitro modeling of liver fibrosis. Cell Stem Cell 23, 101.e7-113.e7. doi: 10.1016/ j.stem.2018.05.027

Conway, D. E., Sakurai, Y., Weiss, D., Vega, J. D., Taylor, W. R., Jo, H., et al. (2009). Expression of CYP1A1 and CYP1B1 in human endothelial cells: regulation by fluid shear stress. Cardiovasc. Res. 81, 669-677. doi: 10.1093/cvr/cvn360

Cook, D., Brown, D., Alexander, R., March, R., Morgan, P., Satterthwaite, G., et al. (2014). Lessons learned from the fate of AstraZeneca's drug pipeline: a five-dimensional framework. Nat. Rev. Drug Discov. 13, 419-431. doi: 10.1038/ nrd4309
Daly, A. K., Aithal, G. P., Leathart, J. B. S., Swainsbury, R. A., Dang, T. S., and Day, C. P. (2007). Genetic susceptibility to diclofenac-induced hepatotoxicity: contribution of UGT2B7, CYP2C8, and ABCC2 genotypes. Gastroenterology 132, 272-281. doi: 10.1053/j.gastro.2006.11.023

Danoy, M., Bernier, M. L., Kimura, K., Poulain, S., Kato, S., Mori, D., et al. (2019). Optimized protocol for the hepatic differentiation of induced pluripotent stem cells in a fluidic microenvironment. Biotechnol. Bioeng. 116, 1762-1776. doi: 10.1002/bit.26970

Danoy, M., Poulain, S., Lereau-Bernier, M., Kato, S., Scheidecker, B., Kido, T., et al. (2020). Characterization of liver zonation-like transcriptomic patterns in HLCs derived from hiPSCs in a microfluidic biochip environment. Biotechnol. Prog. 36:e3013. doi: 10.1002/btpr.3013

Darnell, M., Schreiter, T., Zeilinger, K., Urbaniak, T., Söderdahl, T., Rossberg, I., et al. (2011). Cytochrome P450-dependent metabolism in HepaRG cells cultured in a dynamic three-dimensional bioreactor. Drug Metab. Dispos. 39, 1131-1138. doi: 10.1124/dmd.110.037721

Darnell, M., Ulvestad, M., Ellis, E., Weidolf, L., and Andersson, T. B. (2012). In vitro evaluation of major in vivo drug metabolic pathways using primary human hepatocytes and HepaRG cells in suspension and a dynamic three-dimensional bioreactor system. J. Pharmacol. Exp. Ther. 343, 134-144. doi: 10.1124/jpet.112. 195834

Dash, A., Inman, W., Hoffmaster, K., Sevidal, S., Kelly, J., Obach, R. S., et al. (2009). Liver tissue engineering in the evaluation of drug safety. Expert Opin. Drug Metab. Toxicol. 5, 1159-1174. doi: 10.1517/17425250903160664

Daston, G., Knight, D. J., Schwarz, M., Gocht, T., Thomas, R. S., Mahony, C., et al. (2015). SEURAT: Safety Evaluation Ultimately Replacing Animal Testing recommendations for future research in the field of predictive toxicology. Arch. Toxicol. 89, 15-23. doi: 10.1007/s00204-014-1421-5

Davila, J. C., Cezar, G. G., Thiede, M., Strom, S., Miki, T., and Trosko, J. (2004). Use and application of stem cells in toxicology. Toxicol. Sci. 79, 214-223. doi: $10.1093 /$ toxsci/kfh100

Davis, M., and Stamper, B. D. (2016). TAMH: a useful in vitro model for assessing hepatotoxic mechanisms. Biomed Res. Int. 2016:4780872. doi: 10.1155/2016/ 4780872

Deharde, D., Schneider, C., Hiller, T., Fischer, N., Kegel, V., Lübberstedt, M., et al. (2016). Bile canaliculi formation and biliary transport in 3D sandwichcultured hepatocytes in dependence of the extracellular matrix composition. Arch. Toxicol. 90, 2497-2511. doi: 10.1007/s00204-016-1758-Z

Deng, J., Zhang, X., Chen, Z., Luo, Y., Lu, Y., Liu, T., et al. (2019). A cell lines derived microfluidic liver model for investigation of hepatotoxicity induced by drug-drug interaction. Biomicrofluidics 13:024101. doi: 10.1063/1.5070088

Devarbhavi, H. (2012). An Update on Drug-induced Liver Injury. J. Clin. Exp. Hepatol. 2, 247-259. doi: 10.1016/j.jceh.2012.05.002

Di Stefano, A., Sozio, P., Serafina Cerasa, L., and Iannitelli, A. (2011). L-dopa prodrugs: an overview of trends for improving parkinsons disease treatment. Curr. Pharm. Des. 17, 3482-3493. doi: 10.2174/138161211798194495

Domansky, K., Inman, W., Serdy, J., Dash, A., Lim, M. H. M., and Griffith, L. G. (2010). Perfused multiwell plate for 3D liver tissue engineering. Lab Chip 10, 51-58. doi: 10.1039/B913221J

Domansky, K., Inman, W., Serdy, J., and Griffith, L. G. (2005). Perfused microreactors for liver tissue engineering. Annu. Int. Conf. IEEE Eng. Med. Biol. Proc. 7, 7490-7492. doi: 10.1109/iembs.2005.1616244

Dong, X. J., Zhang, G. R., Zhou, Q. J., Pan, R. L., Chen, Y., Xiang, L. X., et al. (2009). Direct hepatic differentiation of mouse embryonic stem cells induced by valproic acid and cytokines. World J. Gastroenterol. 15, 5165-5175. doi: 10.3748/wjg.15.5165

Dowden, H., and Munro, J. (2019). Trends in clinical success rates and therapeutic focus. Nat. Rev. Drug Discov. 18, 495-496. doi: 10.1038/d41573-019-00074-z

Dumas, E. O., and Pollack, G. M. (2008). Opioid tolerance development: a pharmacokinetic/pharmacodynamic perspective. AAPS J. 10, 537-551. doi: 10. 1208/s12248-008-9056-1

Edington, C. D., Chen, W. L. K., Geishecker, E., Kassis, T., Soenksen, L. R., Bhushan, B. M., et al. (2018). Interconnected microphysiological systems for quantitative biology and pharmacology studies. Sci. Rep. 8:4530. doi: 10.1038/ s41598-018-22749-0

EMEA (2000). Public Statement on Viramune (Nevirapine) - Severe and Life-Threatening Cutaneous and Hepatic Reactions. Available online at: 
https://www.ema.europa.eu/en/news/public-statement-viramune-nevirapinesevere-life-threatening-cutaneous-hepatic-reactions (accessed May 30, 2020).

Engler, A. J., Sen, S., Sweeney, H. L., and Discher, D. E. (2006). Matrix elasticity directs stem cell lineage specification. Cell 126, 677-689. doi: 10.1016/j.cell. 2006.06.044

Farzaneh, Z., Abbasalizadeh, S., Asghari-Vostikolaee, M. H., Alikhani, M., Cabral, J. M. S., and Baharvand, H. (2020). Dissolved oxygen concentration regulates human hepatic organoid formation from pluripotent stem cells in a fully controlled bioreactor. Biotechnol. Bioeng. 117, 3739-3756. doi: 10.1002/bit. 27521

Fey, S. J., Korzeniowska, B., and Wrzesinski, K. (2020). Response to and recovery from treatment in human liver-mimetic clinostat spheroids: a model for assessing repeated-dose drug toxicity. Toxicol. Res. 9, 379-389. doi: 10.1093/ toxres/tfaa033

Fey, S. J., and Wrzesinski, K. (2012). Determination of drug toxicity using 3D spheroids constructed from an immortal human hepatocyte cell line. Toxicol. Sci. 127, 403-411. doi: 10.1093/toxsci/kfs122

Foster, A. J., Chouhan, B., Regan, S. L., Rollison, H., Amberntsson, S., Andersson, L. C., et al. (2019). Integrated in vitro models for hepatic safety and metabolism: evaluation of a human Liver-Chip and liver spheroid. Arch. Toxicol. 93, 10211037. doi: 10.1007/s00204-019-02427-4

Frederick, D. M., Jacinto, E. Y., Patel, N. N., Rushmore, T. H., Tchao, R., and Harvison, P. J. (2011). Cytotoxicity of 3-(3,5-dichlorophenyl)-2,4thiazolidinedione (DCPT) and analogues in wild type and CYP3A4 stably transfected HepG2 cells. Toxicol. Vitr. 25, 2113-2119. doi: 10.1016/j.tiv.2011. 09.015

Freyer, N., Knöspel, F., Strahl, N., Amini, L., Schrade, P., Bachmann, S., et al. (2016). Hepatic differentiation of human induced pluripotent stem cells in a perfused three-dimensional multicompartment bioreactor. Biores. Open Access 5, 235-248. doi: 10.1089/biores.2016.0027

Fu, S., Wu, D., Jiang, W., Li, J., Long, J., Jia, C., et al. (2020). Molecular biomarkers in drug-induced liver injury: challenges and future perspectives. Front. Pharmacol. 10:1667. doi: 10.3389/fphar.2019.01667

Fu, Y., Deng, J., Jiang, Q., Wang, Y., Zhang, Y., Yao, Y., et al. (2016). Rapid generation of functional hepatocyte-like cells from human adipose-derived stem cells. Stem Cell Res. Ther. 7:105. doi: 10.1186/s13287-016-0364-6

Fung, M., Thornton, A., Mybeck, K., Wu, J. H. H., Hornbuckle, K., and Muniz, E. (2001). Evaluation of the characteristics of safety withdrawal of prescription drugs from worldwide pharmaceutical markets-1960 to 1999. Ther. Innov. Regul. Sci. 35, 293-317. doi: 10.1177/009286150103500134

Funk, C., Ponelle, C., Scheuermann, G., and Pantze, M. (2001). Cholestatic potential of troglitazone as a possible factor contributing to troglitazoneinduced hepatotoxicity: in vivo and in vitro interaction at the canalicular bile salt export pump (Bsep) in the rat. Mol. Pharmacol. 59, 627-635. doi: 10.1124/ MOL.59.3.627

Gao, B., Yang, Q., Zhao, X., Jin, G., Ma, Y., and Xu, F. (2016). 4D bioprinting for biomedical applications. Trends Biotechnol. 34, 746-756. doi: 10.1016/j.tibtech. 2016.03.004

Gao, X., and Liu, Y. (2017). A transcriptomic study suggesting human iPSC-derived hepatocytes potentially offer a better in vitro model of hepatotoxicity than most hepatoma cell lines. Cell Biol. Toxicol. 33, 407-421. doi: 10.1007/s10565-0179383-z

Gaskell, H., Sharma, P., Colley, H. E., Murdoch, C., Williams, D. P., and Webb, S. D. (2016). Characterization of a functional C3A liver spheroid model. Toxicol. Res. 5, 1053-1065. doi: 10.1039/c6tx00101g

Gerets, H. H. J., Tilmant, K., Gerin, B., Chanteux, H., Depelchin, B. O., Dhalluin, S., et al. (2012). Characterization of primary human hepatocytes, HepG2 cells, and HepaRG cells at the mRNA level and CYP activity in response to inducers and their predictivity for the detection of human hepatotoxins. Cell Biol. Toxicol. 28, 69-87. doi: 10.1007/s10565-011-9208-4

Gerlach, J. C., Encke, J., Hole, O., Müller, C., Ryan, C. J., and Neuhaus, P. (1994). Bioreactor for a larger scale hepatocyte in vitro perfusion. Transplantation 58, 984-988. doi: 10.1097/00007890-199411150-00002

Gerlach, J. C., Mutig, K., Sauer, I. M., Schrade, P., Efimova, E., Mieder, T., et al. (2003). Use of primary human liver cells originating from discarded grafts in a bioreactor for liver support therapy and the prospects of culturing adult liver stem cells in bioreactors: a morphologic study. Transplantation 76, 781-786. doi: 10.1097/01.TP.0000083319.36931.32
Ghabril, M., Fontana, R., Rockey, D., Jiezhun, G., and Chalasani, N. (2013). Drug-induced liver injury caused by intravenously administered medications: the drug-induced liver injury network experience. J. Clin. Gastroenterol. 47, 553-558. doi: 10.1097/MCG.0b013e31827 $6 \mathrm{bf00}$

Gieseck, R. L. III, Hannan, N. R. F., Bort, R., Hanley, N. A., Drake, R. A. L., Cameron, G. W. W., et al. (2014). Maturation of induced pluripotent stem cell derived hepatocytes by 3D-culture. PLoS One 9:e86372. doi: 10.1371/journal. pone.0086372

Gijbels, E., and Vinken, M. (2017). An update on adverse outcome pathways leading to liver injury. Appl. Vitr. Toxicol. 3, 283-285. doi: 10.1089/aivt.2017. 0027

Giri, S., Nieber, K., and Bader, A. (2010). Hepatotoxicity and hepatic metabolism of available drugs: current problems and possible solutions in preclinical stages. Expert Opin. Drug Metab. Toxicol. 6, 895-917. doi: 10.1517/ 17425251003792521

Glicklis, R., Merchuk, J. C., and Cohen, S. (2004). Modeling mass transfer in hepatocyte spheroids via cell viability, spheroid size, and hepatocellular functions. Biotechnol. Bioeng. 86, 672-680. doi: 10.1002/bit.20086

Goda, K., Takahashi, T., Kobayashi, A., Shoda, T., Kuno, H., and Sugai, S. (2016). Usefulness of in vitro combination assays of mitochondrial dysfunction and apoptosis for the estimation of potential risk of idiosyncratic drug induced liver injury. J. Toxicol. Sci. 41, 605-615. doi: 10.2131/jts.41.605

Godoy, P., Hewitt, N. J., Albrecht, U., Andersen, M. E., Ansari, N., Bhattacharya, S., et al. (2013). Recent advances in $2 \mathrm{D}$ and $3 \mathrm{D}$ in vitro systems using primary hepatocytes, alternative hepatocyte sources and non-parenchymal liver cells and their use in investigating mechanisms of hepatotoxicity, cell signaling and ADME. Arch. Toxicol. 87, 1315-1530. doi: 10.1007/s00204-013-1078-5

Gomez-Lechon, M., Donato, M., Lahoz, A., and Castell, J. (2008). Cell lines: a tool for in vitro drug metabolism studies. Curr. Drug Metab. 9, 1-11. doi: $10.2174 / 138920008783331086$

Gomez-Lechon, M. J., Lahoz, A., Gombau, L., Castell, J. V., and Donato, M. T. (2010). In vitro evaluation of potential hepatotoxicity induced by drugs. Curr. Pharm. Des. 16, 1963-1977. doi: 10.2174/138161210791208910

Goulart, E., de Caires-Junior, L. C., Telles-Silva, K. A., Araujo, B. H. S., Rocco, S. A., et al. (2019). 3D bioprinting of liver spheroids derived from human induced pluripotent stem cells sustain liver function and viability in vitro. Biofabrication 12:015010. doi: 10.1088/1758-5090/ab4a30

Granitzny, A., Knebel, J., Müller, M., Braun, A., Steinberg, P., Dasenbrock, C., et al. (2017). Evaluation of a human in vitro hepatocyte-NPC co-culture model for the prediction of idiosyncratic drug-induced liver injury: a pilot study. Toxicol. Rep. 4, 89-103. doi: 10.1016/j.toxrep.2017.02.001

Grattagliano, I., Bonfrate, L., Diogo, C. V., Wang, H. H., Wang, D. Q. H., and Portincasa, P. (2009). Biochemical mechanisms in drug-induced liver injury: certainties and doubts. World J. Gastroenterol. 15, 4865-4876. doi: 10.3748/wjg. 15.4865

Gregus, Z. (2013). “Chapter 3: mechanisms of toxicity," in Casarett and Doull's Toxicology: Basic Science of Poisons -, 8th Edn, ed. C. D. Klaassen (San Francisco: McGraw-Hill, Medical Publishing Division), 45-107.

Grilo, N. M., João Correia, M., Miranda, J. P., Cipriano, M., Serpa, J., Matilde Marques, M., et al. (2017). Unmasking efavirenz neurotoxicity: time matters to the underlying mechanisms. Eur. J. Pharm. Sci. 105, 47-54. doi: 10.1016/j.ejps. 2017.05.010

Grix, T., Ruppelt, A., Thomas, A., Amler, A., Noichl, B., Lauster, R., et al. (2018). Bioprinting Perfusion-Enabled Liver Equivalents for Advanced Organ-on-aChip Applications. Genes 9:176. doi: 10.3390/genes9040176

Guillouzo, A., Corlu, A., Aninat, C., Glaise, D., Morel, F., and Guguen-Guillouzo, C. (2007). The human hepatoma HepaRG cells: a highly differentiated model for studies of liver metabolism and toxicity of xenobiotics. Chem. Biol. Interact. 168, 66-73. doi: 10.1016/j.cbi.2006.12.003

Gunness, P., Mueller, D., Shevchenko, V., Heinzle, E., Ingelman-Sundberg, M., and Noor, F. (2013). 3D organotypic cultures of human heparg cells: a tool for in vitro toxicity studies. Toxicol. Sci. 133, 67-78. doi: 10.1093/toxsci/ $\mathrm{kft} 021$

Hafiz, E. O. A., Bulutoglu, B., Mansy, S. S., Chen, Y., Abu-Taleb, H., Soliman, S. A. M., et al. (2020). Development of liver microtissues with functional biliary ductular network. Biotechnol. Bioeng. 118, 17-29. doi: 10. 1002/bit. 27546 
Hammond, T., Allen, P., and Birdsall, H. (2016). Is there a space-based technology solution to problems with preclinical drug toxicity testing? Pharm. Res. 33, 1545-1551. doi: 10.1007/s11095-016-1942-0

Haque, A., Gheibi, P., Gao, Y., Foster, E., Son, K. J., You, J., et al. (2016). Cell biology is different in small volumes: endogenous signals shape phenotype of primary hepatocytes cultured in microfluidic channels. Sci. Rep. 6, 1-15. doi: $10.1038 /$ srep 33980

Haschek, W. M., Rousseaux, C. G., and Wallig, M. A. (2009). Fundamentals of toxicologic pathology: second edition. Fundam. Toxicol. Pathol. 2009, 1-691. doi: 10.1016/C2009-0-02051-0

Hass, R., Kasper, C., Böhm, S., and Jacobs, R. (2011). Different populations and sources of human mesenchymal stem cells (MSC): a comparison of adult and neonatal tissue-derived MSC. Cell Commun. Signal. 9:12. doi: 10.1186/1478811X-9-12

Hay, D. C., Fletcher, J., Payne, C., Terrace, J. D., Gallagher, R. C. J., Snoeys, J., et al. (2008a). Highly efficient differentiation of hESCs to functional hepatic endoderm requires ActivinA and Wnt3a signaling. Proc. Natl. Acad. Sci. U.S.A. 105, 12301-12306. doi: 10.1073/pnas.0806522105

Hay, D. C., Zhao, D., Fletcher, J., Hewitt, Z. A., McLean, D., UrruticoecheaUriguen, A., et al. (2008b). Efficient differentiation of hepatocytes from human embryonic stem cells exhibiting markers recapitulating liver development in vivo. Stem Cells 26, 894-902. doi: 10.1634/stemcells.2007-0718

Haycock, J. W. (2011). 3D Cell Culture: A Review of Current Approaches and Techniques. Totowa, NJ: Humana Press.

Hendriks, D. F. G., Puigvert, L. F., Messner, S., Mortiz, W., and IngelmanSundberg, M. (2016). Hepatic 3D spheroid models for the detection and study of compounds with cholestatic liability. Sci. Rep. 6:35434. doi: 10.1038/srep35434

Hinson, J. A., Roberts, D. W., and James, L. P. (2010). Mechanisms of acetaminophen-induced liver necrosis. Handb. Exp. Pharmacol. 196, 396-405. doi: 10.1007/978-3-642-00663-0_12

Hoffmann, S. A., Müller-Vieira, U., Biemel, K., Knobeloch, D., Heydel, S., Lübberstedt, M., et al. (2012). Analysis of drug metabolism activities in a miniaturized liver cell bioreactor for use in pharmacological studies. Biotechnol. Bioeng. 109, 3172-3181. doi: 10.1002/bit.24573

Holmgren, G., Sjögren, A. K., Barragan, I., Sabirsh, A., Sartipy, P., Synnergren, J., et al. (2014). Long-term chronic toxicity testing using human pluripotent stem cell-derived hepatocytes. Drug Metab. Dispos. 42, 1401-1406. doi: 10.1124/dmd. 114.059154

Horvath, P., Aulner, N., Bickle, M., Davies, A. M., Del Nery, E., Ebner, D., et al. (2016). Screening out irrelevant cell-based models of disease. Nat. Rev. Drug Discov. 15, 751-769. doi: 10.1038/nrd.2016.175

Huch, M., Dorrell, C., Boj, S. F., Van Es, J. H., Li, V. S. W., Van De Wetering, M., et al. (2013). In vitro expansion of single Lgr 5 + liver stem cells induced by Wnt-driven regeneration. Nature 494, 247-250. doi: 10.1038/nature11826

Huch, M., Gehart, H., Van Boxtel, R., Hamer, K., Blokzijl, F., Verstegen, M. M. A., et al. (2015). Long-term culture of genome-stable bipotent stem cells from adult human liver. Cell 160, 299-312. doi: 10.1016/j.cell.2014.11.050

Hultman, I., Vedin, C., Abrahamsson, A., Winiwarter, S., and Darnell, M. (2016). Use of H $\mu$ REL human coculture system for prediction of intrinsic clearance and metabolite formation for slowly metabolized compounds. Mol. Pharm. 13, 2796-2807. doi: 10.1021/acs.molpharmaceut.6b00396

Ingber, D. E. (2020). Is it time for reviewer 3 to request human organ chip experiments instead of animal validation studies? Adv. Sci. 2020:2002030. doi: 10.1002/advs.202002030

Jackson, J. P., Freeman, K. M., St. Claire, R. L., Black, C. B., and Brouwer, K. R. (2018). Cholestatic drug induced liver injury: a function of bile salt export pump inhibition and farnesoid X receptor antagonism. Appl. Vitr. Toxicol. 4, 265-279. doi: 10.1089/aivt.2018.0011

Jaeschke, H. (2013). "Chapter 13: toxic responses of the liver," in Casarett and Doull's Toxicology: Basic Science of Poisons -, 8th Edn, ed. C. D. Klaassen (San Francisco: McGraw-Hill, Medical Publishing Division), 557-583.

Jang, M., Kleber, A., Ruckelshausen, T., Betzholz, R., and Manz, A. (2019). Differentiation of the human liver progenitor cell line (HepaRG) on a microfluidic-based biochip. J. Tissue Eng. Regen. Med. 13, 482-494. doi: 10. $1002 /$ term. 2802

Jang, M., Neuzil, P., Volk, T., Manz, A., and Kleber, A. (2015). On-chip threedimensional cell culture in phaseguides improves hepatocyte functions in vitro. Biomicrofluidics 9:034113. doi: 10.1063/1.4922863
Jemnitz, K., Veres, Z., Monostory, K., Kóbori, L., and Vereczkey, L. (2008). Interspecies differences in acetaminophen sensitivity of human, rat, and mouse primary hepatocytes. Toxicol. Vitr. 22, 961-967. doi: 10.1016/j.tiv.2008.02.001

Jeon, J. W., Choi, N., Lee, S. H., and Sung, J. H. (2020). Three-tissue microphysiological system for studying inflammatory responses in gut-liver Axis. Biomed. Microdevices 22:65. doi: 10.1007/s10544-020-00 $519-\mathrm{y}$

Jiang, J., Pieterman, C. D., Ertaylan, G., Peeters, R. L. M., and de Kok, T. M. C. M. (2019). The Application of Omics-Based Human Liver Platforms for Investigating the Mechanism of Drug-Induced Hepatotoxicity in Vitro. Berlin: Springer.

Jones, S. C., Kortepeter, C., and Brinker, A. D. (2018). "Postmarketing surveillance of drug-induced liver injury," in Methods in Pharmacology and Toxicology, ed. K. Y. James (New York, NY: Springer), 459-474.

Kamihira, M., Yamada, K., Hamamoto, R., and Iijima, S. (1997). Spheroid formation of hepatocytes using synthetic polymer. Ann. N. Y. Acad. Sci. 831, 398-407. doi: 10.1111/j.1749-6632.1997.tb52213.x

Kanamori, Y., Fujita, K. I, Nakayama, K., Kamataki, T., and Kawai, H. (2003). Large-scale production of genetically engineered CYP3A4 in E. coli: application of a Jarfermenter. Drug Metab. Pharmacokinet. 18, 42-47. doi: 10.2133/dmpk. 18.42

Kang, Y. B. A., Sodunke, T. R., Lamontagne, J., Cirillo, J., Rajiv, C., Bouchard, M. J., et al. (2015). Liver sinusoid on a chip: long-term layered co-culture of primary rat hepatocytes and endothelial cells in microfluidic platforms. Biotechnol. Bioeng. 112, 2571-2582. doi: 10.1002/bit. 25659

Kappelhoff, B. S., Van Leth, F., MacGregor, T. R., Lange, J. M. A., Beijnen, J. H., and Huitema, A. D. R. (2005). Nevirapine and efavirenz pharmacokinetics and covariate analysis in the 2NN study. Antivir. Ther. 10, 145-155.

Kassahun, K., Pearson, P. G., Tang, W., McIntosh, I., Leung, K., Elmore, C., et al. (2001). Studies on the metabolism of troglitazone to reactive intermediates in vitro and in vivo. Evidence for novel biotransformation pathways involving quinone methide formation and thiazolidinedione ring scission. Chem. Res. Toxicol. 14, 62-70. doi: 10.1021/tx000180q

Kazemnejad, S., Allameh, A., Seoleimani, M., Gharehbaghian, A., Mohammadi, Y., Amirizadeh, N., et al. (2008). Functional hepatocyte-like cells derived from human bone marrow mesenchymal stem cells on a novel 3-dimensional biocompatible nanofibrous scaffold. Int. J. Artif. Organs 31, 500-507. doi: 10. $1177 / 039139880803100605$

Kenna, J. G., and Uetrecht, J. (2018). Do In Vitro assays predict drug candidate idiosyncratic drug-induced liver injury risk? Drug Metab. Dispos. 46, 16581669. doi: $10.1124 / \mathrm{dmd} .118 .082719$

Khetani, S. R., and Bhatia, S. N. (2008). Microscale culture of human liver cells for drug development. Nat. Biotechnol. 26, 120-126. doi: 10.1038/nbt1361

Khetani, S. R., Kanchagar, C., Ukairo, O., Krzyzewski, S., Moore, A., Shi, J., et al. (2013). Use of micropatterned cocultures to detect compounds that cause druginduced liver injury in humans. Toxicol. Sci. 132, 107-117. doi: 10.1093/toxsci/ kfs326

Kholodenko, I. V., Kurbatov, L. K., Kholodenko, R. V., Manukyan, G. V., and Yarygin, K. N. (2019). Mesenchymal stem cells in the adult human liver: hype or hope? Cells. 8:1127. doi: 10.3390/cells8101127

Kim, D. E., Jang, M.-J., Kim, Y. R., Lee, J.-Y., Cho, E. B., Kim, E., et al. (2017). Prediction of drug-induced immune-mediated hepatotoxicity using hepatocyte-like cells derived from human embryonic stem cells. Toxicology 387 , 1-9. doi: 10.1016/j.tox.2017.06.005

Kizawa, H., Nagao, E., Shimamura, M., Zhang, G., and Torii, H. (2017). Scaffoldfree 3D bio-printed human liver tissue stably maintains metabolic functions useful for drug discovery. Biochem. Biophys. Rep. 10, 186-191. doi: 10.1016/j. bbrep.2017.04.004

Kleiner, D. E. (2017). The histopathological evaluation of drug-induced liver injury. Histopathology 70, 81-93. doi: 10.1111/his.13082

Knospel, F., Jacobs, F., Freyer, N., Damm, G., De Bondt, A., van den Wyngaert, I., et al. (2016). In vitro model for hepatotoxicity studies based on primary human hepatocyte cultivation in a perfused 3D bioreactor system. Int. J. Mol. Sci. 17:584. doi: 10.3390/ijms17040584

Kola, I., and Landis, J. (2004). Can the pharmaceutical industry reduce attrition rates? Nat. Rev. Drug Discov. 3, 711-716. doi: 10.1038/nrd1470

Kostadinova, R., Boess, F., Applegate, D., Suter, L., Weiser, T., Singer, T., et al. (2013). A long-term three dimensional liver co-culture system for improved 
prediction of clinically relevant drug-induced hepatotoxicity. Toxicol. Appl. Pharmacol. 268, 1-16. doi: 10.1016/j.taap.2013.01.012

Koui, Y., Kido, T., Ito, T., Oyama, H., Chen, S. W., Katou, Y., et al. (2017). An in vitro human liver model by iPSC-derived parenchymal and nonparenchymal cells. Stem Cell Rep. 9, 490-498. doi: 10.1016/j.stemcr.2017.06. 010

Koyama, S., Arakawa, H., Itoh, M., Masuda, N., Yano, K., Kojima, H., et al. (2018). Evaluation of the metabolic capability of primary human hepatocytes in threedimensional cultures on microstructural plates. Biopharm. Drug Dispos. 39, 187-195. doi: 10.1002/bdd.2125

Kranendonk, M., Alves, M., Antunes, P., and Rueff, J. (2014). Human sulfotransferase $1 \mathrm{Al}$-dependent mutagenicity of 12-hydroxy-nevirapine: the missing link? Chem. Res. Toxicol. 27, 1967-1971. doi: 10.1021/tx5003113

Krasniqi, V., Dimovski, A., Domjanovic, I. K., Bilic, I., and Bozina, N. (2016). How polymorphisms of the cytochrome P450 genes affect ibuprofen and diclofenac metabolism and toxicity. Arh. Hig. Rada Toksikol. 67, 1-8. doi: 10.1515/aiht2016-67-2754

Kratochwil, N. A., Triyatni, M., Mueller, M. B., Klammers, F., Leonard, B., Turley, D., et al. (2018). Simultaneous assessment of clearance, metabolism, induction, and drug-drug interaction potential using a long-term in vitro liver model for a novel hepatitis b virus inhibitor. J. Pharmacol. Exp. Ther. 365, 237-248. doi: $10.1124 /$ jpet.117.245712

Krewski, D., Andersen, M. E., Mantus, E., and Zeise, L. (2009). Toxicity testing in the 21st century: implications for human health risk assessment: perspective. Risk Anal. 29, 474-479. doi: 10.1111/j.1539-6924.2008.01150.x

Kučera, O., Endlicher, R., Rychtrmoc, D., Lotková, H., Sobotka, O., and Červinková, Z. (2017). Acetaminophen toxicity in rat and mouse hepatocytes in vitro. Drug Chem. Toxicol. 40, 448-456. doi: 10.1080/01480545.2016. 1255953

Kuna, L., Bozic, I., Kizivat, T., Bojanic, K., Mrso, M., Kralj, E., et al. (2018). Models of drug induced liver injury (DILI) - current issues and future perspectives. Curr. Drug Metab. 19, 830-838. doi: 10.2174/1389200219666180523095355

Kuntz, E., and Kuntz, H.-D. (2008). Hepatology Textbook and Atlas, 3rd Edn. Berlin: Springer.

Langhans, S. A. (2018). Three-dimensional in vitro cell culture models in drug discovery and drug repositioning. Front. Pharmacol. 9:6. doi: 10.3389/fphar. 2018.00006

Larson, A. M. (2010). Diagnosis and management of acute liver failure. Curr. Opin. Gastroenterol. 26, 214-221. doi: 10.1097/MOG.0b013e32833847c5

Lauer, B., Tuschl, G., Kling, M., and Mueller, S. O. (2009). Species-specific toxicity of diclofenac and troglitazone in primary human and rat hepatocytes. Chem. Biol. Interact. 179, 17-24. doi: 10.1016/j.cbi.2008.10.031

Lauschke, V. M., Hendriks, D. F. G., Bell, C. C., Andersson, T. B., and Ingelman-Sundberg, M. (2016). Novel 3D culture systems for studies of human liver function and assessments of the hepatotoxicity of drugs and drug candidates. Chem. Res. Toxicol. 29, 1936-1955. doi: 10.1021/acs.chemrestox. $6 \mathrm{~b} 00150$

Lee, H. J., Jung, J., Cho, K. J., Lee, C. K., Hwang, S. G., and Kim, G. J. (2012). Comparison of in vitro hepatogenic differentiation potential between various placenta-derived stem cells and other adult stem cells as an alternative source of functional hepatocytes. Differentiation 84, 223-231. doi: 10.1016/j.diff.2012.05. 007

Lee, P. J., Hung, P. J., and Lee, L. P. (2007). An artificial liver sinusoid with a microfluidic endothelial-like barrier for primary hepatocyte culture. Biotechnol. Bioeng. 97, 1340-1346. doi: 10.1002/bit.21360

Leite, S. B., Roosens, T., El Taghdouini, A., Mannaerts, I., Smout, A. J., Najimi, M., et al. (2016). Novel human hepatic organoid model enables testing of druginduced liver fibrosis in vitro. Biomaterials 78, 1-10. doi: 10.1016/j.biomaterials. 2015.11.026

Leite, S. B., Teixeira, A. P., Miranda, J. P., Tostões, R. M., Clemente, J. J., Sousa, M. F., et al. (2011). Merging bioreactor technology with 3D hepatocytefibroblast culturing approaches: improved in vitro models for toxicological applications. Toxicol. Vitr. 25, 825-832. doi: 10.1016/j.tiv.2011.02.002

Leite, S. B., Wilk-Zasadna, I., Zaldivar, J. M., Airola, E., Reis-Fernandes, M. A., Mennecozzi, M., et al. (2012). Three-dimensional HepaRG model as an attractive tool for toxicity testing. Toxicol. Sci. 130, 106-116. doi: 10.1093/ toxsci/kfs 232
Lerche-Langrand, C., and Toutain, H. J. (2000). Precision-cut liver slices: characteristics and use for in vitro pharmaco-toxicology. Toxicology 153, 221253. doi: 10.1016/S0300-483X(00)00316-4

Lewerenz, V., Hanelt, S., Nastevska, C., El-Bahay, C., Röhrdanz, E., and Kahl, R. (2003). Antioxidants protect primary rat hepatocyte cultures against acetaminophen-induced DNA strand breaks but not against acetaminopheninduced cytotoxicity. Toxicology 191, 179-187. doi: 10.1016/S0300-483X(03) 00256-7

Li, F., Cao, L., Parikh, S., and Zuo, R. (2020). Three-Dimensional Spheroids With Primary Human Liver Cells and Differential Roles of Kupffer Cells in DrugInduced Liver Injury. J. Pharm. Sci. 109, 1912-1923. doi: 10.1016/j.xphs.2020. 02.021

Li, M., Yuan, H., Li, N., Song, G., Zheng, Y., Baratta, M., et al. (2008). Identification of interspecies difference in efflux transporters of hepatocytes from dog, rat, monkey and human. Eur. J. Pharm. Sci. 35, 114-126. doi: 10.1016/j.ejps.2008. 06.008

Lin, J., Schyschka, L., Mühl-Benninghaus, R., Neumann, J., Hao, L., Nussler, N., et al. (2012). Comparative analysis of phase I and II enzyme activities in 5 hepatic cell lines identifies Huh-7 and HCC-T cells with the highest potential to study drug metabolism. Arch. Toxicol. 86, 87-95. doi: 10.1007/s00204-0110733-y

Lin, R.-Z., and Chang, H.-Y. (2008). Recent advances in three-dimensional multicellular spheroid culture for biomedical research. Biotechnol. J. 3, 11721184. doi: $10.1002 /$ biot.200700228

Liu, H., Wang, Y., Cui, K., Guo, Y., Zhang, X., and Qin, J. (2019). Advances in hydrogels in organoids and organs-on-a-chip. Adv. Mater. 31, 1-28. doi: 10.1002/adma.201902042

Loi, C. M., Alvey, C. W., Vassos, A. B., Randinitis, E. J., Sedman, A. J., and Koup, J. R. (1999). Steady-state pharmacokinetics and dose proportionality of troglitazone and its metabolites. J. Clin. Pharmacol. 39, 920-926. doi: 10.1177/ 00912709922008533

Loskill, P., Marcus, S. G., Mathur, A., Reese, W. M., and Healy, K. E. (2015). $\mu$ Organo: a lego ${ }^{\circledR}$-like plug \& play system for modular multi-organ-chips. PLoS One 10:e0139587. doi: 10.1371/journal.pone.0139587

Lübberstedt, M., Müller-Vieira, U., Biemel, K. M., Darnell, M., Hoffmann, S. A., Knöspel, F., et al. (2015). Serum-free culture of primary human hepatocytes in a miniaturized hollow-fibre membrane bioreactor for pharmacological in vitro studies. J. Tissue Eng. Regen. Med. 9, 1017-1026. doi: 10.1002/term.1652

Lübberstedt, M., Müller-Vieira, U., Mayer, M., Biemel, K. M., Knöspel, F., Knobeloch, D., et al. (2011). HepaRG human hepatic cell line utility as a surrogate for primary human hepatocytes in drug metabolism assessment in vitro. J. Pharmacol. Toxicol. Methods 63, 59-68. doi: 10.1016/j.vascn.2010. 04.013

Luo, X., Gupta, K., Ananthanarayanan, A., Wang, Z., Xia, L., Li, A., et al. (2018). Directed differentiation of adult liver derived mesenchymal like stem cells into functional hepatocytes. Sci. Rep. 8:2818. doi: 10.1038/s41598-018-20304-5

Ma, C., Zhao, L., Zhou, E. M., Xu, J., Shen, S., and Wang, J. (2016). On-chip construction of liver lobule-like microtissue and its application for adverse drug reaction assay. Anal. Chem. 88, 1719-1727. doi: 10.1021/acs.analchem.5b03869

Ma, J., Wang, Y., and Liu, J. (2018). Bioprinting of 3D tissues/organs combined with microfluidics. RSC Adv. 8, 21712-21727. doi: 10.1039/C8RA03022G

Ma, X., Qu, X., Zhu, W., Li, Y. S., Yuan, S., Zhang, H., et al. (2016). Deterministically patterned biomimetic human iPSC-derived hepatic model via rapid 3D bioprinting. Proc. Natl. Acad. Sci. U.S.A. 113, 2206-2211. doi: 10.1073/pnas.1524510113

Mandenius, C. F., Andersson, T. B., Alves, P. M., Batzl-Hartmann, C., Björquist, P., Carrondo, M. J. T., et al. (2011). Toward preclinical predictive drug testing for metabolism and hepatotoxicity by using in vitro models derived from human embryonic stem cells and human cell lines - A report on the vitrocellomics EU-project. ATLA Altern. Lab. Anim. 39, 147-171. doi: 10.1177/ 026119291103900210

Mannaerts, I., Eysackers, N., Anne van Os, E., Verhulst, S., Roosens, T., Smout, A., et al. (2020). The fibrotic response of primary liver spheroids recapitulates in vivo hepatic stellate cell activation. Biomaterials 261:120335. doi: 10.1016/j. biomaterials.2020.120335

Marinho, A. T., Miranda, J. P., Caixas, U., Charneira, C., Gonçalves-Dias, C., Marques, M. M., et al. (2019). Singularities of nevirapine metabolism: from 
sex-dependent differences to idiosyncratic toxicity. Drug Metab. Rev. 51, 76-90. doi: 10.1080/03602532.2019.1577891

Martignoni, M., Groothuis, G. M. M., and de Kanter, R. (2006). Species differences between mouse, rat, dog, monkey and human CYP-mediated drug metabolism, inhibition and induction. Expert Opin. Drug Metab. Toxicol. 2, 875-894. doi: 10.1517/17425255.2.6.875

Maschmeyer, I., Hasenberg, T., Jaenicke, A., Lindner, M., Lorenz, A. K., Zech, J., et al. (2015). Chip-based human liver-intestine and liver-skin co-cultures - A first step toward systemic repeated dose substance testing in vitro. Eur. J. Pharm. Biopharm. 95, 77-87. doi: 10.1016/j.ejpb.2015.03.002

Mastrangeli, M., Millet, S., Orchid Partners, T., and Van den Eijnden-van Raaij, J. (2019). Organ-on-chip in development: towards a roadmap for organs-on-chip. ALTEX 36, 650-668. doi: 10.14573/altex.1908271

Mazaleuskaya, L. L., Sangkuhl, K., Thorn, C. F., Fitzgerald, G. A., Altman, R. B., and Klein, T. E. (2015). PharmGKB summary: pathways of acetaminophen metabolism at the therapeutic versus toxic doses. Pharmacogenet. Genomics 25, 416-426. doi: 10.1097/FPC.0000000000000150

Mazzocchi, A., Devarasetty, M., Huntwork, R., Soker, S., and Skardal, A. (2018). Optimization of collagen type I-hyaluronan hybrid bioink for 3D bioprinted liver microenvironments. Biofabrication 11:015003. doi: 10.1088/1758-5090/ aae 543

Mazzocchi, A., Soker, S., and Skardal, A. (2019). 3D bioprinting for highthroughput screening: drug screening, disease modeling, and precision medicine applications. Appl. Phys. Rev. 6:011302. doi: 10.1063/1.5056188

McCarty, W. J., Usta, O. B., and Yarmush, M. L. (2016). A microfabricated platform for generating physiologically-relevant hepatocyte zonation. Sci. Rep. 6:26868. doi: $10.1038 /$ srep 26868

McGill, M. R., and Jaeschke, H. (2013). Metabolism and disposition of acetaminophen: recent advances in relation to hepatotoxicity and diagnosis. Pharm. Res. 30, 2174-2187. doi: 10.1007/s11095-013-1007-6

Ménochet, K., Kenworthy, K. E., Houston, J. B., and Galetin, A. (2012). Use of mechanistic modeling to assess interindividual variability and interspecies differences in active uptake in human and rat hepatocytes. Drug Metab. Dispos. 40, 1744-1756. doi: 10.1124/dmd.112.046193

Messner, S., Agarkova, A., Moritz, W., and Kelm, J. M. (2013). Multi-cell type human liver microtissues for hepatotoxicity testing. Arch. Toxicol. 87, 209-213. doi: 10.1007/s00204-012-0968-2

Messner, S., Fredriksson, L., Lauschke, V. M., Roessger, K., Escher, C., Bober, M., et al. (2018). Transcriptomic, proteomic, and functional long-term characterization of multicellular three-dimensional human liver microtissues. Appl. Vitr. Toxicol. 4, 1-12. doi: 10.1089/aivt.2017.0022

Meyer, U. A., and Zanger, U. M. (1997). Molecular mechanisms of genetic polymorphisms of drug metabolism. Annu. Rev. Pharmacol. Toxicol. 37, 269296. doi: 10.1146/annurev.pharmtox.37.1.269

Miranda, J. P., Leite, S. B., Muller-Vieira, U., Rodrigues, A., Carrondo, M. J. T., and Alves, P. M. (2009). Towards an extended functional hepatocyte in vitro culture. Tissue Eng. Part C Methods 15, 157-167. doi: 10.1089/ten.tec.2008.0352

Miranda, J. P., Rodrigues, A., Tostoes, R. M., Leite, S., Zimmerman, H., Carrondo, M. J. T., et al. (2010). Extending hepatocyte functionality for drug-testing applications using high-viscosity alginate-encapsulated threedimensional cultures in bioreactors. Tissue Eng. Part C Methods 16, 1223-1232. doi: 10.1089/ten.TEC.2009.0784

Molina-Jimenez, F., Benedicto, I., Dao Thi, V. L., Gondar, V., Lavillette, D., Marin, J. J., et al. (2012). Matrigel-embedded 3D culture of Huh-7 cells as a hepatocytelike polarized system to study hepatitis C virus cycle. Virology 425, 31-39. doi: 10.1016/j.virol.2011.12.021

Mueller, D., Tascher, G., Muller-Vieira, U., Knobeloch, D., Nuessler, A. K., Zeilinger, K., et al. (2011). In-depth physiological characterization of primary human hepatocytes in a 3D hollow-fiber bioreactor. J. Tissue Eng. Regen. Med. 5, e207-e218. doi: 10.1002/term.418

Mustafa, M. G., Khan, M. G. M., Nguyen, D., and Iqbal, S. (2018). “Techniques in biotechnology," in Omics Technologies and Bio-Engineering, ed. V. Azevedo (Amsterdam: Elsevier), 233-249.

Nakamura, K., Kato, N., Aizawa, K., Mizutani, R., Yamauchi, J., and Tanoue, A. (2011). Expression of albumin and cytochrome P450 enzymes in HepG2 cells cultured with a nanotechnology-based culture plate with microfabricated scaffold. J. Toxicol. Sci. 36, 625-633. doi: 10.2131/jts.36.625
Nelson, L. J., Walker, S. W., Hayes, P. C., and Plevris, J. N. (2010). Low-shear modelled microgravity environment maintains morphology and differentiated functionality of primary porcine hepatocyte cultures. Cells Tissues Organs 192, 125-140. doi: 10.1159/000308893

Nguyen, D. G., Funk, J., Robbins, J. B., and Crogan-grundy, C. (2016). Bioprinted 3D primary liver tissues allow assessment of organ-level response to clinical drug induced toxicity in vitro. PLoS One 11:e0158674. doi: 10.1371/journal. pone. 0158674

Norrman, K., Strömbeck, A., Semb, H., and Ståhlberg, A. (2013). Distinct gene expression signatures in human embryonic stem cells differentiated towards definitive endoderm at single-cell level. Methods 59, 59-70. doi: 10.1016/j. ymeth.2012.03.030

Novik, E. I., Dwyer, J., Morelli, J. K., Parekh, A., Cho, C., Pludwinski, E., et al. (2017). Long-enduring primary hepatocyte-based co-cultures improve prediction of hepatotoxicity. Toxicol. Appl. Pharmacol. 336, 20-30. doi: 10.1016/ j.taap.2017.09.013

Nudischer, R., Renggli, K., Hierlemann, A., Roth, A. B., and Bertinetti-Lapatki, C. (2020). Characterization of a long-term mouse primary liver 3D tissue model recapitulating innate-immune responses and drug-induced liver toxicity. PLoS One 15:e0235745. doi: 10.1371/journal.pone.0235745

O’Brien, P. J., Irwin, W., Diaz, D., Howard-Cofield, E., Krejsa, C. M., Slaughter, M. R., et al. (2006). High concordance of drug-induced human hepatotoxicity with in vitro cytotoxicity measured in a novel cell-based model using high content screening. Arch. Toxicol. 80, 580-604. doi: 10.1007/s00204-006-0091-3

Ogawa, M., Ogawa, S., Bear, C. E., Ahmadi, S., Chin, S., Li, B., et al. (2015). Directed differentiation of cholangiocytes from human pluripotent stem cells. Nat. Biotechnol. 33, 853-861. doi: 10.1038/nbt.3294

Ogimura, E., Sekine, S., and Horie, T. (2011). Bile salt export pump inhibitors are associated with bile acid-dependent drug-induced toxicity in sandwichcultured hepatocytes. Biochem. Biophys. Res. Commun. 416, 313-317. doi: 10. 1016/j.bbrc.2011.11.032

Okura, H., Komoda, H., Saga, A., Kakuta-Yamamoto, A., Hamada, Y., Fumimoto, Y., et al. (2010). Properties of hepatocyte-like cell clusters from human adipose tissue-derived mesenchymal stem cells. Tissue Eng. Part C Methods 16, 761-770. doi: 10.1089/ten.TEC.2009.0208

Olson, H., Betton, G., Robinson, D., Thomas, K., Monro, A., Kolaja, G., et al. (2000). Concordance of the toxicity of pharmaceuticals in humans and in animals. Regul. Toxicol. Pharmacol. 32, 56-67. doi: 10.1006/rtph.2000.1399

Omiecinski, C. J., Vanden Heuvel, J. P., Perdew, G. H., and Peters, J. M. (2011). Xenobiotic metabolism, disposition, and regulation by receptors: from biochemical phenomenon to predictors of major toxicities. Toxicol. Sci. 120, S49-S75. doi: 10.1093/toxsci/kfq338

Onakpoya, I. J., Heneghan, C. J., and Aronson, J. K. (2016). Post-marketing withdrawal of 462 medicinal products because of adverse drug reactions: a systematic review of the world literature. BMC Med. 14:10. doi: 10.1186/s12916016-0553-2

Overi, D., Carpino, G., Cardinale, V., Franchitto, A., Safarikia, S., Onori, P., et al. (2018). Contribution of resident stem cells to liver and biliary tree regeneration in human diseases. Int. J. Mol. Sci. 19:2917. doi: 10.3390/ijms19102917

Padda, M. S., Sanchez, M., Akhtar, A. J., and Boyer, J. L. (2011). Drug-induced cholestasis. Hepatology 53, 1377-1387. doi: 10.1002/hep.24229

Paniagua, A. C., and Amariles, P. (2018). "Hepatotoxicity by drugs," in Pharmacokinetics and Adverse Effects of Drugs - Mechanisms and Risks Factors, (Ntambwe Malangu: IntechOpen). doi: 10.5772/intechopen.72005

Pareja, E., Gómez-Lechón, M. J., and Tolosa, L. (2020). Induced pluripotent stem cells for the treatment of liver diseases: challenges and perspectives from a clinical viewpoint. Ann. Transl. Med. 8:566. doi: 10.21037/atm.2020.02.164

Paul, S. M., Mytelka, D. S., Dunwiddie, C. T., Persinger, C. C., Munos, B. H., Lindborg, S. R., et al. (2010). How to improve R\&D productivity: the pharmaceutical industry's grand challenge. Nat. Rev. Drug Discov. 9, 203-214. doi: $10.1038 / \mathrm{nrd} 3078$

Peng, W. C., Logan, C. Y., Fish, M., Anbarchian, T., Aguisanda, F., ÁlvarezVarela, A., et al. (2018). Inflammatory cytokine TNF $\alpha$ promotes the long-term expansion of primary hepatocytes in 3D culture. Cell 175, 1607.e15-1619.e15. doi: 10.1016/j.cell.2018.11.012

Pessayre, D. (1993). Cytochromes P450 and formation of reactive metabolites. Role in hepatotoxicity of drugs. Therapie 48, 537-548. 
Pinheiro, P. F., Pereira, S. A., Harjivan, S. G., Martins, I. L., Marinho, A. T., Cipriano, M., et al. (2017). Hepatocyte spheroids as a competent in vitro system for drug biotransformation studies: nevirapine as a bioactivation case study. Arch. Toxicol. 91, 1199-1211. doi: 10.1007/s00204-016$1792-\mathrm{x}$

Poietis (2018). Servier and Poietis Announce Scientific Partnership in 4D Bioprinting of Liver Tissues. Available online at: https://poietis.com/servier-and-poietisannounce-scientific-partnership-in-4d-bioprinting-of-liver-tissues/ (accessed May 8, 2020).

Ponsoda, X., Bort, R., Jover, R., Gómez-lechón, M. J., and Castell, J. V. (1995). Molecular mechanism of diclofenac hepatotoxicity: association of cell injury with oxidative metabolism and decrease in ATP levels. Toxicol. Vitr. 9, 439-444. doi: 10.1016/0887-2333(95)00035-7

Prakash, C., Sharma, R., Gleave, M., and Nedderman, A. (2008). In vitro screening techniques for reactive metabolites for minimizing bioactivation potential in drug discovery. Curr. Drug Metab. 9, 952-964. doi: 10.2174/ 138920008786485209

Preissner, S., Simmaco, M., Gentile, G., and Preissner, R. (2015). Personalized cancer therapy considering cytochrome P450 variability. Adv. Pharmacol. 74, 113-130. doi: 10.1016/bs.apha.2015.03.004

Prill, S., Bavli, D., Levy, G., Ezra, E., Schmälzlin, E., Jaeger, M. S., et al. (2016). Real-time monitoring of oxygen uptake in hepatic bioreactor shows CYP450independent mitochondrial toxicity of acetaminophen and amiodarone. Arch. Toxicol. 90, 1181-1191. doi: 10.1007/s00204-015-1537-2

Proctor, W. R., Foster, A. J., Vogt, J., Summers, C., Middleton, B., Pilling, M. A., et al. (2017). Utility of spherical human liver microtissues for prediction of clinical drug-induced liver injury. Arch. Toxicol. 91, 2849-2863. doi: 10.1007/ s00204-017-2002-1

Prodanov, L., Jindal, R., Bale, S. S., Hegde, M., Mccarty, W. J., Golberg, I., et al. (2016). Long-term maintenance of a microfluidic 3D human liver sinusoid. Biotechnol. Bioeng. 113, 241-246. doi: 10.1002/bit.25700

Prot, J. M., Bunescu, A., Elena-Herrmann, B., Aninat, C., Snouber, L. C., Griscom, L., et al. (2012). Predictive toxicology using systemic biology and liver microfluidic "on chip" approaches: application to acetaminophen injury. Toxicol. Appl. Pharmacol. 259, 270-280. doi: 10.1016/j.taap.2011.12.017

Qureshi, Z. P., Seoane-Vazquez, E., Rodriguez-Monguio, R., Stevenson, K. B., and Szeinbach, S. L. (2011). Market withdrawal of new molecular entities approved in the United States from 1980 to 2009. Pharmacoepidemiol. Drug Saf. 20, 772-777. doi: $10.1002 /$ pds. 2155

Raasch, M., Fritsche, E., Kurtz, A., Bauer, M., and Mosig, A. S. (2019). Microphysiological systems meet hiPSC technology - New tools for disease modeling of liver infections in basic research and drug development. Adv. Drug Deliv. Rev. 140, 51-67. doi: 10.1016/j.addr.2018.06.008

Raju, R., Chau, D., Notelaers, T., Myers, C. L., Verfaillie, C. M., and Hu, W. S. (2018). In vitro pluripotent stem cell differentiation to hepatocyte ceases further maturation at an equivalent stage of e15 in mouse embryonic liver development. Stem Cells Dev. 27, 910-921. doi: 10.1089/scd.2017.0270

Ramachandran, A., and Jaeschke, H. (2018). Acetaminophen toxicity: novel insights into mechanisms and future perspectives. Gene Expr. 18, 19-30. doi: 10.3727/105221617X15084371374138

Ramaiahgari, S. C., Den Braver, M. W., Herpers, B., Terpstra, V., Commandeur, J. N. M., Van De Water, B., et al. (2014). A 3D in vitro model of differentiated HepG2 cell spheroids with improved liver-like properties for repeated dose high-throughput toxicity studies. Arch. Toxicol. 88, 1083-1095. doi: 10.1007/ s00204-014-1215-9

Ramli, M. N., Bin, Lim, Y. S., Koe, C. T., Demircioglu, D., Tng, W., et al. (2020). Human pluripotent stem cell-derived organoids as models of liver disease. Gastroenterology 159, 1471.e12-1486.e12. doi: 10.1053/j.gastro.2020.06.010

Reder-Hilz, B., Ullrich, M., Ringel, M., Hewitt, N., Utesch, D., Oesch, F., et al. (2004). Metabolism of propafenone and verapamil by cryopreserved human, rat, mouse and dog hepatocytes: comparison with metabolism in vivo. Naunyn. Schmiedebergs. Arch. Pharmacol. 369, 408-417. doi: 10.1007/s00210-004-0875$\mathrm{z}$

Regenthal, R., Krueger, M., Koeppel, C., and Preiss, R. (1999). Drug levels: therapeutic and toxic serum/plasma concentrations of common drugs. J. Clin. Monit. Comput. 15, 529-544. doi: 10.1023/A:1009935116877

Rennert, K., Steinborn, S., Gröger, M., Ungerböck, B., Jank, A. M., Ehgartner, J., et al. (2015). A microfluidically perfused three dimensional human liver model. Biomaterials 71, 119-131. doi: 10.1016/j.biomaterials.2015. 08.043

Riches, Z., Bloomer, J., Patel, A., Nolan, A., and Coughtrie, M. (2009). Assessment of cryopreserved human hepatocytes as a model system to investigate sulfation and glucuronidation and to evaluate inhibitors of drug conjugation. Xenobiotica 39, 374-381. doi: 10.1080/004982509027 63440

Robinton, D. A., and Daley, G. Q. (2012). The promise of induced pluripotent stem cells in research and therapy. Nature 481, 295-305. doi: 10.1038/nature10761

Ronaldson-Bouchard, K., and Vunjak-Novakovic, G. (2018). Organs-on-a-chip: a fast track for engineered human tissues in drug development. Cell Stem Cell 22, 310-324. doi: 10.1016/j.stem.2018.02.011

Roth, R. A., and Ganey, P. E. (2010). Intrinsic versus idiosyncratic drug-induced hepatotoxicity - Two villains or one? J. Pharmacol. Exp. Ther. 332, 692-697. doi: 10.1124/jpet.109.162651

Rowe, C., Gerrard, D. T., Jenkins, R., Berry, A., Durkin, K., Sundstrom, L., et al. (2013). Proteome-wide analyses of human hepatocytes during differentiation and dedifferentiation. Hepatology 58, 799-809. doi: 10.1002/hep.26414

Rowe, C., Shaeri, M., Large, E., Cornforth, T., Robinson, A., Kostrzewski, T., et al. (2018). Perfused human hepatocyte microtissues identify reactive metaboliteforming and mitochondria-perturbing hepatotoxins. Toxicol. Vitr. 46, 29-38. doi: 10.1016/j.tiv.2017.09.012

Ruoß, M., Vosough, M., Königsrainer, A., Nadalin, S., Wagner, S., Sajadian, S., et al. (2020). Towards improved hepatocyte cultures: progress and limitations. Food Chem. Toxicol. 138:111188. doi: 10.1016/j.fct.2020.111188

Russmann, S., Kullak-Ublick, G., and Grattagliano, I. (2009). Current concepts of mechanisms in drug-induced hepatotoxicity. Curr. Med. Chem. 16, 3041-3053. doi: 10.2174/092986709788803097

Sahi, J., Hamilton, G., Sinz, M., Barros, S., Huang, S. M., Lesko, L. J., et al. (2000). Effect of troglitazone on cytochrome P450 enzymes in primary cultures of human and rat hepatocytes. Xenobiotica 30, 273-284. doi: 10.1080/ 004982500237668

Sainz, B., Tencate, V., and Uprichard, S. L. (2009). Three-dimensional Huh7 cell culture system for the study of Hepatitis C virus infection. Virol. J. 6, 1-8. doi: 10.1186/1743-422X-6-103

Saiz-Rodríguez, M., Almenara, S., Navares-Gómez, M., Ochoa, D., Román, M., Zubiaur, P., et al. (2020). Effect of the most relevant CYP3A4 and CYP3A5 polymorphisms on the pharmacokinetic parameters of 10 CYP3A substrates. Biomedicines 8:94. doi: 10.3390/biomedicines8040094

Sakai, Y., Naruse, K., Nagashima, I., Muto, T., and Suzuki, M. (1996). Large-scale preparation and function of porcine hepatocyte spheroids. Int. J. Artif. Organs 19, 294-301. doi: 10.1177/039139889601900507

Sampaziotis, F., De Brito, M. C., Madrigal, P., Bertero, A., Saeb-Parsy, K., Soares, F. A. C., et al. (2015). Cholangiocytes derived from human induced pluripotent stem cells for disease modeling and drug validation. Nat. Biotechnol. 33, 845852. doi: $10.1038 /$ nbt. 3275

Sandker, G. W., Vos, R. M. E., Delbressine, L. P. C., Slooff, M. J. H., Meijer, D. K. F., and Groothuis, G. M. M. (1994). Metabolism of three pharmacologically active drugs in isolated human and rat hepatocytes: analysis of interspecies variability and comparison with metabolism in vivo. Xenobiotica 24, 143-155. doi: 10. 3109/00498259409043228

Sarkar, U., Ravindra, K. C., Large, E., Young, C. L., Rivera-Burgos, D., Yu, J., et al. (2017). Integrated assessment of diclofenac biotransformation, pharmacokinetics, and omics-based toxicity in a three-dimensional human liver-immunocompetent coculture systems. Drug Metab. Dispos. 45, 855-866. doi: $10.1124 / \mathrm{dmd} .116 .074005$

Sauer, V., Roy-Chowdhury, N., Guha, C., and Roy-Chowdhury, J. (2014). Induced pluripotent stem cells as a source of hepatocytes. Curr. Pathobiol. Rep. 2, 11-20. doi: 10.1007/s40139-013-0039-2

Schadt, S., Simon, S., Kustermann, S., Boess, F., McGinnis, C., Brink, A., et al. (2015). Minimizing DILI risk in drug discovery - A screening tool for drug candidates. Toxicol. Vitr. 30, 429-437. doi: 10.1016/j.tiv.2015.09.019

Schneeberger, K., Sánchez-Romero, N., Ye, S., Steenbeek, F. G., Oosterhoff, L. A., Pla Palacin, I., et al. (2020). Large-Scale Production of LGR5-positive bipotential human liver stem cells. Hepatology 72, 257-270. doi: 10.1002/hep. 31037

Schyschka, L., Sánchez, J. J. M., Wang, Z., Burkhardt, B., Müller-Vieira, U., Zeilinger, K., et al. (2013). Hepatic 3D cultures but not 2D cultures preserve 
specific transporter activity for acetaminophen-induced hepatotoxicity. Arch. Toxicol. 87, 1581-1593. doi: 10.1007/s00204-013-1080-y

Shah, F., Leung, L., Barton, H. A., Will, Y., Rodrigues, A. D., Greene, N., et al. (2015). Setting clinical exposure levels of concern for drug-induced liver injury (DILI) using mechanistic in vitro assays. Toxicol. Sci. 147, 500-514. doi: 10. 1093/toxsci/kfv152

Shanks, N., Greek, R., and Greek, J. (2009). Are animal models predictive for humans? Philos. Ethics Humanit. Med. 4:2. doi: 10.1186/1747-5341-4-2

Sharma, N. S., Shikhanovich, R., Schloss, R., and Yarmush, M. L. (2006). Sodium butyrate-treated embryonic stem cells yield hepatocyte-like cells expressing a glycolytic phenotype. Biotechnol. Bioeng. 94, 1053-1063. doi: 10.1002/bit.20936

Shen, C., Meng, Q., and Zhang, G. (2012). Species-specific toxicity of troglitazone on rats and human by gel entrapped hepatocytes. Toxicol. Appl. Pharmacol. 258, 19-25. doi: 10.1016/j.taap.2011.10.020

Shen, M. M. (2007). Nodal signaling: developmental roles and regulation. Development 134, 1023-1034. doi: 10.1242/dev.000166

Shi, D., Xin, J., Lu, Y., Ding, W., Jiang, J., Zhou, Q., et al. (2020). Transcriptome profiling reveals distinct phenotype of human bone marrow mesenchymal stem cell-derived hepatocyte-like cells. Int. J. Med. Sci. 17, 263-273. doi: 10.7150/ ijms.36255

Shukla, S. J., Huang, R., Austin, C. P., and Xia, M. (2010). The future of toxicity testing: a focus on in vitro methods using a quantitative high-throughput screening platform. Drug Discov. Today 15, 997-1007. doi: 10.1016/j.drudis. 2010.07.007

Shvartsman, I., Dvir, T., Harel-Adar, T., and Cohen, S. (2009). Perfusion cell seeding and cultivation induce the assembly of thick and functional hepatocellular tissue-like construct. Tissue Eng. Part A 15, 751-760. doi: 10. 1089/ten.tea.2008.0024

Sidenius, U., Skonberg, C., Olsen, J., and Hansen, S. H. (2004). In vitro reactivity of carboxylic acid-CoA thioesters with glutathione. Chem. Res. Toxicol. 17, 75-81. doi: $10.1021 /$ tx034127o

Singh, B. K., Tripathi, M., Pandey, P. K., and Kakkar, P. (2010). Nimesulide aggravates redox imbalance and calcium dependent mitochondrial permeability transition leading to dysfunction in vitro. Toxicology 275, 1-9. doi: 10.1016/j. tox.2010.05.001

Siramshetty, V. B., Nickel, J., Omieczynski, C., Gohlke, B. O., Drwal, M. N., and Preissner, R. (2016). WITHDRAWN - A resource for withdrawn and discontinued drugs. Nucleic Acids Res. 44, D1080-D1086. doi: 10.1093/nar/ gkv1192

Sirenko, O., Hancock, M. K., Hesley, J., Hong, D., Cohen, A., Gentry, J., et al. (2016). Phenotypic characterization of toxic compound effects on liver spheroids derived from ipsc using confocal imaging and three-dimensional image analysis. Assay Drug Dev. Technol. 14, 381-394. doi: 10.1089/adt.2016. 729

Sison-Young, R. L., Lauschke, V. M., Johann, E., Alexandre, E., Antherieu, S., Aerts, H., et al. (2017). A multicenter assessment of single-cell models aligned to standard measures of cell health for prediction of acute hepatotoxicity. Arch. Toxicol. 91, 1385-1400. doi: 10.1007/s00204-016-1745-4

Skonberg, C., Olsen, J., Madsen, K. G., Hansen, S. H., and Grillo, M. P. (2008). Metabolic activation of carboxylic acids. Expert Opin. Drug Metab. Toxicol. 4, 425-438. doi: 10.1517/17425255.4.4.425

Smith, M. T. (2003). Mechanisms of troglitazone hepatotoxicity. Chem. Res. Toxicol. 16, 679-687. doi: 10.1021/tx034033e

Snykers, S., Vanhaecke, T., De Becker, A., Papeleu, P., Vinken, M., Van Riet, I., et al. (2007). Chromatin remodeling agent trichostatin A: a key-factor in the hepatic differentiation of human mesenchymal stem cells derived of adult bone marrow. BMC Dev. Biol. 7:24. doi: 10.1186/1471-213X-7-24

Snykers, S., Vanhaecke, T., Papeleu, P., Luttun, A., Jiang, Y., Vander Heyden, Y., et al. (2006). Sequential exposure to cytokines reflecting embryogenesis: the key for in vitro differentiation of adult bone marrow stem cells into functional hepatocyte-like cells. Toxicol. Sci. 94, 330-341. doi: 10.1093/toxsci/kfl058

Sohn, L. L., Schwille, P., Hierlemann, A., Tay, S., Samitier, J., Fu, J., et al. (2020). How can microfluidic and microfabrication approaches make experiments more physiologically relevant? Cell Syst. 11, 209-211. doi: 10.1016/j.cels.2020. 07.003

Soldatow, V. Y., Lecluyse, E. L., Griffith, L. G., and Rusyn, I. (2013). In vitro models for liver toxicity testing. Toxicol. Res. 2, 23-39. doi: 10.1039/c2tx20051a
Songyang, R., Irudayam, J., Contrearas, D., Sareen, D., Talavera-Adame, D. Svendsen, C. N., et al. (2015). Bioartificial liver device based on induced pluripotent stem cell-derived hepatocytes. J. Stem Cell Res. Ther. 5, 1-9. doi: 10.4172/2157-7633.1000263

Sosa-Hernández, J. E., Villalba-Rodríguez, A. M., Romero-Castillo, K. D., AguilarAguila-Isaías, M. A., García-Reyes, I. E., Hernández-Antonio, A., et al. (2018). Organs-on-a-chip module: a review from the development and applications perspective. Micromachines 9:536. doi: 10.3390/mi9100536

Stefan, D., and Hamilton, J. P. (2010). Drug-induced liver injury. US Gastroenterol. Hepatol. Rev. 6, 73-80.

Stevens, J. L., and Baker, T. K. (2009). The future of drug safety testing: expanding the view and narrowing the focus. Drug Discov. Today 14, 162-167. doi: 10. 1016/j.drudis.2008.11.009

Subramanian, K., Owens, D. J., O’Brien, T. D., Verfaillie, C. M., and Hu, W. S. (2011). Enhanced differentiation of adult bone marrow-derived stem cells to liver lineage in aggregate culture. Tissue Eng. Part A 17, 2331-2341. doi: 10. 1089/ten.tea.2010.0667

Syed, M., Skonberg, C., and Hansen, S. H. (2016). Mitochondrial toxicity of diclofenac and its metabolites via inhibition of oxidative phosphorylation (ATP synthesis) in rat liver mitochondria: possible role in drug induced liver injury (DILI). Toxicol. Vitr. 31, 93-102. doi: 10.1016/j.tiv.2015.11.020

Szkolnicka, D., Farnworth, S. L., Lucendo-Villarin, B., Storck, C., Zhou, W., Iredale, J. P., et al. (2014). Accurate prediction of drug-induced liver injury using stem cell-derived populations. Stem Cells Transl. Med. 3, 141-148. doi: 10.5966/sctm. 2013-0146

Takahashi, Y., Hori, Y., Yamamoto, T., Urashima, T., Ohara, Y., and Tanaka, H. (2015). 3D spheroid cultures improve the metabolic gene expression profiles of HepaRG cells. Biosci. Rep. 35, 1-7. doi: 10.1042/BSR20150034

Takayama, K., Kawabata, K., Nagamoto, Y., Kishimoto, K., Tashiro, K., Sakurai, F., et al. (2013). 3D spheroid culture of hESC/hiPSC-derived hepatocytelike cells for drug toxicity testing. Biomaterials 34, 1781-1789. doi: 10.1016/j. biomaterials.2012.11.029

Takayama, K., Morisaki, Y., Kuno, S., Nagamoto, Y., Harada, K., Furukawa, N., et al. (2014). Prediction of interindividual differences in hepatic functions and drug sensitivity by using human iPS-derived hepatocytes. Proc. Natl. Acad. Sci. U.S.A. 111, 16772-16777. doi: 10.1073/pnas.1413481111

Takebe, T., Sekine, K., Kimura, M., Yoshizawa, E., Ayano, S., Koido, M., et al. (2017). Massive and reproducible production of liver buds entirely from human pluripotent stem cells. Cell Rep. 21, 2661-2670. doi: 10.1016/j.celrep.2017.11. 005

Tamay, D. G., Usal, T. D., Alagoz, A. S., and Yucel, D. (2019). 3D and 4D printing of polymers for tissue engineering applications. Front. Bioeng. Biotechnol. 7:164. doi: 10.3389/fbioe.2019.00164

Tasnim, F., Phan, D., Toh, Y. C., and Yu, H. (2015). Cost-effective differentiation of hepatocyte-like cells from human pluripotent stem cells using small molecules. Biomaterials 70, 115-125. doi: 10.1016/j.biomaterials.2015.08.002

Tasnim, F., Toh, Y. C., Qu, Y., Li, H., Phan, D., Narmada, B. C., et al. (2016). Functionally enhanced human stem cell derived hepatocytes in galactosylated cellulosic sponges for hepatotoxicity testing. Mol. Pharm. 13, 1947-1957. doi: 10.1021/acs.molpharmaceut.6b00119

Tasnim, F., Xing, J., Huang, X., Mo, S., Wei, X., Tan, M. H., et al. (2019). Generation of mature kupffer cells from human induced pluripotent stem cells. Biomaterials 192, 377-391. doi: 10.1016/j.biomaterials.2018.11.016

Tibbitt, M. W., and Anseth, K. S. (2009). Hydrogels as extracellular matrix mimics for 3D cell culture. Biotechnol. Bioeng. 103, 655-663. doi: 10.1002/bit. 22361

Tolosa, L., Jiménez, N., Pérez, G., Castell, J. V., Gómez-Lechón, M. J., and Donato, M. T. (2018). Customised in vitro model to detect human metabolismdependent idiosyncratic drug-induced liver injury. Arch. Toxicol. 92, 383-399. doi: 10.1007/s00204-017-2036-4

Tomlinson, L., Hyndman, L., Firman, J. W., Bentley, R., Kyffin, J. A., Webb, S. D., et al. (2019). In vitro liver zonation of primary rat hepatocytes. Front. Bioeng. Biotechnol. 7:17. doi: 10.3389/fbioe.2019.00017

Tostoes, R. M., Leite, S. B., Miranda, J. P., Sousa, M., Wang, D. I. C., Carrondo, M. J. T., et al. (2011). Perfusion of 3D encapsulated hepatocytes-a synergistic effect enhancing long-term functionality in bioreactors. Biotechnol. Bioeng. 108, 41-49. doi: 10.1002/bit.22920 
Tostoes, R. M., Leite, S. B., Serra, M., Jensen, J., Bjorquist, P., Carrondo, M. J., et al. (2012). Human liver cell spheroids in extended perfusion bioreactor culture for repeated-dose drug testing. Hepatology 55, 1227-1236. doi: 10.1002/hep.24760

Trask, O. J., Moore, A., and Lecluyse, E. L. (2014). A micropatterned hepatocyte coculture model for assessment of liver toxicity using high-content imaging analysis. Assay Drug Dev. Technol. 12, 16-27. doi: 10.1089/adt.2013.525

Treyer, A., and Müsch, A. (2013). Hepatocyte polarity. Compr. Physiol. 3, 243-287. doi: $10.1002 /$ cphy.c120009

Tripathi, A., and Melo, J. S. (2015). Preparation of a sponge-like biocomposite agarose-chitosan scaffold with primary hepatocytes for establishing an in vitro 3D liver tissue model. RSC Adv. 5, 30701-30710. doi: 10.1039/c5ra04153h

Tsamandouras, N., Kostrzewski, T., Stokes, C. L., Griffith, L. G., Hughes, D. J., and Cirit, M. (2017). Quantitative assessment of population variability in hepatic drug metabolism using a perfused three-dimensional human liver microphysiological system. J. Pharmacol. Exp. Ther. 360, 95-105. doi: 10.1124/ jpet.116.237495

Tuschl, G., Hrach, J., Walter, Y., Hewitt, P. G., and Mueller, S. O. (2009). Serumfree collagen sandwich cultures of adult rat hepatocytes maintain liver-like properties long term: a valuable model for in vitro toxicity and drug-drug interaction studies. Chem. Biol. Interact. 181, 124-137. doi: 10.1016/j.cbi.2009. 05.015

Umehara, K. I., and Camenisch, G. (2012). Novel in vitro-in vivo extrapolation (IVIVE) method to predict hepatic organ clearance in rat. Pharm. Res. 29, 603-617. doi: 10.1007/s11095-011-0607-2

van Tonder, J. J., Steenkamp, V., and Gulumi, M. (2013). "Pre-clinical assessment of the potential intrinsic hepatotoxicity of candidate drugs," in New Insights into Toxicity and Drug Testing, ed. S. Gowder (IntechOpen). doi: 10.5772/54792

Vernetti, L. A., Vogt, A., Gough, A., and Taylor, D. L. (2017). Evolution of experimental models of the liver to predict human drug hepatotoxicity and efficacy. Clin. Liver Dis. 21, 197-214. doi: 10.1016/j.cld.2016.08.013

Vinci, B., Duret, C., Klieber, S., Gerbal-Chaloin, S., Sa-Cunha, A., Laporte, S., et al. (2011). Modular bioreactor for primary human hepatocyte culture: medium flow stimulates expression and activity of detoxification genes. Biotechnol. J. 6, 554-564. doi: 10.1002/biot.201000326

Vinken, M., and Hengstler, J. G. (2018). Characterization of hepatocyte-based in vitro systems for reliable toxicity testing. Arch. Toxicol. 92, 2981-2986. doi: 10.1007/s00204-018-2297-6

Vivares, A., Salle-Lefort, S., Arabeyre-Fabre, C., Ngo, R., Penarier, G., Bremond, M., et al. (2015). Morphological behaviour and metabolic capacity of cryopreserved human primary hepatocytes cultivated in a perfused multiwell device. Xenobiotica 45, 29-44. doi: 10.3109/00498254.2014.944612

Vorrink, S. U., Ullah, S., Schmidt, S., Nandania, J., Velagapudi, V., Beck, O., et al. (2017). Endogenous and xenobiotic metabolic stability of primary human hepatocytes in long-term $3 \mathrm{D}$ spheroid cultures revealed by a combination of targeted and untargeted metabolomics. FASEB J. 31, 2696-2708. doi: 10.1096/ fj.201601375R

Vorrink, S. U., Zhou, Y., Ingelman-Sundberg, M., and Lauschke, V. M. (2018). Prediction of drug-induced hepatotoxicity using long-term stable primary hepatic 3D spheroid cultures in chemically defined conditions. Toxicol. Sci. 163, 655-665. doi: 10.1093/toxsci/kfy058

Walker, P. A., Ryder, S., Lavado, A., Dilworth, C., and Riley, R. J. (2020). The evolution of strategies to minimise the risk of human drug-induced liver injury (DILI) in drug discovery and development. Arch. Toxicol. 94, 2559-2585. doi: 10.1007/s00204-020-02763-w

Wang, B., Zhao, L., Fish, M., Logan, C. Y., and Nusse, R. (2015). Self-renewing diploid Axin2+ cells fuel homeostatic renewal of the liver. Nature 524, 180-185. doi: 10.1038/nature14863

Wang, K., Shindoh, H., Inoue, T., and Horii, I. (2002). Advantages of in vitro cytotoxicity testing by using primary rat hepatocytes in comparison with established cell lines. J. Toxicol. Sci. 27, 229-237. doi: 10.2131/jts.27.229

Wang, S., Wang, X., Tan, Z., Su, Y., Liu, J., Chang, M., et al. (2019). Human ESCderived expandable hepatic organoids enable therapeutic liver repopulation and pathophysiological modeling of alcoholic liver injury. Cell Res. 29, 1009-1026. doi: 10.1038/s41422-019-0242-8

Wang, W. W. W., Khetani, S. R., Krzyzewski, S., Duignan, D. B., and Obach, R. S. (2010). Assessment of a micropatterned hepatocyte coculture system to generate major human excretory and circulating drug metabolites. Drug Metab. Dispos. 38, 1900-1905.
Wang, Y. I., Carmona, C., Hickman, J. J., and Shuler, M. L. (2018). Multiorgan microphysiological systems for drug development: strategies, advances, and challenges. Adv. Healthc. Mater. 7:201701000. doi: 10.1002/adhm.201701000

Wang, Z., Li, W., Jing, H., Ding, M., Fu, G., Yuan, T., et al. (2019). Generation of hepatic spheroids using human hepatocyte-derived liver progenitor-like cells for hepatotoxicity screening. Theranostics 9, 6690-6705. doi: 10.7150/thno. 34520

Werner, A., Duvar, S., Müthing, J., Büntemeyer, H., Lünsdorf, H., Strauss, M., et al. (2000). Cultivation of immortalized human hepatocytes HepZ on macroporous CultiSpher G microcarriers. Biotechnol. Bioeng. 68, 59-70.

Westerink, W. M. A., and Schoonen, W. G. E. J. (2007a). Cytochrome P450 enzyme levels in HepG2 cells and cryopreserved primary human hepatocytes and their induction in HepG2 cells. Toxicol. Vitr. 21, 1581-1591. doi: 10.1016/j.tiv.2007. 05.014

Westerink, W. M. A., and Schoonen, W. G. E. J. (2007b). Phase II enzyme levels in HepG2 cells and cryopreserved primary human hepatocytes and their induction in HepG2 cells. Toxicol. Vitr. 21, 592-602. doi: 10.1016/j.tiv.2007. 06.017

Wienkers, L. C., and Heath, T. G. (2005). Predicting in vivo drug interactions from in vitro drug discovery data. Nat. Rev. Drug Discov. 4, 825-833. doi: $10.1038 / \mathrm{nrd} 1851$

Wikswo, J. P. (2014). The relevance and potential roles of microphysiological systems in biology and medicine. Exp. Biol. Med. 239, 1061-1072. doi: 10.1177/ 1535370214542068

Williams, D. P., Lazic, S. E., Foster, A. J., Semenova, E., and Morgan, P. (2020). Predicting drug-induced liver injury with bayesian machine learning. Chem. Res. Toxicol. 33, 239-248. doi: 10.1021/acs.chemrestox.9b00264

Wolverton, S. E., and Wu, J. J. (2020). Comprehensive Dermatologic Drug Therapy, 4th Edn. Cham: Springer.

Woolbright, B. L., and Jaeschke, H. (2018). Mechanisms of inflammatory liver injury and drug-induced hepatotoxicity. Curr. Pharmacol. Rep. 4, 346-357. doi: 10.1007/s40495-018-0147-0

Wooten, J. M. (2015). Rules for improving pharmacotherapy in older adult patients: part 2 (Rules 6-10). S. Med. J. 108, 97-104. doi: 10.14423/SMJ. 0000000000000243

Wouters, O. J., McKee, M., and Luyten, J. (2020). Estimated research and development investment needed to bring a new medicine to market, 2009-2018. JAMA J. Am. Med. Assoc. 323, 844-853. doi: 10.1001/jama.2020.1166

Wrzesinski, K., Rogowska-Wrzesinska, A., Kanlaya, R., Borkowski, K., Schwämmle, V., Dai, J., et al. (2014). The cultural divide: exponential growth in classical 2D and metabolic equilibrium in 3D environments. PLoS One 9:e0106973. doi: 10.1371/journal.pone.0106973

Xu, J., Ma, M., and Purcell, W. M. (2003). Characterisation of some cytotoxic endpoints using rat liver and HepG2 spheroids as in vitro models and their application in hepatotoxicity studies. II. Spheroid cell spreading inhibition as a new cytotoxic marker. Toxicol. Appl. Pharmacol. 189, 112-119. doi: 10.1016/ S0041-008X(03)00090-5

Xu, J. J., Diaz, D., and O’Brien, P. J. (2004). Applications of cytotoxicity assays and pre-lethal mechanistic assays for assessment of human hepatotoxicity potential. Chem. Biol. Interact. 150, 115-128. doi: 10.1016/j.cbi.2004.09.011

Xu, J. J., Henstock, P. V., Dunn, M. C., Smith, A. R., Chabot, J. R., and de Graaf, D. (2008). Cellular imaging predictions of clinical drug-induced liver injury. Toxicol. Sci. 105, 97-105. doi: 10.1093/toxsci/kfn109

Xu, S., Chen, Y., Ma, Y., Liu, T., Zhao, M., Wang, Z., et al. (2019). Lipidomic profiling reveals disruption of lipid metabolism in valproic acid-induced hepatotoxicity. Pharmacology 10:819. doi: 10.3389/fphar.2019.00819

Yamashita, T., Takayama, K., Sakurai, F., and Mizuguchi, H. (2018). Billion-scale production of hepatocyte-like cells from human induced pluripotent stem cells. Biochem. Biophys. Res. Commun. 496, 1269-1275. doi: 10.1016/j.bbrc.2018.01. 186

Yang, B., Duan, W., Wei, L., Zhao, Y., Han, Z., Wang, J., et al. (2020). Bone marrow mesenchymal stem cell-derived hepatocyte-like cell exosomes reduce hepatic ischemia/reperfusion injury by enhancing autophagy. Stem Cells Dev. 29, 372-379. doi: 10.1089/scd.2019.0194

Yang, K., Guo, C., Woodhead, J. L., St Claire, R. L., Watkins, P. B., Siler, S. Q., et al. (2016). Sandwich-cultured hepatocytes as a tool to study drug disposition and drug-induced liver injury. J. Pharm. Sci. 105, 443-459. doi: 10.1016/j.xphs.2015. 11.008 
Yin, L., Zhu, Y., Yang, J., Ni, Y., Zhou, Z., Chen, Y., et al. (2015). Adipose tissuederived mesenchymal stem cells differentiated into hepatocyte-like cells in vivo and in vitro. Mol. Med. Rep. 11, 1722-1732. doi: 10.3892/mmr.2014.2935

Yoshii, Y., Waki, A., Yoshida, K., Kakezuka, A., Kobayashi, M., Namiki, H., et al. (2011). The use of nanoimprinted scaffolds as 3D culture models to facilitate spontaneous tumor cell migration and well-regulated spheroid formation. Biomaterials 32, 6052-6058. doi: 10.1016/j.biomaterials.2011.04.076

Yu, C., Ma, X., Zhu, W., Wang, P., Miller, K. L., Stupin, J., et al. (2019). Scanningless and continuous $3 \mathrm{D}$ bioprinting of human tissues with decellularized extracellular matrix. Biomaterials 194, 1-13. doi: 10.1016/j.biomaterials.2018. 12.009

Yu, F., Goh, Y. T., Li, H., Chakrapani, N. B., Ni, M., Xu, G. L., et al. (2020). A vascular-liver chip for sensitive detection of nutraceutical metabolites from human pluripotent stem cell derivatives. Biomicrofluidics 14:034108. doi: 10 . 1063/5.0004286

Yu, K. N., Nadanaciva, S., Rana, P., Lee, D. W., Ku, B., Roth, A. D., et al. (2018). Prediction of metabolism-induced hepatotoxicity on three-dimensional hepatic cell culture and enzyme microarrays. Arch. Toxicol. 92, 1925-1310. doi: 10. 1007/s00204-017-2126-3

Yu, Y. B., Song, Y., Chen, Y., Zhang, F., and Qi, F. Z. (2018). Differentiation of umbilical cord mesenchymal stem cells into hepatocytes in comparison with bone marrow mesenchymal stem cells. Mol. Med. Rep. 18, 2009-2016. doi: 10.3892/mmr.2018.9181

Yuan, L., and Kaplowitz, N. (2013). Mechanisms of drug-induced liver injury. Clin. Liver Dis. 17, 507-518. doi: 10.1016/j.cld.2013.07.002

Zanger, U. M., Klein, K., Saussele, T., Blievernicht, J., Hofmann, M. H., and Schwab, M. (2007). Polymorphic CYP2B6: molecular mechanisms and emerging clinical significance. Pharmacogenomics 8, 743-759. doi: 10.2217/14622416.8. 7.743

Zeigerer, A., Wuttke, A., Marsico, G., Seifert, S., Kalaidzidis, Y., and Zerial, M. (2017). Functional properties of hepatocytes in vitro are correlated with cell polarity maintenance. Exp. Cell Res. 350, 242-252. doi: 10.1016/j.yexcr.2016.11. 027

Zeilinger, K., Freyer, N., Damm, G., Seehofer, D., and Knöspel, F. (2016). Cell sources for in vitro human liver cell culture models. Exp. Biol. Med. 241, 1684-1698. doi: 10.1177/1535370216657448

Zeilinger, K., Schreiter, T., Darnell, M., Söderdahl, T., Lübberstedt, M., Dillner, B., et al. (2011). Scaling down of a clinical three-dimensional perfusion multicompartment hollow fiber liver bioreactor developed for extracorporeal liver support to an analytical scale device useful for hepatic pharmacological in vitro studies. Tissue Eng. Part C Methods 17, 549-556. doi: 10.1089/ten.tec. 2010.0580
Zhang, C., Zhang, Q., Li, J., Yu, L., Li, F., Li, W., et al. (2020). Integration of in vitro data from three dimensionally cultured HepaRG cells and physiologically based pharmacokinetic modeling for assessment of acetaminophen hepatotoxicity. Regul. Toxicol. Pharmacol. 114:104661. doi: 10.1016/j.yrtph.2020.104661

Zhang, C. Y., Yuan, W. G., He, P., Lei, J. H., and Wang, C. X. (2016). Liver fibrosis and hepatic stellate cells: etiology, pathological hallmarks and therapeutic targets. World J. Gastroenterol. 22, 10512-10522. doi: 10.3748/wjg.v22.i48. 10512

Zhang, S., Tong, W., Zheng, B., Susanto, T. A. K., Xia, L., Zhang, C., et al. (2011). A robust high-throughput sandwich cell-based drug screening platform. Biomaterials 32, 1229-1241. doi: 10.1016/j.biomaterials.2010.09.064

Zhang, X., Jiang, T., Chen, D., Wang, Q., and Zhang, L. W. (2020). Three-dimensional liver models: state of the art and their application for hepatotoxicity evaluation. Crit. Rev. Toxicol. 50, 279-309. doi: 10.1080/ 10408444.2020.1756219

Zhang, Y. N., Lie, P. C., and Wei, X. (2009). Differentiation of mesenchymal stromal cells derived from umbilical cord Wharton's jelly into hepatocyte-like cells. Cytotherapy 11, 548-558. doi: 10.1080/14653240903051533

Zhao, Q., Ren, H., Li, X., Chen, Z., Zhang, X., Gong, W., et al. (2009). Differentiation of human umbilical cord mesenchymal stromal cells into low immunogenic hepatocyte-like cells. Cytotherapy 11, 414-426. doi: 10.1080/ 14653240902849754

Zhou, Q., Patel, D., Kwa, T., Haque, A., Matharu, Z., Stybayeva, G., et al. (2015). Liver injury-on-a-chip: microfluidic co-cultures with integrated biosensors for monitoring liver cell signaling during injury. Lab Chip 15, 4467-4478. doi: $10.1039 / \mathrm{c} 51 \mathrm{c} 00874 \mathrm{c}$

Zhou, R., Li, Z., He, C., Li, R., Xia, H., Li, C., et al. (2014). Human umbilical cord mesenchymal stem cells and derived hepatocyte-like cells exhibit similar therapeutic effects on an acute liver failure mouse model. PLoS One 9:e0104392. doi: 10.1371/journal.pone.0104392

Conflict of Interest: The authors declare that the research was conducted in the absence of any commercial or financial relationships that could be construed as a potential conflict of interest.

Copyright (c) 2021 Serras, Rodrigues, Cipriano, Rodrigues, Oliveira and Miranda. This is an open-access article distributed under the terms of the Creative Commons Attribution License (CC BY). The use, distribution or reproduction in other forums is permitted, provided the original author(s) and the copyright owner(s) are credited and that the original publication in this journal is cited, in accordance with accepted academic practice. No use, distribution or reproduction is permitted which does not comply with these terms. 